\title{
WEEDS IN A CHANGING ENVIRONMENT
}

Responses to altered temperature and soil water potential in four soil types and relative future habitat suitability for potential distribution of three range-expanding weed species in northwest Germany

\author{
Dissertation \\ zur Erlangung des Doktorgrades \\ der Fakultät für Agrarwissenschaften \\ der Georg-August-Universität Göttingen
}

\author{
vorgelegt von \\ Barbara Edler \\ geboren in Voitsberg, Österreich
}

Arnstein, March 2015 
D 7

1. Referent: Prof. Dr. Johannes Isselstein

2. Korreferentin: Prof. Dr. Bärbel Gerowitt

Tag der mündlichen Prüfung: 28. November 2013 
s) To my grandfather es

80 Plants are so unlike people that it's very difficult for us to appreciate their complexity and sophistication. $\mathrm{os}$

Michael Pollan, The Botany of Desire 


\section{Contents}

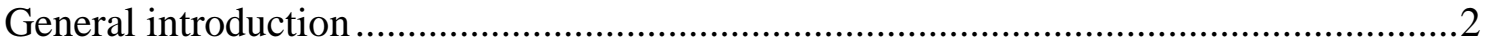

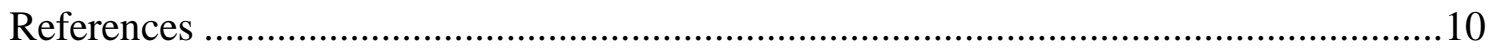

Effects of altered temperature and soil water potential in four soil types on the emergence characteristics of three range-expanding annual weeds

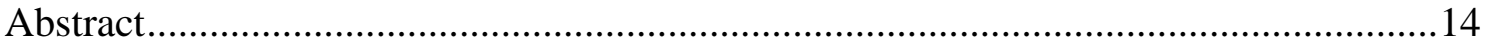

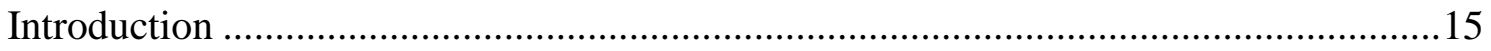

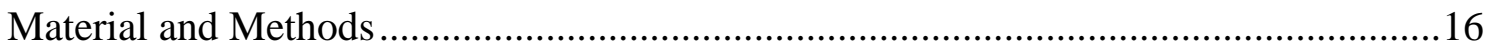

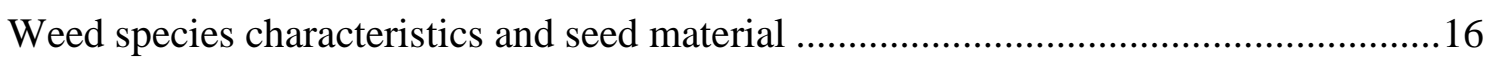

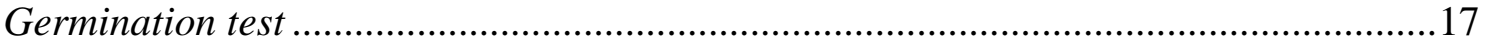

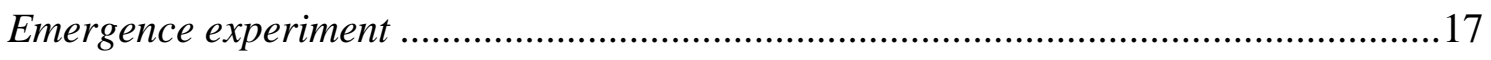

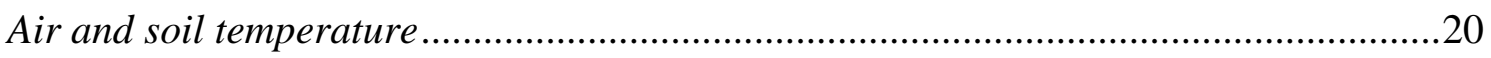

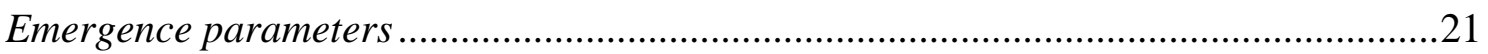

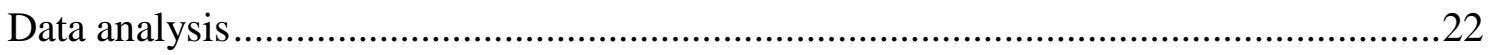

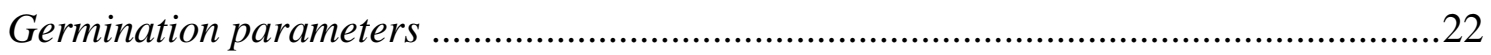

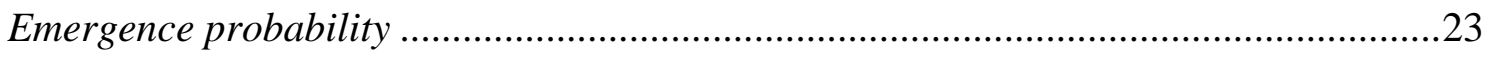

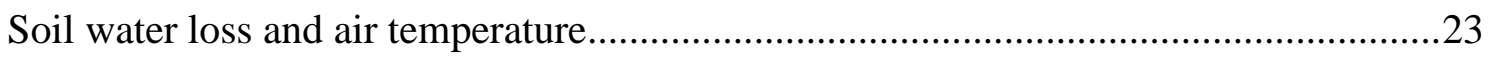

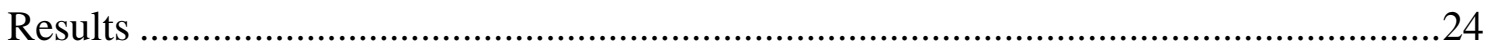

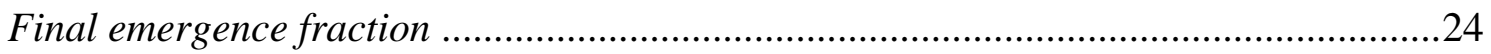

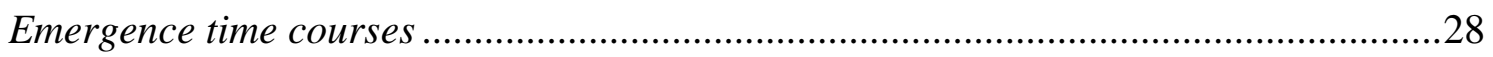

Emergence time courses versus final emergence fraction ........................................... 30

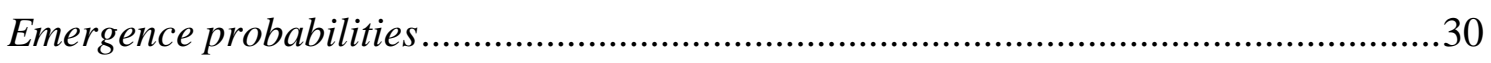

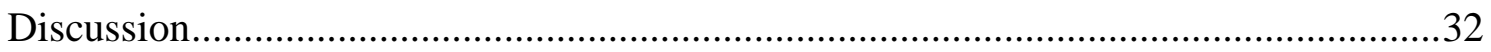

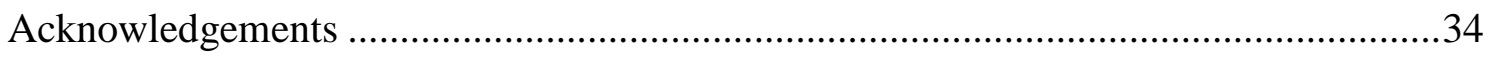

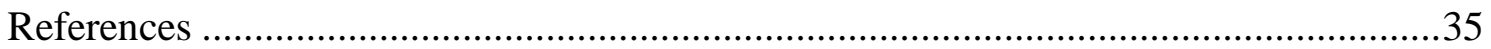

Growth responses of three range-expanding weeds to elevated temperature and

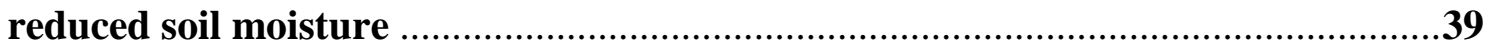

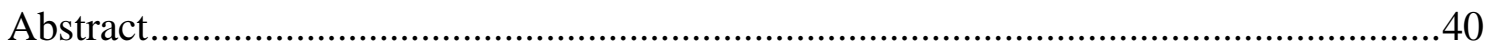

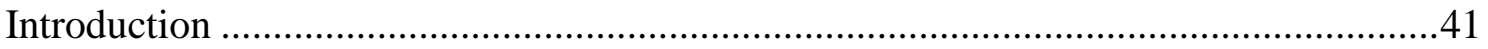

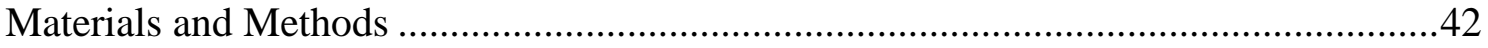

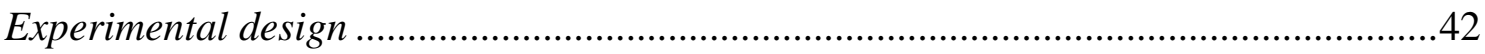

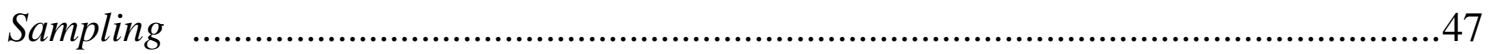

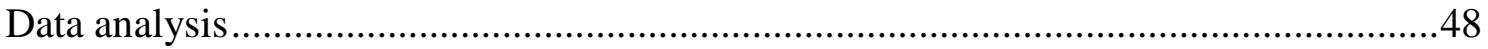


Results

Total aboveground biomass per pot and aboveground biomass proportions of maize

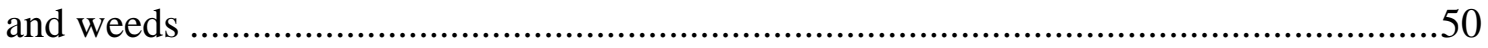

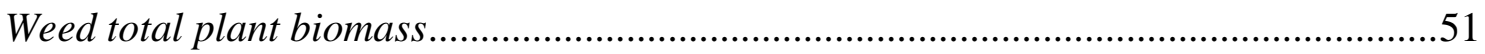

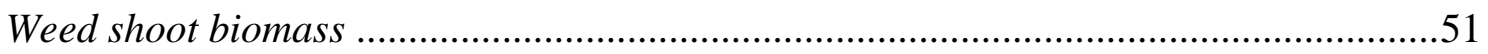

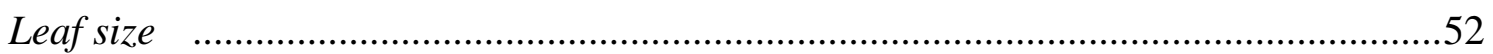

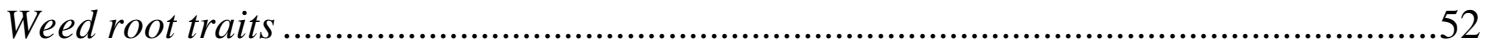

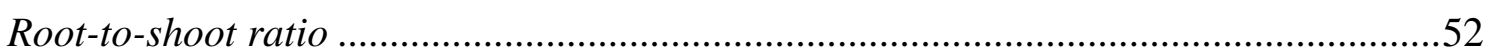

Correlation of aboveground and belowground traits .................................................52

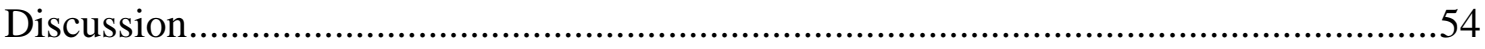

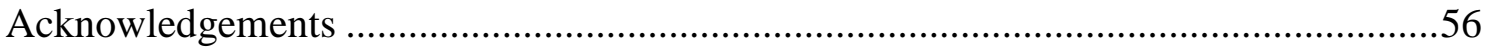

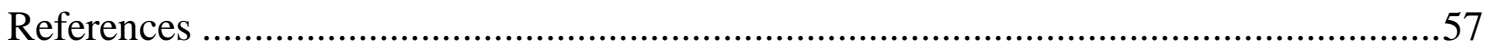

Implications of climate change, land use, cover type, and soil on habitat suitability and potential distribution for three weeds in Lower Saxony ................61

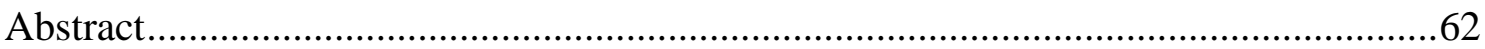

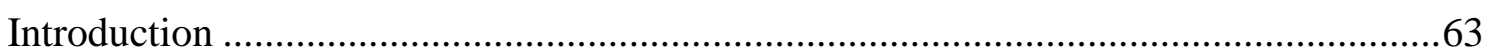

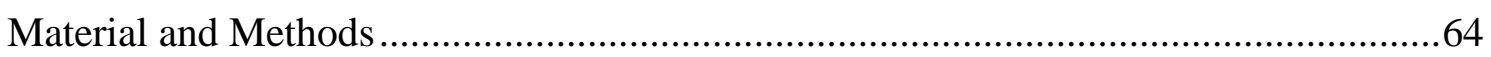

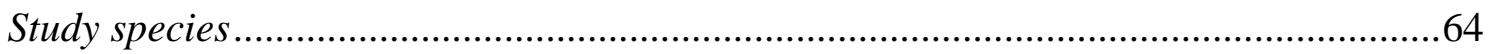

Study area in general, Soil-Climate-Area, Lower Saxony Vegetation Survey, arable

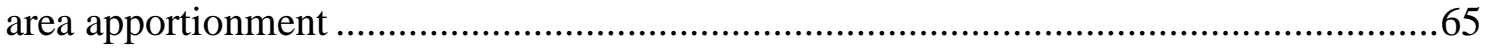

Study area and time horizon for the modelling approach.............................................69

European species occurrence data for modelling approach.........................................69

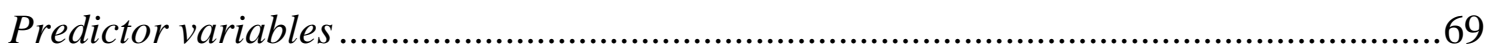

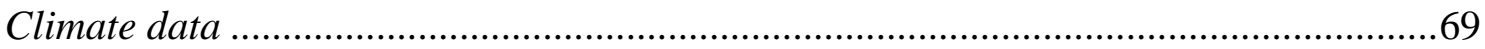

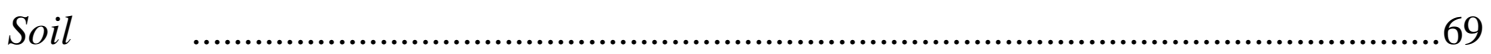

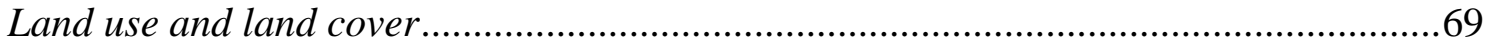

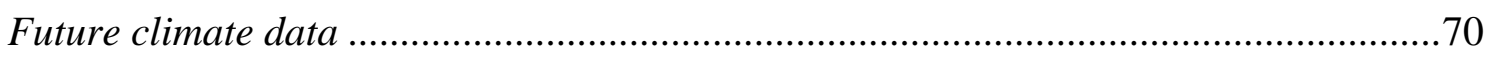

Model fitting, calibration, evaluation and prediction .............................................. 70

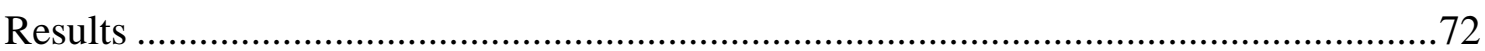

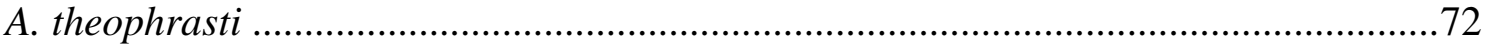

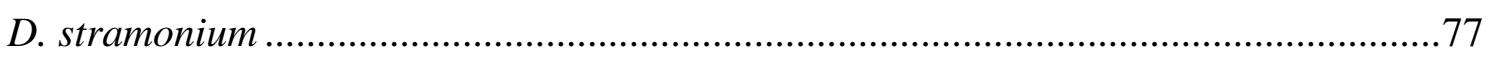

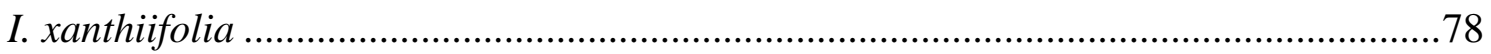

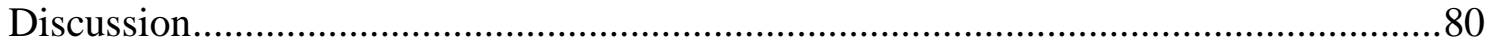

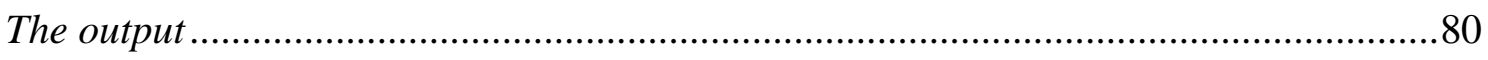

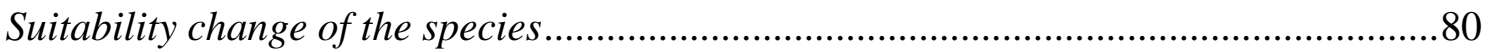

Influence of land use and agricultural practices ........................................................ 81

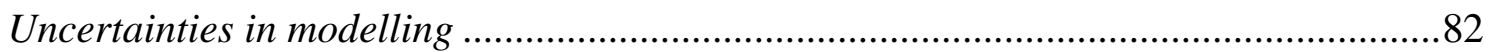


Appropriate management strategies of spreading weeds

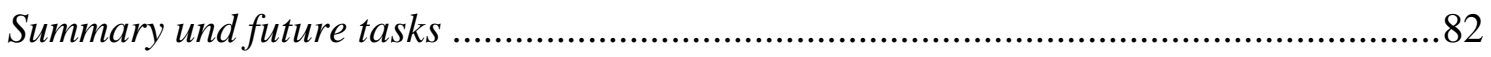

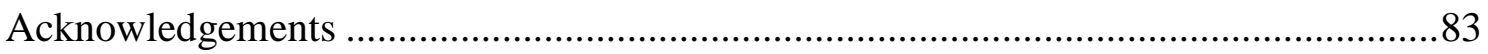

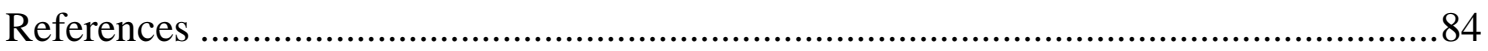

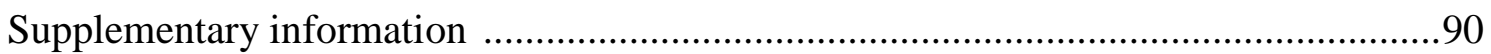

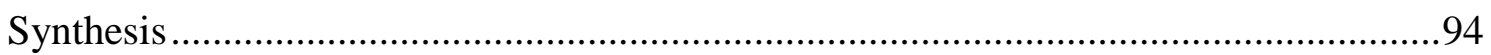

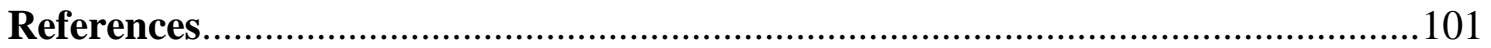

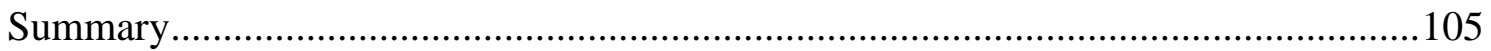

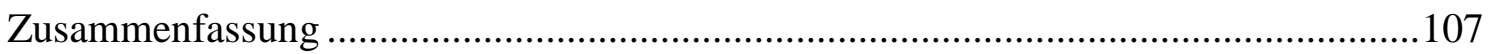

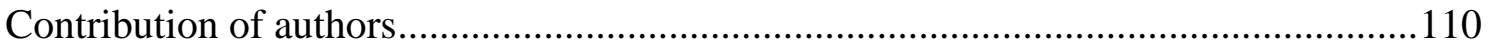

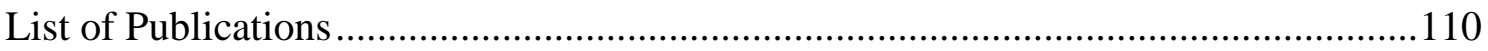

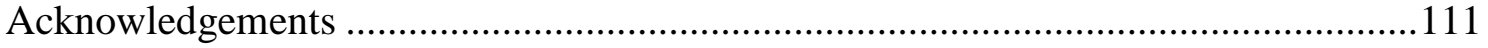

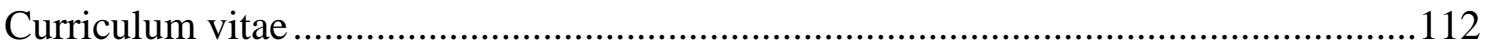




\section{Chapter}

1

\section{General introduction}

During recent decades climatic conditions have been changing. Within the last thirty years, global temperatures have risen by approximately $0.6 \mathrm{~K}$ and are expected to continue at ever growing rates in the current century (Sommer et al., 2010). For northwest Germany, the focus region of the present work, a scenario by Moseley et al. (2012) indicates a rise of temperature by up to $4 \mathrm{~K}$ until 2100. Additionally, precipitation is expected to shift seasonally and regionally. This increases the risk of regional extreme weather events such as long-term droughts or intense floods (Tölle et al., 2012).

These environmental alterations will have numerous consequences; among others, they will affect plant life profoundly. Responses of plants to a changing environment may include:

(i) shifts of geographical distribution (Holt, 1990; Wiens et al., 2010). On species level, distributional changes will affect ecosystem processes and functioning over time and space in highly complex feedback processes (Walther, 2010), with inter alia biodiversity loss (Thomas, 2010) and/or "invasive" species increase (Broennimann et al., 2007; Clements and DiTommaso, 2011).

(ii) adaptation and/or acclimatisation to changing conditions in place. Changes in phenology, like the timing of germination and emergence (Donohue et al., 2010), and changes in physiology, like plant trait adaptations/acclimatisation (Walther, 2010) have been assessed with increasing sophistication.

(iii) persistence in an isolated refugia (Holt, 1990; Wiens et al., 2010).

(iv) extinction (Holt 1990; Wiens et al., 2010). 
The transformation of ecosystems by plant species change has been identified as a major component of global change (Bradley, 2009). Especially arable land is highly sensitive to the introduction of new and the endemic growth of already introduced species (e.g., sleeper weeds) and to shifts of the species composition (Mack et al., 2000; Glemnitz et al., 2010). Sleeper weeds are naturalised exotic plants, that are currently only present in small areas, but they have the potential to spread widely, due to an alteration in changing climate (Scott et al., 2008). However, these transformations may create economic loss via direct impact on the economy of agricultural systems, as well as through costs associated with slowing invasion, or restoring invaded ecosystems (Bradley, 2009). To proactively advise adjustment actions, like biodiversity conservation planning or weed management strategies (Broennimann et al., 2007; Clements and DiTommaso, 2011) it is becoming ever more important to identify potential vulnerability and anticipate plant responses in managed ecosystems (Hulme, 2009; McDonald et al., 2009).

Despite the considerable breadth of recent research dedicated to understanding the consequences of changing climate, relatively little attention has been given to the potential response of arable weed species to changing environmental conditions on a small, regional scale.

Here we investigated the impacts of changing environmental conditions on performance and relative habitat suitability for potential species distribution of three weed species under projected future climatic conditions in northwest Germany in a mechanistic (processedbased) approach on the one hand, and a correlative approach of bioclimatic niche modelling on the other.

For this thesis, and after an extensive literature search, we focused on the species Abutilon theophrasti, Datura stramonium and Iva xanthiifolia. They are already present in Northern Germany's agro-ecosystems in different abundance, and are currently expanding their range in Europe (Weber and Gut, 2005; Garve, 2007).

The species belong to a guild, or assemblage of species of highly competitive, ruderal, stress-tolerant, thermophile, annual C3 weeds, which have a distinct impact on agricultural productivity. I. xanthiifolia is additionally relevant for causing harm on human health, because of its highly allergenic pollen (McDonald et al., 2009; Clements and DiTommaso, 2011; Follak et al., 2013). Besides, weed species can be classified into functional groups in terms of their expected responses to environmental change, with inter alia a classification into $\mathrm{C} 3 / \mathrm{C} 4$ species, or neophytes and archaeophytes. Neophyte weeds have been found to be more prominent in maize and rape than in cereals (Hyvönen et al., 2011). Supplementary information on the species is listed below (Tab. 1.1, Tab. 1.2, Tab. 1.3, Tab. 1.4).

Table 1.1 Chosen weeds for assessment

\begin{tabular}{|c|c|c|c|}
\hline Species name $^{1}$ & Family $^{1}$ & English name & EPPO-Code ${ }^{2}$ \\
\hline Abutilon theophrasti Medic. & Malvaceae & Velvetleaf, China Jute & ABUTH \\
\hline Datura stramonium L. & Solanaceae & Jimson Weed, Datura & DATST \\
\hline $\begin{array}{l}\text { Iva xanthiifolia Nutt. } \\
\text { Syn. Cyclachaena xanthiifolia }\end{array}$ & Asteraceae & $\begin{array}{l}\text { False Ragweed, } \\
\text { Burweed Marsh-elder }\end{array}$ & IVAXA \\
\hline
\end{tabular}

${ }^{1}$ FloraWeb (2013) ${ }^{2}$ EPPO (2013) 
Table 1.2 Aspects of Abutilon theophrasti Medic.

\begin{tabular}{|c|c|}
\hline Floristic status $^{1}$ & archaeophyte \\
\hline Region of origion $^{1}$ & not specified \\
\hline Mode of introduction & seed contaminant \\
\hline Degree of neutralization $^{1}$ & ephemerophyte \\
\hline 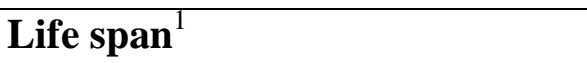 & annual \\
\hline Strategy type $^{1}$ & competitors/ruderals \\
\hline Floristic zone and altitude level $^{\top}$ & $\mathrm{m}$ \\
\hline $\begin{array}{l}\text { Floristic region }^{1} \\
\text { Asia (Status: natural range) } \\
\text { Europe (Status: natural range) }\end{array}$ & \\
\hline
\end{tabular}

\section{Physiological optimum characteristics}

\begin{tabular}{rcccl}
$\mathrm{T}_{\text {Base/ } / \mathrm{C}}$ & $\mathrm{T}_{\mathrm{Optima/} /{ }^{\circ} \mathrm{C}}$ & $\psi_{\text {Base/M PA }}$ & $\psi_{\text {Optimal/M PA }}$ & References \\
\hline 7.0 & 15.65 & -1.00 & 0 & Dorado et al. $(2009)$ \\
2.0 & $/$ & 0.00 & $/$ & Gardarin et al. $(2010)$ \\
3.9 & 25 & -0.78 & $/$ & Masin et al. $(2010)$ \\
9.0 & $/$ & $/$ & $/$ & Myers et al. $(2004)$
\end{tabular}

\begin{tabular}{|c|c|}
\hline Hemeroby $^{1}$ & $\mathrm{p}$ \\
\hline Number of hemerobic levels ${ }^{1}$ & 1 \\
\hline Spread potential $^{2}[1(\min )-3(\max )]$ & 2.08 \\
\hline Weediness $^{2}[1$ (min) $-3(\max )]$ & 2.15 \\
\hline Control success $^{2}[1(\min )-3(\max )]$ & 1.7 \\
\hline Crop system $^{2}$ & $1,2,3,4,5,6$ \\
\hline Regions $^{2}$ & $\mathrm{C}, \mathrm{E}, \mathrm{S}$ \\
\hline Invasive in Germany/other continents ${ }^{3}$ & No/Yes \\
\hline \multicolumn{2}{|l|}{ Ellenberg indicator values ${ }^{4}$} \\
\hline \multicolumn{2}{|l|}{ Height: $50-100^{5}(150)^{7} \mathrm{~cm}$} \\
\hline \multicolumn{2}{|l|}{ Leaves: up $15 \mathrm{~cm}^{5}$} \\
\hline \multicolumn{2}{|l|}{ Cultivated ground and waste places ${ }^{5}$} \\
\hline \multicolumn{2}{|c|}{$\begin{array}{l}\text { Common in South-East Europe and Mediterranean region, but probably } \\
\text { introduced in western and northern parts out of is range } \mathrm{e}^{5}\end{array}$} \\
\hline \multicolumn{2}{|l|}{ Competitiveness $^{7}: 5$} \\
\hline Thermophile, prefers moist and well nutrient s & pplied soils ${ }^{7}$ \\
\hline
\end{tabular}


Table 1.3 Aspects of Datura stramonium L.

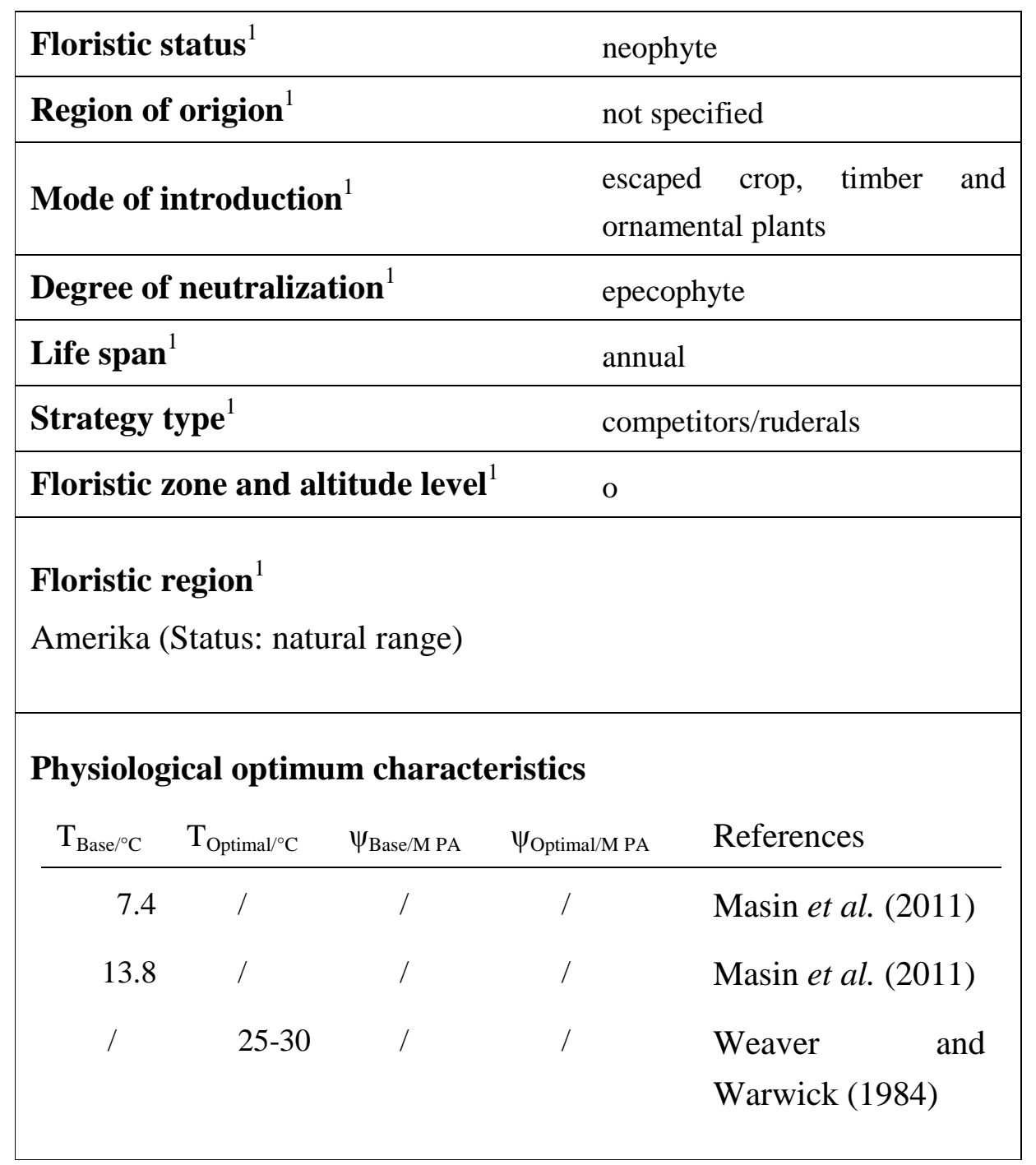

\begin{tabular}{|c|c|}
\hline Hemeroby $^{1}$ & $\mathrm{c} ; \mathrm{p}$ \\
\hline Number of hemerobic levels ${ }^{1}$ & 2 \\
\hline Spread potential $^{2}[1(\min )-3(\max )]$ & 2.07 \\
\hline Weediness $^{2}[1(\min )-3(\max )]$ & 2 \\
\hline Control success $^{2}[1(\min )-3(\max )]$ & 1.93 \\
\hline Crop system $^{2}$ & $1,2,3,4,5,6,7$ \\
\hline Regions $^{2}$ & E,S \\
\hline Invasive in Germany/other continents ${ }^{3}$ & $\mathrm{No} / \mathrm{Yes}$ \\
\hline \multicolumn{2}{|l|}{ Ellenberg indicator values ${ }^{4}$} \\
\hline $\begin{array}{lllll}\text { L } 8 & \text { T } 6 & \text { K x } & \text { F } 4 & \text { R 7 }\end{array}$ & N 8 \\
\hline \multicolumn{2}{|l|}{ Additional information: } \\
\hline \multicolumn{2}{|c|}{ Height: $50-200^{5}(250)^{7} \mathrm{~cm}$; extreme polymorphous ${ }^{7}$} \\
\hline \multicolumn{2}{|l|}{ Leaves: (2.5) $3.5-7 \mathrm{x}(2-) 3-5 \mathrm{~cm}^{5} ; 15 \times 20 \mathrm{~cm}^{6}$} \\
\hline \multicolumn{2}{|l|}{ Competitiveness $^{7}: 4-5$} \\
\hline \multicolumn{2}{|c|}{$\begin{array}{l}\text { Cultivated ground, waste places and other habitats }{ }^{5} \text {; Naturalized in most of } \\
\text { Europe expect the extreme north, but in some regions very irregular in its } \\
\text { appearances }{ }^{5} \text {; Prefers nitrogen rich soils }{ }^{6} \text {, and warm climatic conditions }{ }^{7} \text {; } \\
\text { Germination is slowly and erratic }{ }^{6 ;} \text { Germination in Austria, in late in spring } \\
\text { (April/May) }{ }^{7}\end{array}$} \\
\hline
\end{tabular}


This thesis presents the results of three studies (Tab. 1.5). In Chapters 2 and 3 (processedbased approach) experiments are reported which aimed at testing the effect of increased temperature and reduced soil moisture availability on weed emergence and growth characteristics in four types of soil substrate. The experiments referred to the concept of the biotically reduced niche as the theoretical basis for the experimental design. The concept of a niche was first defined by Grinnell in the year 1917 (Grinell, 1917; Wake et al., 2009; Chuine, 2010). He described a niche as all the sites where organisms of a species can live, or in other words, where conditions are suitable for life. Based on Grinnell's approach, Hutchinson (1957) proposed a broadly used definition of a species fundamental niche, as a set of biotic and abiotic conditions in which a species is able to persist and maintain a stable population size (Hutchinson, 1957; Wiens and Graham, 2005; Soberón and Nakamura, 2009). Per definition the "biotically reduced niche" is conceptually closely related to the realized niche of Hutchinson, because it represents the part of the existing fundamental niche that remains after interactions with the competitors (Peterson et al., 2011).

The purpose of the experiments was to evaluate the environmental plasticity of the weeds. Weeds are generally known to succeed through a plastic response to environmental conditions (Clements and DiTommaso, 2011). Therefore, a changed plant response to the environment in an experiment provides information on how the weeds may react on the site scale under future climatic conditions (Fig. 1.1). We presumed that a faster fulfilled emergence and a higher emergence fraction, accompanied by a better growth performance under a wide range of environmental conditions might be beneficial for distributional success under conditions of a prospective climate change (Chapter 2 and 3).

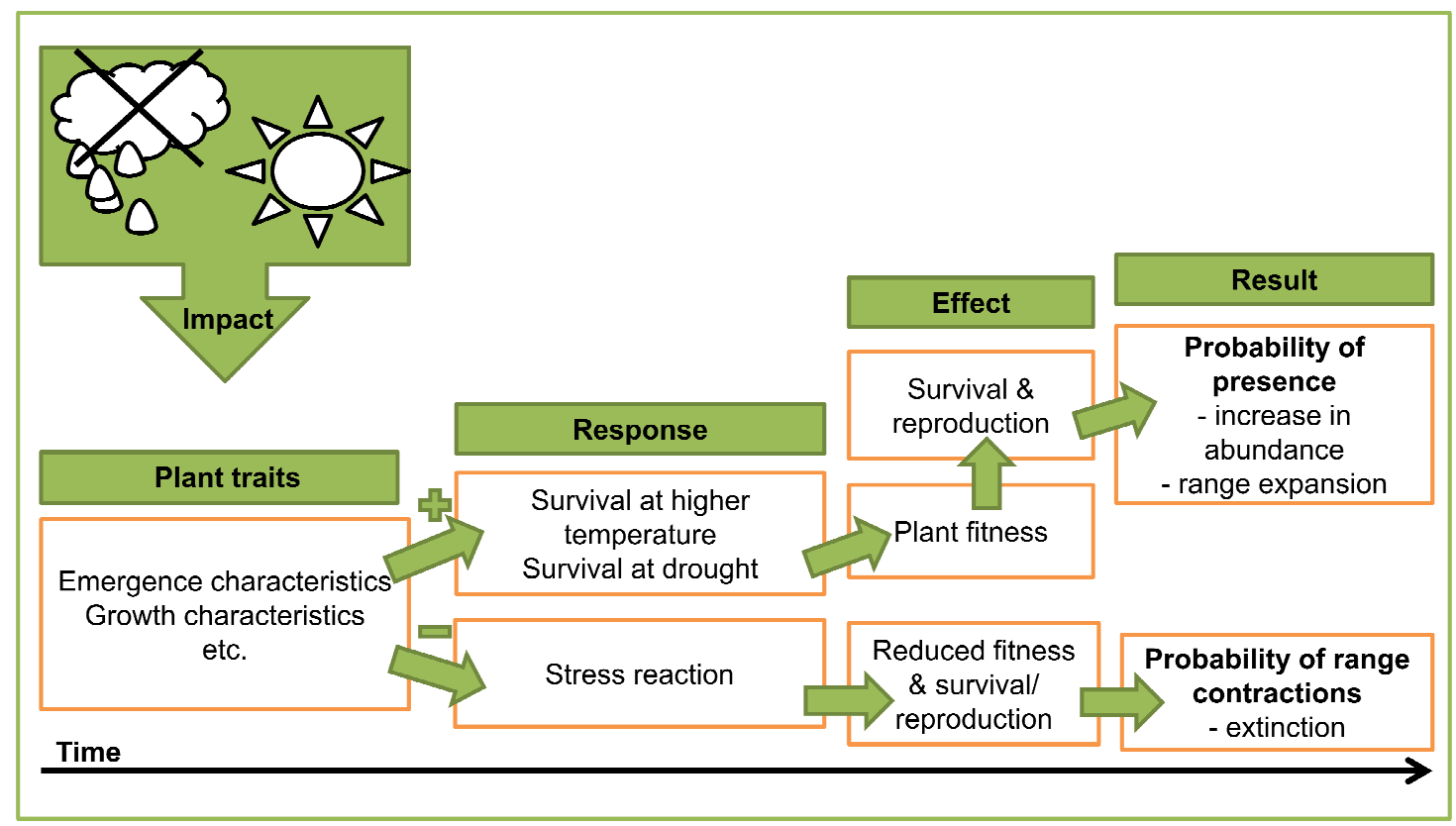

Figure 1.1 Conceptual scheme of how emergence and growth characteristics may affect species distribution under changing climatic conditions. Adapted from Chuine (2010). 
In Chapter 4, we present the use of a correlative approach of bioclimatic niche modelling with the software MaxEnt. We correlate survey data of three target weed species with high-resolution data of environmental factors like climate, land use, land cover and soil type to retrace their current distribution, to project habitat suitability under modelled climatic conditions for the end of the century, and based on this, to conclude on their future potential distribution in northwest Germany (Bürger et al., 2014). Here we assumed that as a result of climate change, areas that have previously been climatically unsuitable for species in northwest Germany may become suitable new habitats (Chapter 4).

However, environmental factors controlling distribution generally operate within a nested hierarchy at certain scale domains. Climatic factors may influence distribution most strongly at a coarse scale. The climatic requirements of a species must be fulfilled, before lower order factors may influence the spatial distribution. Land use features might have a stronger effect at the mesoscale, whereas soil types influence plant distribution at local scales (Pearson and Dawson, 2003). The combined action of these factors provides the bioclimatic niche of a species (Fig. 1.2). The information about the bioclimatic niche and the potential distribution is not equivalent to a realized distribution. Dispersal, disturbance and competition processes have to be considered to assume on the possibility for a weed species to effectively occupy the biotically reduced niche under future climatic conditions (McDonald et al., 2009) (Fig. 1.2).

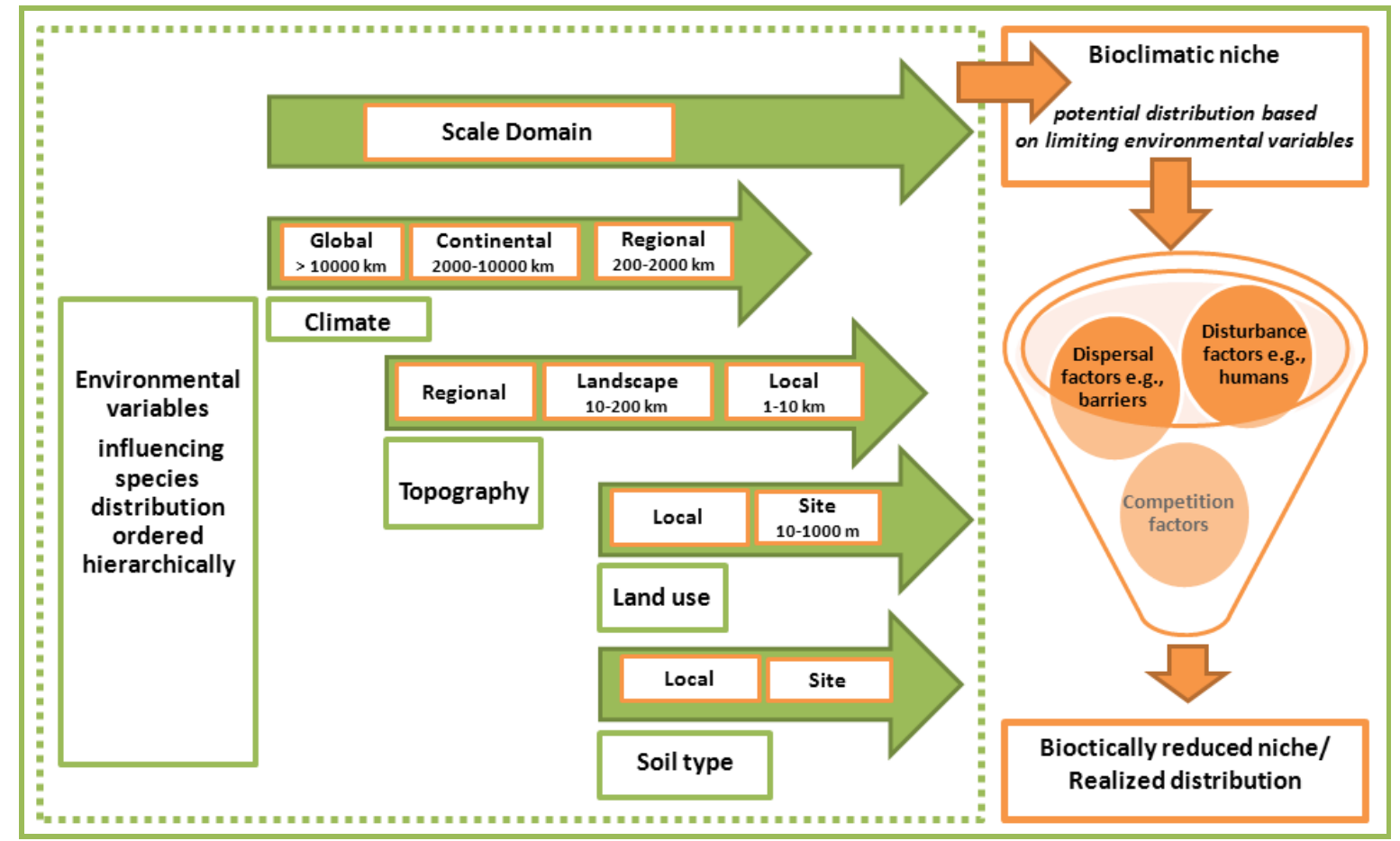

Figure 1.2 A scheme of how different environmental variables govern the distribution of weed species across a range of spatial scales. The scale domain indicates the geographical range at which a set of ecological factors are assumed to act most strongly. The bioclimatic niche determines the potential geographic distribution range of a species. The biotically reduced niche of a species is influenced by factors and processes such as dispersal, disturbance, and competition. Adapted from Pearson and Dawson (2003) in combination with McDonald et al. (2009). 
In the following section of this general introduction the investigated variables and used methods are summarized and roughly outlined in Table 1.5. In the last chapter of this thesis (chapter 5), the results of the studies are comprehensively discussed and general conclusions are drawn (synthesis), followed by a German summary of the thesis.

Table 1.5 An outline of the investigated predictor and response variables and methods, as well as the modelling framework employed within the studies presented in chapter 2 to chapter 4 .

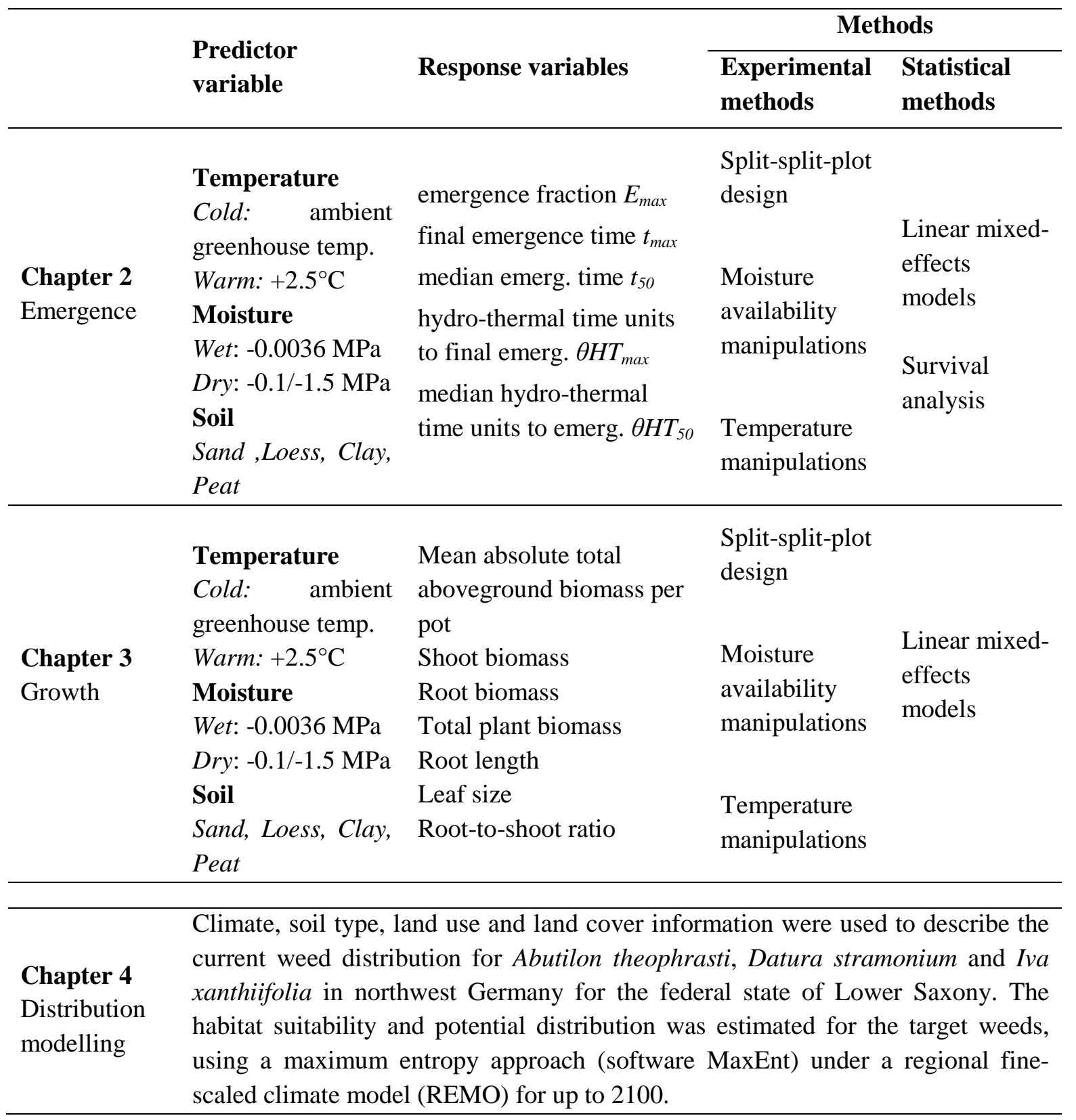




\section{References}

BIOLFLOR - Search and information system on vascular plants in Germany. URL: http://www2.ufz.de/biolflor/index.jsp; last access date 10.09.2013.

BRADLEY, B.A. 2009. Regional analysis of the impacts of climate change on cheatgrass invasion shows potential risk and opportunity. Global Change Biology 15 (1).

Broennimann, O., Treier, U.A., Müller-Schärer, H., Thuiller, W., Peterson, A.T. \& GUISAN, A. 2007. Evidence of climatic niche shift during biological invasion. Ecology Letters 10 (8): 701-709.

Bürger, J., Edler, B., Gerowitt, B. \& Steinmann, H.-H. 2014. Predicting weed problems in maize cropping by species distribution modelling. 26th German Conference on Weed Biology and Weed Control, Julius-Kühn Archiv 443: 379-386.

Chuine, I. 2010. Why does phenology drive species distribution? Philosophical Transactions of the Royal Society B: Biological Sciences 365 (1555): 3149-3160.

Clements, D.R. \& DiTommaso, A. 2011. Climate change and weed adaptation: Can evolution of invasive plants lead to greater range expansion than forecasted? Weed Research 51 (3): 227-240.

Donohue, K., Casas, R.R. De, Burghardt, L., Kovach, K. \& Willis, C.G. 2010. Germination, Postgermination Adaptation, and Species Ecological Ranges 41: 293319.

Dorado, J., Sousa, E., Calha, I.M., Gonzales-Andujar, J.L. \& FernandezQuiNTANILL, C. 2009. Predicting weed emergence in maize crops under two contrasting climatic conditions. Weed Research 49 (3): 251-260.

EllenBERG, H. 1991. Zeigerwerte der Gefäßpflanzen (ohne Rubus)- in: Ellenberg, H., Weber, H. E., Düll, R., Wirth, V., Werner, W., Paulissen, D.: Zeigerwerte von Pflanzen in Mitteleuropa. - Scripta geobotanica 18: 9-166.

EPPO 2013. European and Mediterranean plant protection organisation.

URL: www.eppo.com; last access date 10.09.2013.

FlORAWEB 2013. FloraWeb- Daten und Informationen zu Wildpflanzen und zur Vegetation Deutschlands. URL: www.floraweb.de; last access date 10.09.2013.

Follak, S., Dullinger, S., Kleinbauer, I., Moser, D. \& Essl, F. 2013. Invasion dynamics of three allergenic invasive Asteraceae (Ambrosia trifida, Artemisia annua, Iva xanthiifolia) in Central and Eastern Europe. Preslia 85 (1): 41-61.

Gardarin, A., Guillemin, J.-P., Munier-Jolain, N.M. \& ColbaCh, N. 2010. Estimation of key parameters for weed population dynamics models: Base temperature and base water potential for germination. European Journal of Agronomy 32 (2): 162-168.

GARVE, E. 2007. Verbreitungsatlas der Farn- und Blütenpflanzen in Niedersachsen und Bremen. Naturschutz und Landschaftspflege in Niedersachsen. Niedersächsisches Landesamt für Ökologie, Hannover. 
Glemnitz, M., Hyvönen, T., Radics, L., Hoffmann, J. \& Czimber, G. 2010. Weeds in changing climate - a north European perspective. NJF Report 6 (1): 55-57.

GRINNELL, J. The niche-relationships of the California thrasher. The Auk 1927 (34): 427433.

HeGI, G. 1935 ff. Illustrierte Flora von Mitteleuropa. Band VI, Teil 3. Parey, Berlin, West Germany.

Holzner, W. \& Glauninger, J. 2005. Ackerunkräuter. Bestimmung, Biologie, landwirtschaftliche Bedeutung. Stocker, Leopold, Graz [etc.].

Hutchinson, G.E. 1957. Concluding remarks. Cold Spring Harbor Symposia on Quantitative Biology 22 (2): 415-427.

HuLME, P.E. 2009. Relative roles of life-form, land use and climate in recent dynamics of alien plant distributions in the British Isles. Weed Research 49 (1): 19-28.

KÜHN, I., DURKA, W. \& KLOTZ, S. 2004. BiolFlor - a new plant-trait database as a tool for plant invasion ecology. Diversity and Distributions 10 (5-6): 363-365.

Mack, R.N., Simberloff, D., Lonsdale, W.M., Evans, H., Clout, M. \& Bazzaz, F.A. 2000. Biotic Invasions: Causes, Epidemiology, Global Consequences, and Control. Ecological Applications 10 (3): 689-710.

Masin, R., Loddo, D., Benvenuti, S., Otto, S. \& Zanin, G. 2011. Modeling Weed Emergence in Italian Maize Fields. Weed Science 60 (2): 254-259.

Masin, R., Loddo, D., Benvenuti, S., Zuin, M.C., Macchia, M. \& Zanin, G. 2010. Temperature and Water Potential as Parameters for Modeling Weed Emergence in Central-Northern Italy. Weed Science 58 (3): 216-222.

McDonald, A., Riha, S., DiTommaso, A. \& DeGaetano, A. 2009. Climate change and the geography of weed damage: Analysis of U.S. maize systems suggests the potential for significant range transformations. Agriculture, Ecosystems \& Environment 130 (34): 131-140.

Moseley, C., Panferov, O., Döring, C., Dietrich, J., Haberlandt, U., Ebermann, V., RECHID, D., BEESE, F. \& JACOB, D. 2012. Klimaentwicklung und Klimaszenarien. In: Niedersächsisches Ministerium für Umwelt, Energie und Klimaschutz (ed.) Empfehlung für eine niedersächsische Strategie zur Anpassung an die Folgen des Klimawandels. Regierungskommision Klimaschutz, pp. 18-41.

Myers, M.W., Curran, W.S., VanGessel, M.J., Calvin, D.D., Mortensen, D.A., MajeK, B.A., Karsten, H.D. \& Roth, G.W. 2004. Predicting weed emergence for eight annual species in the northeastern United States. Weed Science 52 (6): 913-919.

NIEDERSÄCHSISCHES MINISTERIUM FÜR UMWELT, ENERGIE UND KLIMASCHUTZ (ed.) 2012. Empfehlung für eine niedersächsische Strategie zur Anpassung an die Folgen des Klimawandels. Regierungskommision Klimaschutz.

PEARson, R.G. \& DAwSON, T.P. 2003. Predicting the impacts of climate change on the distribution of species: are bioclimate envelope models useful? Global Ecology and Biogeography 12 (5): 361-371. 
Peterson, A.T., Soberón, J., Pearson, R.G., Anderson, R.P., Martínez-Meyer, E., NAKAMURA, M. \& ARAúJo, M.B. 2011. Ecological niches and geographic distributions. Princeton University Press, Princeton, NJ.

HoLT, R.D. 1990. The microevolutionary consequences of climate change. Trends in Ecology \& Evolution 5 (9): 311-315.

Scott, J.K., BAtchelor, K.L., OtA, N. \& Yeoh, P.B. 2008. Modelling Climate Change Impacts on Sleeper and Alert Weeds: APPENDIX B: RESULTS OF CLIMEX MODELS Part 1 [CSIRO Entomology, Private Bag, P.O. Wembley WA 6913, Australia].

Soberón, J. \& NAKAmURA, M. 2009. Niches and distributional areas: Concepts, methods, and assumptions. Proceedings of the National Academy of Sciences 106 (Supplement 2): 19644-19650.

Sommer, J.H., Kreft, H., Kier, G., Jetz, W., Mutke, J. \& Barthlott, W. 2010. Projected impacts of climate change on regional capacities for global plant species richness. Proceedings of the Royal Society B: Biological Sciences.

Thomas, C.D. 2010. Climate, climate change and range boundaries. Diversity and Distributions 16 (3): 488-495.

Tölle, M.H., Moseley, C., Panferov, O., Busch, G. \& Knohl, A. 2012. Water supply patterns in two agricultural areas of Central Germany under climate change conditions. Biogeosciences Discussions 9 (4): 5153-5176.

Tutin, T.G., Heywood, V.H., Burges, N.A., Moore, D.M., Valentine, D.H., Walters, S.M. \& WeBB, D.A. (eds.) 1964 ff. Flora Europaea. Cambridge University Press, Cambridge.

WAKE, D.B., HADLY, E.A. \& ACKERLY, D.D. 2009. Biogeography, changing climates, and niche evolution. Proceedings of the National Academy of Sciences 106 (Supplement 2): 19631-19636.

Walther, G.-R. 2010. Community and ecosystem responses to recent climate change. Philosophical Transactions of the Royal Society B: Biological Sciences 365 (1549): 2019-2024.

Weaver, S.E. \& WARWICK, S.I. 1984. The biology of Canadian weeds. 64. Datura stramonium L. Canadian Journal of Plant Science 64: 979-991.

WEBER, E. \& GUT, D. 2005. A survey of weeds that are increasingly spreading in Europe. Agronomy for Sustainable Development 25: 109-121.

Weber, E. \& Schrader, G. 2006. New weed threats; extent, origins and proper managment. Perspectives in Agriculture, Veterinary Science, Nutrition and Natural Resources 47 (1).

Wiens, J.J., Ackerly, D.D., Allen, A.P., Anacker, B.L., Buckley, L.B., Cornell, H.V., Damschen, E.I., Jonathan Davies, T., Grytnes, J.-A., Harrison, S.P., Hawkins, B.A., Holt, R.D., McCain, C.M. \& Stephens, P.R. 2010. Niche conservatism as an emerging principle in ecology and conservation biology. Ecology Letters 13 (10): 1310-1324. 


\section{CHAPTER}

2

Effects of altered temperature and soil water potential in four soil types on the emergence characteristics of three range-expanding annual weeds

Barbara Edler, Laura Breitsameter, Jana Bürger, Horst-Henning Steinmann \& Johannes Isselstein 


\begin{abstract}
In a greenhouse pot experiment, we studied the impact of elevated temperature, reduced soil moisture, and soil type and their interactions on emergence parameters of three annual weed species which are currently spreading in Europe (Abutilon theophrasti, Datura stramonium and Iva xanthiifolia). We assessed the final emergence fraction $\left(E_{\text {max }}\right)$ for each weed species under conditions of ambient temperature ("cold") versus artificial warming (ambient temperature $+2.5^{\circ} \mathrm{C}$; "warm") and at artificial drought (soil water potential between -0.1 to $-1.5 \mathrm{MPa}$; "dry") versus conditions of a soil water potential of -0.0036 MPa ("wet") in four artificial soils (loess, clay, peat and sand based mixtures). We additionally determined emergence time courses: time to final emergence $t_{\max }$, time to emergence of $50 \%$ of the seeds $t_{50}$, hydro-thermal time units to final emergence $\theta H T_{\max }$, and hydro-thermal time units to emergence of $50 \%$ of the seeds $\theta H T_{50}$, and the emergence probability per set of environmental conditions.
\end{abstract}

We found species-specific responses to the different environmental and microsite conditions the seeds were exposed. Drought decreased the number of emerged seedlings in most environmental settings, except for A. theophrasti grown under loess-cold-dry and loess-warm-dry conditions. In the wet treatments, warming enhanced D. stramonium and A. theophrasti seedling emergence in sand soil, and a shorter $t_{\max }$ was observed in loess and clay soils for all three species. For all three species, $t_{50}$ was extended in warm-dry and cold-dry in comparison to warm-wet and cold-wet conditions, with no significant effect of the soil type. Hydrothermal time units were always lowest in sand-warm-dry conditions, for both $\theta H T_{\max }$ and $\theta H T_{50}$. In sand, warm-dry conditions reduced the emergence probability of all three weed species significantly.

Our results indicate that the studied weed species exhibited a rather idiosyncratic response the variety of microsite conditions. The type of soil is important for the emergence characteristics of the studied weeds under elevated temperature and reduced moisture conditions.

Keywords: emergence time course, hydro-thermal units, manipulative experiment, idiosyncratic responses, survival analysis 


\section{Introduction}

Seedling recruitment is one of the first processes in the life cycle that determine whether or not a plant can successfully compete for an ecological niche. It occurs as a result of break of dormancy, germination, and emergence (Walck et al., 2011; Bullied et al., 2012). Various intrinsic and extrinsic factors influence these processes, the underlying core extrinsic factors being temperature, water supply (in particular as provided by precipitation) and the conditions of the soil environment (Baskin and Baskin, 2001). Soil properties influence the process of soil water (Ridolfi et al., 2003) and heat (Hares and Novak, 1992) transfer.

Current changes in global climatic conditions have been recognized to bring about alterations of temperature and precipitation patterns (Parmesan and Yohe, 2003; Thomas, 2010; Moseley et al., 2012). Among various impacts on plant life, they may impede, delay or facilitate early-stage development (Walck et al., 2011). Possible consequences may not only be changes in germination characteristics (Fay and Schultz, 2009), but also altered rates of seedling survival (Lloret et al., 2004) and modified post germination traits (Donohue et al., 2010) of which the effects may scale up to community level and entail changes in population size and structure and in competitive interactions (Larsen et al., 2004; Fay and Schultz, 2009). It is likely that changes in emergence characteristics may be of comparable importance as those concerning reproductive or leaf-out phenology (Donohue et al., 2010). Additionally, plant species with a broader emergence niche may have advantages, both spatially and temporally, which can benefit their abundance and/or distribution (Grime, 1981; Donohue et al., 2010) due to the fact that they have a broad range of environmental tolerance (Brown, 1984; Brändle et al., 2003).

In European agricultural systems, the spatial range expansion of a number of weed species originating from the Mediterranean and subtropical regions is currently being observed (Weber and Gut, 2005). Some of these weeds are expected to become problematic because of their high weediness and competitiveness. For the conception of control and management policies, the estimation of their distribution potential is of prior interest (Broennimann et al., 2007; Hyvönen et al., 2011).

An important question in this context is in which way the observed range shifts will be affected by the expected future climatic conditions involving higher temperatures and prolonged summer drought. Considering the importance of seedling recruitment to the success of a weed species, a better understanding of the influence of microsite characteristics on emergence is required (Bullied et al., 2012).

To our knowledge only a few experimental studies have considered the importance of the type of soil and its interaction with temperature and moisture availability on the emergence of weeds. With the present work, we aim at determining the emergence characteristics of three range-expanding, thermophile agricultural weeds under environmental conditions predicted for the future for Central Europe. In a greenhouse pot experiment, we submitted seeds of Abutilon theophrasti, Datura stramonium and Iva xanthiifolia to conditions of 
warming and drought, compared to ambient climatic conditions, in four different artificial soil types.

Specific objectives of this study were to determine the effects of environmental and microsite conditions ranging from optimal to suboptimal for emergence, on the (1) final emergence fraction and (2) the emergence time courses per tested weed species; (3) to estimate the effects of the emergence time courses on the final emergence fraction and (4) to estimate the emergence probability per environmental treatment.

We assumed that the tested weeds would emerge faster in favourable environmental conditions, and that a faster emergence would have a positive effect on the final emergence fraction based on the findings of Guillemin et al. (2013) for germination. We further used hydrothermal time units to quantitatively characterize the individual environments, and assumed that the emergence probability would decrease under unfavourable conditions. We finally assumed that the type of soil substrate would influence these relationships.

\section{Material and Methods}

\section{Weed species characteristics and seed material}

This study investigated the following three weed species: Abutilon theophrasti Medik. (Malvaceae; common name: velvetleaf), Datura stramonium L. (Solanaceae; jimson weed) and Iva xanthiifolia Nutt. (Asteraceae; marsh elder). All three species are summer annuals that occur in wastelands, cultivated fields, and other frequently disturbed habitats. They are of the strategy type of ruderal competitors (BiolFlor, 2013; based on Kühn et al., 2004). All three species are common in cereal, grain legumes, root crops, vegetables and ornamental, additionally A. theophrasti und D. stramonium are common in orchards and fodder plant, and D. stramonium in vineyards only (Weber and Gut, 2005). The three species show a tendency of shifting their distributional ranges in Europe (Weber and Gut, 2005; Gassó et al., 2010; Follak et al., 2013). Further concern is given for I. xanthiifolia due to its impact on human health as a highly allergenic plant (Hodisan, 2009; Follak et al., 2013).

The distribution of A. theophrasti is currently concentrated in Central, South-East Europe and the Mediterranean region. This thermophile species is found on moist and eutrophic soils (Tutin et al., 1964 ff.; Volume 4). Physiological base temperature for germination ranges between 3.9 (Masin et al., 2010) to $9.0^{\circ} \mathrm{C}$ (Myers et al., 2004). The physiological base water potential is between -1.00 (Dorado et al., 2009) and $0 \mathrm{MPa}$ (Gardarin et al,. 2009).

Datura stramonium is naturalized in most of Europe, expect from the extreme northern regions (Tutin, $1964 \mathrm{ff}$; Volume 4). It is associated with warm climate and nitrogen rich soils (Hegi, 1979 ff.; Volume VI). Physiological base temperature for germination ranges between 7 to $13.8^{\circ} \mathrm{C}$ (Masin et al., 2010). 
Iva xanthiifolia is most common in East-Central and South-East Europe (Tutin, 1964 ff.; Volume 4). This thermophile species is associated with nutrient and humus-rich, loose to slightly compact sandy soils (Hegi, 1979 ff.; Volume VI).

Seeds of $A$. theophrasti and $D$. stramonium were acquired from the experimental botanical garden of Göttingen University, seeds of I. xanthiifolia from the botanical garden of Leipzig University, in the year 2009. The seed populations used in the study were nondormant and achieved a close to complete germination in a germination test (see below). The weed seeds were stored dry in paper bags in dark storage at $4{ }^{\circ} \mathrm{C}$ until the germination test and the emergence experiment were conducted.

\section{Germination test}

The germination test, as well as the main experiment, was conducted at the Centre of Biodiversity and Sustainable Land Use, University of Göttingen, Lower Saxony, Germany. For the germination test, both in 2010 and 2011, one hundred seeds from each species were placed on absorbent paper $(180 \mathrm{~mm} \times 225 \mathrm{~mm})$ that was rolled up to a bundle before being stored in polyethylene bags with $50 \mathrm{ml}$ deionised water to obtain non-limiting water conditions (Gardarin et al., 2011). Four bags per species (12 bags in total) were closed hermetically to avoid water loss and placed horizontally in two RUMED light thermostats type 1401S (Rubarth Apparate GmbH, Laatzen, Germany) equipped with 10 wide beam $150 \mathrm{~W}$ ceramic metal halide lamps (Iwasaki Electric Co. Ltd) with a maximum luminous intensity of $5500 \mathrm{~cd}$. Weeds were exposed to temperature regimes of $30 / 20^{\circ} \mathrm{C}$ and $18 / 10^{\circ} \mathrm{C}$ (representing late spring climatic conditions), with the higher temperatures held for 8 hours and the lower temperatures for 16 hours, respectively. An average light intensity of 140 to $170 \mu \mathrm{mol} \mathrm{m} \mathrm{m}^{-2} \mathrm{~s}^{-1}$ was kept constant. Germinated seeds (counted as germinated, if radicle was viewable) were assessed daily for 21 days and removed from the seed lot. At the end of the test, percentage germination per species and temperature setting were determined. The test showed that the mean final germination percentage was $99 \% \pm 6 \mathrm{SD}$ for $A$. theophrasti, $89 \% \pm 4.5 \mathrm{SD}$ for D. stramonium and 50\% \pm 4 SD for I. xanthiifolia under the $30 / 20^{\circ} \mathrm{C}$ temperature setting and $76 \% \pm 3 \mathrm{SD}$ for A. theophrasti, $72 \% \pm 3.5 \mathrm{SD}$ for $D$. stramonium and $58 \% \pm 2 \mathrm{SD}$ for I. xanthiifolia under the $18 / 10^{\circ} \mathrm{C}$ temperature setting in 2010 and 2011.

\section{Emergence experiment}

Four artificial soils (loess, clay, peat and sand based mixtures), two temperature levels and two soil moisture levels were established in an orthogonal procedure approach. They were combined to create 16 different sets of environmental conditions in order to represent a range of microsites. The soil moisture and temperature treatments were devised to mimic a decline of summer precipitation and an increase of mean temperatures based on the climate change scenario which Moseley et al. (2012) predicted for 2100. 
We used artificial soil mixtures to account for different soil physical environments. Using soil mixtures rather than native soils facilitated manageability, e.g., reduced puddling. Four mixtures were prepared for the experiment, consisting of loess (loess minerals), clay (clay minerals), peat (pure "fibrous peat") or sand (graded quarzsand) mixed with common greenhouse soil [180 mg of $\mathrm{N} / \mathrm{l} ; 180 \mathrm{mg}_{2} \mathrm{O}_{5} / \mathrm{l} ; 260 \mathrm{mg} \mathrm{K} \mathrm{K}_{2} \mathrm{O} / \mathrm{l} ; 130 \mathrm{mg} \mathrm{MgO} / \mathrm{l} ; \mathrm{pH}\left(\mathrm{H}_{2} \mathrm{O}\right)$ 5.9] at 50:50 (w/w) ratio. The pots had a volume of $3000 \mathrm{~cm}^{3}$ and were filled with $1900 \mathrm{~g}$ loess, $1770 \mathrm{~g}$ clay, $900 \mathrm{~g}$ peat or $2300 \mathrm{~g}$ sand soil, respectively. Physical and chemical properties, including the maximum dry density $\left[\mathrm{g} / \mathrm{cm}^{3}\right]$ and the soil moisture content [Vol.$\%$ ] per mixture and soil water potential $(-0.0036,-0.1$ and $-1.5 \mathrm{MPa})$, were assessed (Tab.2.1). These four soil mixtures differed strongly in texture and had a slightly different chemical composition (average $\mathrm{pH}$-value was 6.5-7.2).

Table 2.1 Physical and chemical soil properties analysis for the used loess, clay, peat and sand substrate mixtures

\begin{tabular}{|c|c|c|c|c|c|c|c|c|}
\hline \multirow[b]{2}{*}{ 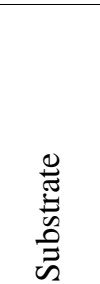 } & \multicolumn{5}{|c|}{ Chemical soil properties } & \multicolumn{3}{|c|}{ Physical soil properties } \\
\hline & $\mathrm{pH}$ & $\begin{array}{c}\mathrm{mg} \\
(\mathrm{C}) / \mathrm{g} \\
\text { (d. m.)* }\end{array}$ & $\begin{array}{c}\mathrm{mg} \\
(\mathrm{N}) / \mathrm{g} \\
\text { (d. m.) }\end{array}$ & $\begin{array}{c}\mathrm{mg} \\
(\mathrm{P}) / \mathrm{g} \\
\text { (d. m.) }\end{array}$ & $\begin{array}{c}\mathrm{mg} \\
(\mathrm{K}) / \mathrm{g} \\
\text { (d. m.) }\end{array}$ & $\begin{array}{l}\text { treatment } \\
\text { "wet" } \\
\text { moist.cont. } \\
\text { (Vol.-\%) }\end{array}$ & $\begin{array}{l}\text { treatment } \\
\text { "dry" } \\
\text { moist. cont. } \\
(\text { Vol.-\%) }\end{array}$ & $\begin{array}{c}\text { dry } \\
\text { density } \\
\left(\mathrm{g} / \mathrm{cm}^{3}\right)\end{array}$ \\
\hline Loess & 7.2 & 60 & 1.3 & 0.5 & 5.8 & 18.4 & 9.1 & 0.633 \\
\hline Clay & 7 & 78 & 1.6 & 0.8 & 13.7 & 20.4 & 9.9 & 0.59 \\
\hline Peat & 6.5 & 295 & 0.7 & 0.7 & 6.7 & 22.7 & 11.4 & 0.3 \\
\hline Sand & 6.7 & 31 & 0.4 & 0.4 & 5.7 & 15 & 7.6 & 0.766 \\
\hline
\end{tabular}

*d. m. dry matter

Half of the pots $(N=32)$ were placed in a greenhouse at ambient temperature (temperature level henceforward named "cold"). The other half were submitted to artificial warming by placing them on a greenhouse table equipped with heater mats and sand as a buffer between the pots and the heating coils (temperature level "warm"). A difference of $+2.5^{\circ} \mathrm{C}$ was established between the two levels of temperature. The measured mean daily air temperatures are shown in Fig. 2.1a. 
a.) Air Temperature

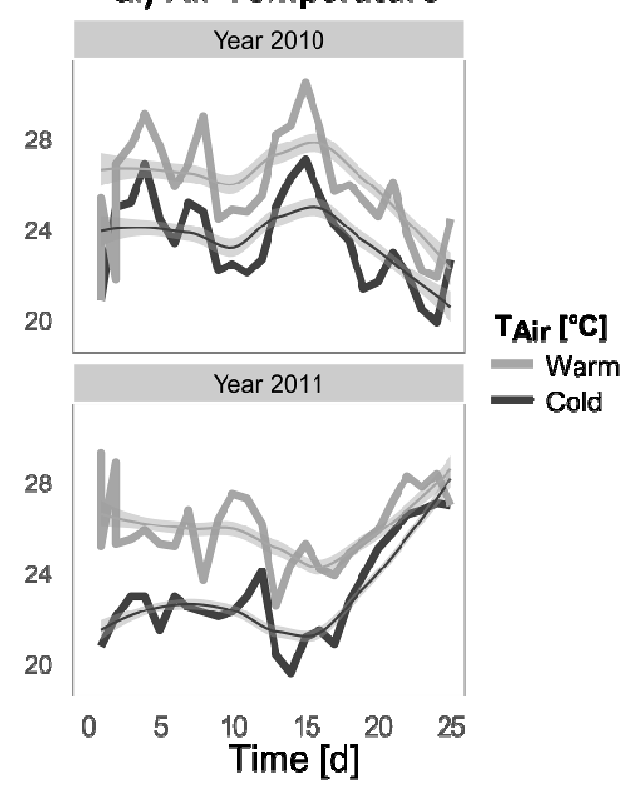

c.) Soil Temperature

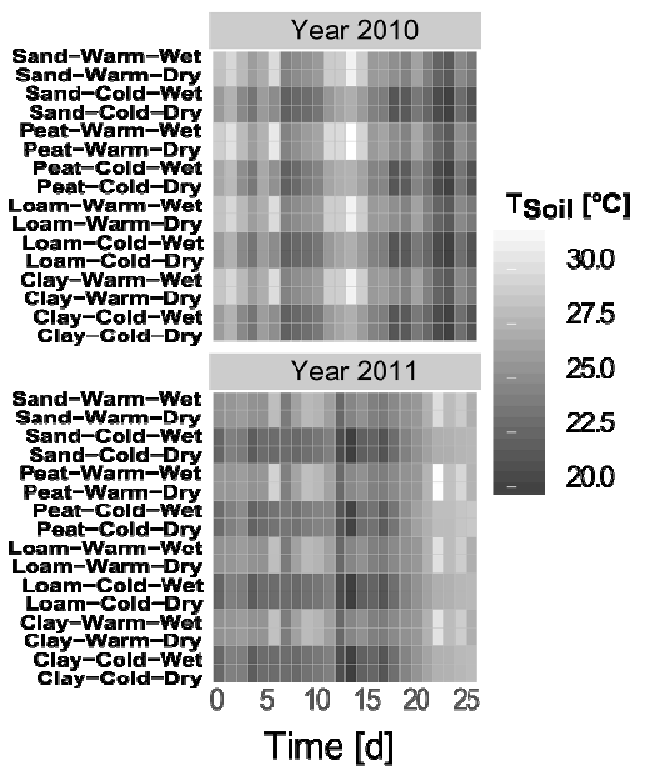

b.) Soil Water Potential

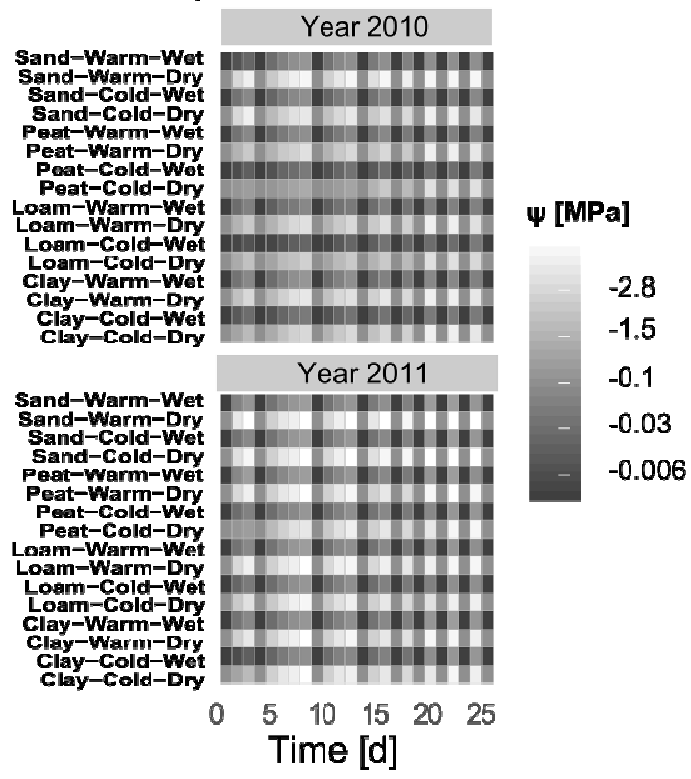

d.) Hydro-Thermal Time

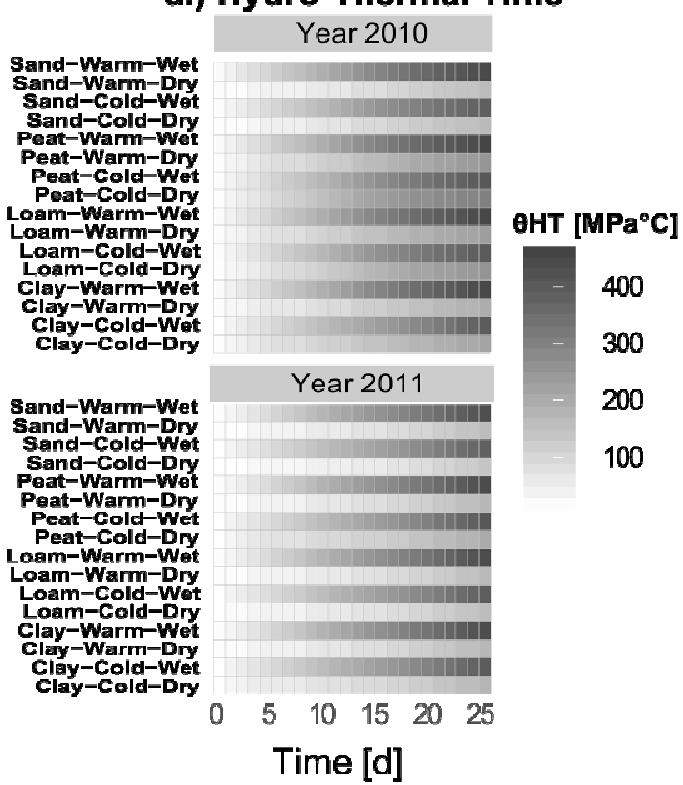

Fig. 2.1 Observed air temperatures (a) and calculated soil water potentials (b), soil temperatures (c) and hydro-thermal time units (d) per artificial environmental treatment during the emergence experiment

For each temperature treatment and each soil we created two levels of soil moisture: In half of the pots $(N=16)$ we simulated drought conditions by keeping a soil water potential of 0.1 to $-1.5 \mathrm{MPa}$ (moisture level "dry"; moisture reduction down to the permanent wilting point of $-1.5 \mathrm{MPa})$. The other half $(N=16)$ were kept at a soil water potential of -0.0036 MPa (moisture level "wet"; at field capacity of $-0.0036 \mathrm{MPa}$ ). Soil moisture levels were produced by differential watering of the pots based on weighing. At the start of the experiment, we had assessed the target weight for each pot which is the sum of the soil 
weight $[\mathrm{g}]$ and the amount of water $[\mathrm{ml}]$ required to create the respective soil moisture level. The amounts of water per soil and moisture treatment were $550 \mathrm{ml}$ for loess-wet with, $230 \mathrm{ml}$ for loess-dry, $610 \mathrm{ml}$ for clay-wet, $300 \mathrm{ml}$ for clay-dry, $680 \mathrm{ml}$ for peat-wet, $340 \mathrm{ml}$ for peat-dry, $450 \mathrm{ml}$ for sand-wet, and $170 \mathrm{ml}$ for sand-dry. The pots were weighed three times per week and the difference to the target weight was balanced with water (Fig. 2.2).

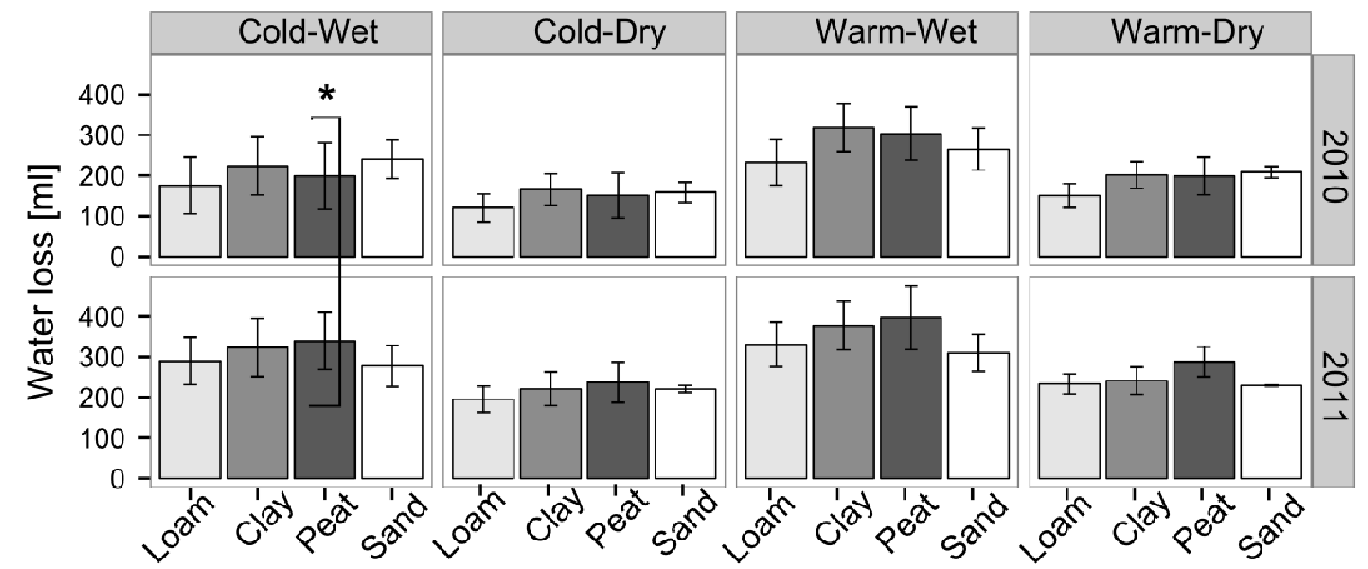

Fig. 2.2 Average water loss $[\mathrm{ml}]$ per date of water supply $(N=15)$ and per artificial environmnetal treatment and year. Significant differences between year and the treatment are marked with *. Errorbas represents ci of the mean.

Water loss was used to calculate soil water potential and content per day, based on the specific relationship between water content and soil water potential for each soil type (Hillel, 1998), with 0,1 $\mathrm{MPa}=100 \mathrm{kPa}=1022 \mathrm{~cm} \mathrm{H}_{2} \mathrm{O}=1$ bar (Fig. 2.1b).

The experiment was set up with a completely randomized design with four replicates per artificial environment (in total 64 pots) and repeated twice in time (years 2010 and 2011).

Seeds of $A$. theophrasti $(N=10), D$. stramonium $(N=10)$ and I. xanthiifolia $(N=12)$ were germinated together in each pot. In sum we used 3584 seeds (4 substrates x 2 temperature treatments x 2 moisture treatments $x 4$ replicates $x 2$ years and 32 seeds per replicate).

Over a period of 25 days, the emergence pattern of the three species was recorded. The number of emerged seeds was determined every day, and specimens were counted as emerged, if the seedling was visible at the soil surface. Emerged weeds were marked with coloured toothpicks per observation date, yielding a temporal sequence of emergence numbers.

\section{Air and soil temperature}

The ambient greenhouse air temperature (level cold) and the heated greenhouse table air temperature (level warm) were measured permanently with two climate data loggers (Log 32, TFA Dostmann, Germany) per temperature treatment (Fig. 2.1a). Loggers were placed in white boxes $5 \mathrm{~cm}$ above the soil surface. 
The high amount of organic matter complexes in the peat, and clay soil substrates impeded a precise soil temperature measurement with a soil thermometer (Hillel, 1998; IAEA, 2008; Wisser et al., 2011). For this reason, soil temperature $T(z, t)\left[{ }^{\circ} \mathrm{C}\right]$ was calculated based on soil surface temperature, soil depth $(z)$ and time $(t)$ for each soil type and moisture level according to the thermal heat conductance equation by Hillel (1998), with a diurnal variation in air temperature as a boundary value [1]:

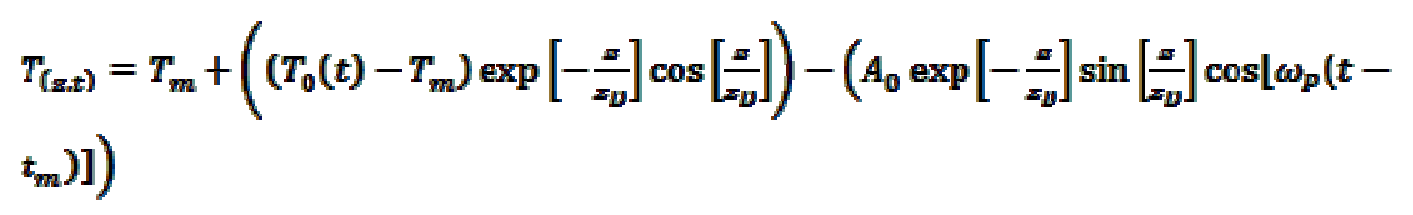

where $T_{0}(t)$ is the soil surface temperature $\left[{ }^{\circ} \mathrm{C}\right]$ as a function of time $\mathrm{t}[\mathrm{s}], T_{m}$ is the mean temperature at the soil surface $\left[{ }^{\circ} \mathrm{C}\right], A_{0}$ is the amplitude of the soil surface temperature fluctuation $\left[{ }^{\circ} \mathrm{C}\right], z$ is the depth $[\mathrm{m}]$ which soil temperature is calculated for, $z_{D}$ is the damping depth $[\mathrm{m}], \omega_{P}$ is the angular frequency of the diurnal oscillation $[1 / \mathrm{s}]$ with $\omega=86400 \mathrm{~s}$ and $t_{m}$ is the time to reach $\mathrm{T}_{\mathrm{m}}[\mathrm{s}]$.

One mean soil temperature value per day for the sowing depth $(z)$ of $0.05 \mathrm{~m}$ was calculated per environmental treatment (Fig. 2.1c). The values of damping depth $z_{D}[\mathrm{~cm}]$ for diurnal variation per soil type, porosity and soil water content were chosen according to the 'average thermal properties of soils and snow' as given in van Wijk (1963). The following $z_{D}$ values were used for calculation: sand-dry: $15.2 \mathrm{~cm}$; sand-wet: $14.3 \mathrm{~cm}$; loess-dry: 13.8 cm; loess-wet: $13.2 \mathrm{~cm}$; clay-dry: $12.4 \mathrm{~cm}$; clay-wet: $12.2 \mathrm{~cm}$; peat-dry: $5.6 \mathrm{~cm}$ and peatwet $6.1 \mathrm{~cm}$.

\section{Emergence parameters}

Twenty-five days after sowing, the final cumulated emergence fraction $\left(E_{\max }\right)$ per weed species and environmental treatment was determined. Emergence time courses in days (d) to final emergence fraction $\left(t_{\max }\right)$ and to emergence of $50 \%$ of the seeds $\left(t_{50}\right)$ were determined for each species and environmental treatment. For each emergence time course, hydro-thermal time units $(\theta \mathrm{HT})\left[\mathrm{MPa}^{\circ} \mathrm{C} \mathrm{d}\right]$ to $E_{\max }\left(\theta H T_{\max }\right)$ and the hydro-thermal time units to emergence of $50 \%$ of the seeds $\left(\theta H T_{50}\right)$ were calculated following an equation of Alvarado and Bradford (2002). The hydro-thermal time provide insight into how physiological and environmental factors interact to regulate the germination behaviour of seed populations.

We distinguished between time and hydro-thermal time units in order to provide precise speed parameters on the one hand $\left(t_{\max }\right.$ and $\left.t_{50}\right)$ and to characterise the environment $\left(\theta H T_{\max }\right.$ and $\left.\theta H T_{50}\right)$ which acted upon the seeds during the emergence phase on the other. We assessed $t_{50}$ and $\theta H T_{50}$ to reveal possible differences in the emergence time courses caused by the finite experimental duration.

We modified the formula given in Alvarado and Bradford (2002) for our approach in the following way: we replaced the factor time to germination $\left(t_{g}\right)$ with the factor time to emergence $\left(t_{e}\right)$, considering the limitation of a possible time delay, or dropout [2]: 


\section{$\theta \mathrm{HT}=\left(\psi\right.$ soil $\left.-\psi_{b}\right) *\left(T\right.$ soil $\left.-T_{b}\right) * t_{a}[2]$}

For each treatment, $\theta \mathrm{HT}$ were calculated for each weed species by summing up the product differences of daily soil water potential $\left(\psi_{\text {soil }}\right)$ and daily soil temperature $\left(T_{\text {soil }}\right)$ to their respective base or minimum values $\left(\psi_{b}, T_{b}\right)$ at a time of a given emergence percentage $t_{e}$ (Köchy and Tielbörger, 2007). According to Alvarado and Bradford (2002), no emergence will occur at soil temperature and water potential values below $T_{b}$ and $\psi_{b}$.

Days where temperature and/or moisture are below the base values do not add to the $\theta H T$ value. Therefore the values of the final observed $\theta H T$ product are lower in environments with very low soil moisture or temperature compared to other environmental conditions (Fig. 2.1d).

Base temperatures and base water potentials were adopted from literature. Data was only available for germination characteristics and may be biased for emergence calculation. In the succeeding sections of this paper the term germination will be equalized with the term emergence. For $A$. theophrasti and D. stramonium a range of $T_{b}$ values from 3 to $11.2{ }^{\circ} \mathrm{C}$ was found (Dorado et al., 2009; Gardarin et al., 2009; Masin et al., 2010; Loddo et al., 2012). For most weeds, $\psi_{b}$ values range from -0.1 to $-1.5 \mathrm{MPa}$ (Bullied et al., 2012). No information was available on the emergence requirements of $I$. xanthiifolia. For simplification we assumed an equal $T_{b}$ of $7^{\circ} \mathrm{C}$ and $\psi_{b}$ of $-1 \mathrm{MPa}$ for all three species, according to Bullied et al. (2012). However, $T_{b}$ and $\psi_{b}$ may vary among species and also within species (ecotypes), because of genetic and phenotypic plasticity (Köchy and Tielbörger, 2007).

Our experimental approach is limited by a number of simplified assumptions e.g., artificial soil types were used and micro-scale processes were not represented in the calculations. The soil hydro and thermal regime is strongly influenced by a complex interaction between climate, topography, hydrology and vegetation (Wisser et al., 2011), which could not be taken into account in this study. However, a good estimation of the environment acting upon seedling recruitment can be made using soil water potential and soil temperature (Roman et al., 2000; Bullied et al., 2012)

\section{Data analysis}

All statistical analyses were conducted using the software R (R Development Core Team, 2013).

\section{Germination parameters}

The package nlme (Pinheiro et al., 2012) was used to calculate a linear mixed effects model to analyse the effects of the treatments on $E_{\max }, t_{\max }, t_{50}, \theta H T_{\max }, \theta H T_{50}$ with the lme () function. We entered soil, soil moisture content and temperature as fixed effects, and included year and replicate as random effects in the maximal model. 
Model simplification was done by successively removing non-significant terms and by comparing the models using Akaike information criterion (AIC) until the minimal adequate model was obtained. The models were checked by plotting standardised residuals against fitted values (Zuur, 2009). Visual inspection of residual plots did not reveal deviation from homoscedasticity or normality in any of the obtained minimal models.

\section{Emergence probability}

To analyse the temporal emergence pattern we used $\theta H T_{\max }$ and $t_{\max }$ to calculate the probability of emergence after a specific time $\mathrm{t}$ [d] or after a specific $\theta H T$ unit $\left[\mathrm{MPa}^{\circ} \mathrm{C} \mathrm{d}\right]$. To visualize the emergence probability for $t_{\max }$ and $\theta H T_{\max }$, and to extract the emergence time courses $\left(t_{\max }, t_{50}, \theta H T_{\max }\right.$ and $\left.\theta H T_{50}\right)$ for each species and treatment we used the Kaplan-Meier estimates, as implemented in the function survit (). We tested for differences in emergence patterns for $t_{\max }$ or $\theta H T_{\max }$ among the environmental treatments using the function survdiff (). We performed a survival analysis (time-to-event method) for $t_{\max }$ and $\theta H T_{\max }$ of emergence using the accelerated failure time (AFT) regression with the survreg function, following the recommendations of Onofri et al. (2010) and of McNair et al. (2012). Therefore, we presumed a right censoring of non-germinated, but still viable seeds; seeds that had not emerged within the 25 days of observation after sowing were expected to emerge at an unknown time after the end of the experiment (Hirsch et al., 2012).

AFT regression is based on the distribution of the emergence time courses, rather than on the cumulative emergence (McNair et al., 2012). The most appropriate form of distribution (e.g., exponential, logistic, lognormal or Weibull) for the emergence time courses was selected by using the AIC. $\theta H T_{\max }$ and $t_{\max }$ were obtained from final minimal adequate AFT models per species with best fits for Weibull distribution. The fit of the models was checked graphically by comparing the fitted curves with those obtained using the KaplanMeier estimator (Déley et al., 2013).

Explanatory variables (soil, soil moisture and temperature level) were introduced as time accelerated factors and year was added as frailty term to test, if the model is affected by their variation. Replicates were pooled for the AFT regression and not taken into account as frailty term. The Kaplan-Meier statistics as well as the survival analysis were calculated with the package survival (Therneau and Lumley, 2012).

\section{Soil water loss and air temperature}

Soil water loss was analysed by calculating a three-way ANOVA with soil, temperature and moisture treatment as fixed factors; year was included as error term and replicates were pooled.

The model was simplified using the step procedure of R. QQL plots were used to inspect for normality of the residuals or variances of heterogeneity. Model corrected mean values, confidence intervals and standard errors of tested effects were calculated with the TukeyHSD function of R (Zuur, 2009). To estimate the differences among the treatments, a post-hoc multiple comparisons of means using Tukey contrasts with a Bonferroni test 
correction was conducted (multcomp package; based on Hothorn et al., 2008) for the observed soil water loss.

The mean water loss per date of water supply in the dry treatment was lower in the year 2010 than 2011 (Fig. 2.2). The soil water loss was significant influenced by the soil type $[F(3,1)=6.84, p=0.0001]$, temperature $[F(1,1)=31.11, p<0.001]$ and moisture $[F(1,3)=$ $79.92, p<0.001]$ treatment. Year also had a significant effect $[F(3,1)=2.79, p=0.04]$ on soil water loss.

Temperature records showed that the surface air temperature of the elevated temperature treatment (level warm) was increased by $2.4 \pm 0.2^{\circ} \mathrm{C}$ for 2010 and $2.3 \pm 1.1^{\circ} \mathrm{C}$ for 2011 compared to the ambient temperature (level cold) in the greenhouse $\left(22.5 \pm 3.9^{\circ} \mathrm{C}\right.$ in 2010 and of $23.6 \pm 5.7^{\circ} \mathrm{C}$ in 2011 ).

\section{Results}

Final emergence fraction $\left(E_{\max }\right)$

Observed emergence fractions over time in days per environmental treatment and species are displayed in Fig. 2.3. For A. theophrasti, the minimum adequate model for $E_{\max }$ comprised the factors soil, moisture, temperature and the soil $\mathrm{x}$ moisture interaction as fixed effects (Tab. 2.2). 
Table 2.2 ANOVA results of three-factorial mixed model after model simplification (/: fixed effect removed to obtain minimum adequate model) showing the effects of soil, temperature and moisture content on the final emergence fraction $\left(E_{\max }\right)$, the time to final emergence $\left(t_{\max }\right)$, the hydro-thermal time units to final emergence $\left(\theta H T_{\max }\right)$, the time to emergence of $50 \%$ of seeds $\left(t_{50}\right)$ and the hydro-thermal time units to emergence of $50 \%$ of the seeds $\left(\theta H T_{50}\right)$ for $A$. theophrasti, D. stramonium, I. xanthiifolia.

\begin{tabular}{|c|c|c|c|c|c|c|c|}
\hline \multirow[b]{2}{*}{$\begin{array}{l}\text { Factor/ } \\
\text { Character }\end{array}$} & \multirow[b]{2}{*}{${ }_{\mathrm{num}} d f$} & \multicolumn{2}{|c|}{ A. theophrasti } & \multicolumn{2}{|c|}{ D.stramonium } & \multicolumn{2}{|c|}{ I. xanthiifolia } \\
\hline & & $\operatorname{den} d f$ & $p$ & $\operatorname{den} d f$ & $p$ & $\operatorname{den} d f$ & $p$ \\
\hline \multicolumn{8}{|l|}{$\mathbf{E}_{\max }$} \\
\hline Soil (S) & 3 & 112 & n.s & 109 & $* * *$ & l & l \\
\hline Temp. (T) & 1 & 112 & $* * *$ & 109 & n.s & 118 & $* * *$ \\
\hline Moist. (M) & 1 & 112 & n.s. & 109 & $* * *$ & 118 & $* * *$ \\
\hline $\mathrm{S} \times \mathrm{T}$ & I & / & / & 109 & $* *$ & I & / \\
\hline$S \times M$ & 3 & 112 & $*$ & 109 & $* * *$ & l & l \\
\hline $\mathrm{T} \times \mathrm{M}$ & / & / & l & I & l & l & l \\
\hline$S \times T \times M$ & I & I & I & l & l & l & l \\
\hline \multicolumn{8}{|l|}{$t_{\max }$} \\
\hline Soil (S) & 3 & 105 & n.s & 105 & n.s & l & l \\
\hline Temp. (T) & 1 & 105 & n.s & 105 & n.s & 118 & $* * *$ \\
\hline Moist. (M) & 1 & 105 & n.s & 105 & n.s & 118 & $* * *$ \\
\hline $\mathrm{S} \times \mathrm{T}$ & 3 & 105 & n.s & 105 & n.s & I & 1 \\
\hline$S \times M$ & 3 & 105 & n.s & 105 & n.s & I & I \\
\hline $\mathrm{T} \times \mathrm{M}$ & 3 & 105 & n.s & 105 & n.s & I & I \\
\hline $\mathrm{S} \times \mathrm{T} \times \mathrm{M}$ & 1 & 105 & n.s & 105 & n.s & l & I \\
\hline \multicolumn{8}{|l|}{$\theta H T_{\max }$} \\
\hline Soil (S) & 3 & 111 & n.s & 116 & $* *$ & I & I \\
\hline Temp. (T) & 1 & 111 & n.s & I & / & 118 & $* * *$ \\
\hline Moist. (M) & 1 & 111 & $* * *$ & 116 & $* * *$ & 118 & $* * *$ \\
\hline $\mathrm{S} \times \mathrm{T}$ & I & I & I & I & I & I & I \\
\hline$S \times M$ & 3 & 111 & $*$ & I & I & I & I \\
\hline $\mathrm{T} \times \mathrm{M}$ & 3 & 111 & $* *$ & I & I & I & I \\
\hline $\mathrm{S} \times \mathrm{T} \times \mathrm{M}$ & I & 1 & 1 & 1 & 1 & I & 1 \\
\hline \multicolumn{8}{|l|}{$t_{50}$} \\
\hline Soil (S) & 3 & 105 & $* * *$ & 105 & $* *$ & 112 & n.s. \\
\hline Temp. (T) & 1 & 105 & n.s & I & I & 112 & $*$ \\
\hline Moist. (M) & 1 & 105 & n.s & 105 & $* * *$ & 112 & n.s. \\
\hline$S \times T$ & 3 & 105 & n.s & I & I & I & I \\
\hline$S \times M$ & 3 & 105 & n.s & I & I & 112 & $*$ \\
\hline $\mathrm{T} \times \mathrm{M}$ & 3 & 105 & n.s & I & I & I & I \\
\hline $\mathrm{S} \times \mathrm{T} \times \mathrm{M}$ & 1 & 105 & n.s & 1 & 1 & I & 1 \\
\hline \multicolumn{8}{|l|}{$\theta H T_{50}$} \\
\hline Soil (S) & 3 & 112 & n.s & 114 & $* *$ & I & I \\
\hline Temp. (T) & 1 & 112 & n.s & 1141 & n.s. & 118 & $* *$ \\
\hline Moist. (M) & 1 & 112 & $* * *$ & 1141 & $* * *$ & 118 & $* * *$ \\
\hline $\mathrm{S} \times \mathrm{T}$ & / & I & I & I & / & I & I \\
\hline$S \times M$ & 3 & 112 & $* *$ & I & I & I & I \\
\hline $\mathrm{T} \times \mathrm{M}$ & I & I & / & 1141 & $* *$ & I & I \\
\hline$S \times T \times M$ & I & I & 1 & I & / & I & I \\
\hline
\end{tabular}




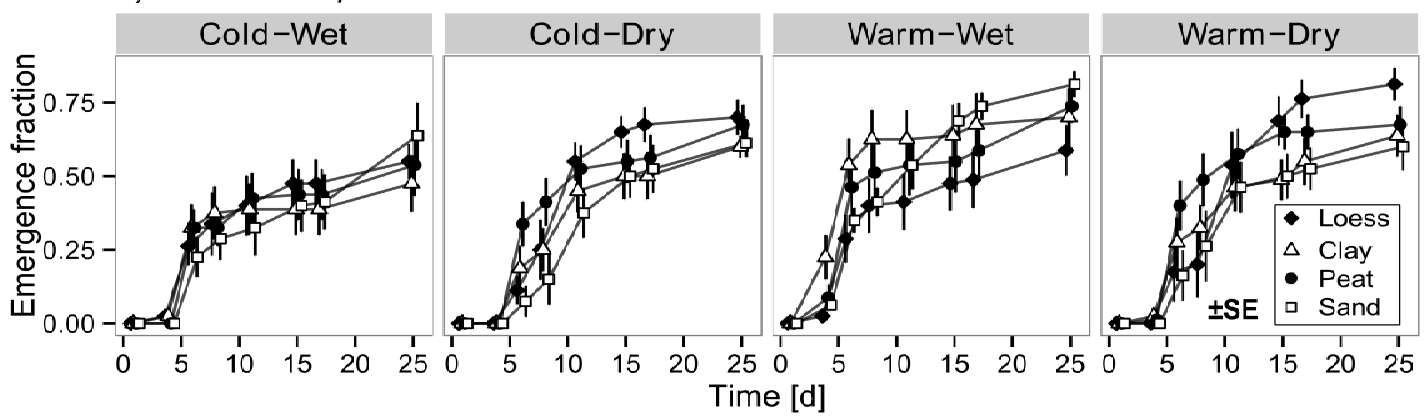

b) Datura stramonium

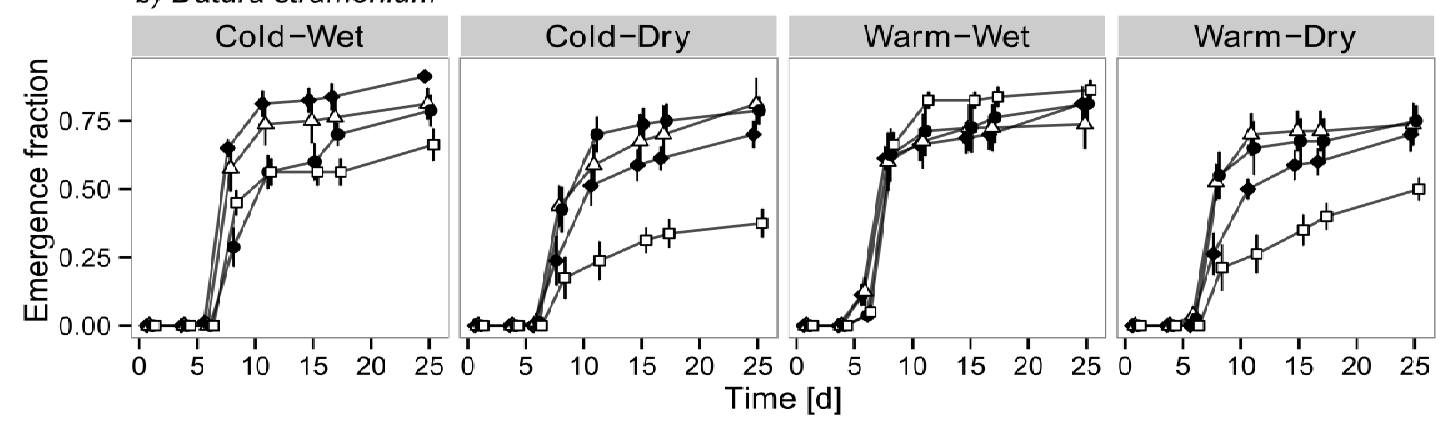

c) Iva xanthiifolia

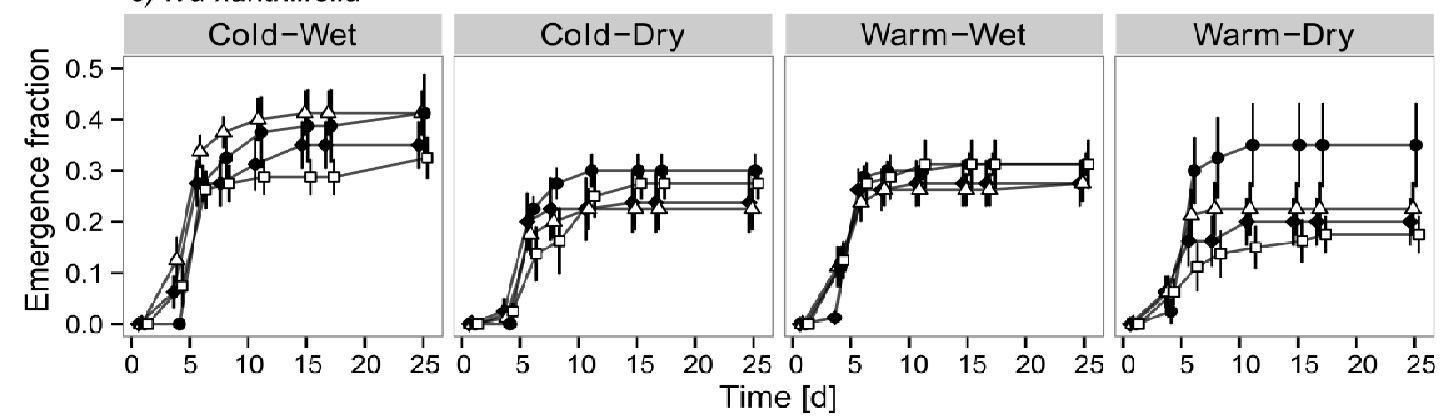

Fig. 2.3 Observed cumulative emergence time courses in four soil substrate mixtures $(\bullet-$ loess, $\triangle$-clay, •-peat, $\square$-sand) per climatic treatment (cold-wet, cold-dry, warm-wet, warm-dry) for A. theophrasti, D. stramonium and I. xanthiifolia. Symbols represent actual data points.

In all four soil types, warm conditions had a significant positive effect on $E_{\max }$ of $A$. theophrasti (Student's t-test, $p=0.0079$ ) (Tab. 2.3). The species tended to achieve a higher $E_{\max }$ under warm-wet than under cold-dry and warm-dry conditions in all soil types except from loess. In loess, dry conditions had a positive effect on $E_{\max }$. The highest emergence of A. theophrasti (Student's t-test, $p=0.0031$ ) was recorded under sand-warm-wet $(0.81)$, the lowest under loess-cold-wet (0.55) and clay-cold-wet conditions (0.47).

For D. stramonium, the factors soil, moisture, and the soil $\mathrm{x}$ temperature and soil $\mathrm{x}$ moisture interactions were significant effect on $E_{\max }$. Emergence was reduced in the dry treatments, but the effect of temperature was smaller than in A. theophrasti. In sand, $E_{\max }$ was significantly reduced under dry in comparison to wet conditions (Student's t-test, $p=$ 0.0001). D. stramonium showed highest emergence under loess-cold-wet and sand-coldwet ( 0.91 and 0.86 , respectively), and the lowest under sand-warm-dry and sand-cold-dry conditions ( 0.50 and 0.37 , respectively) (Tab. 2.3). 
Table 2.3 Emergence parameters for A. theophrasti, D. stramonium and I. xanthiifolia. Emax: final emergence fraction, $t_{\max }$ : time to final emergence, $\theta H T_{\max }$ : hydro-thermal time units to final emergence, $t_{50}$ : time to emergence of $50 \%$ of the seeds, $\theta H T_{50}$ : hydro-thermal time units to emergence of $50 \%$ of the seeds.

A. theophrasti

\begin{tabular}{|c|c|c|c|c|c|c|c|c|c|c|}
\hline Environm. treatment & $E_{\max }$ & SE & $\begin{array}{l}t_{\max } \\
\text { [d] }\end{array}$ & SE & $\begin{array}{c}\theta H T_{\max } \\
{\left[\mathrm{MPa}{ }^{\circ} \mathrm{Cd}\right]}\end{array}$ & SE & $\begin{array}{l}t_{50} \\
{[\mathrm{~d}]}\end{array}$ & SE & $\begin{array}{c}\theta H T_{50} \\
{\left[\mathrm{MPa}^{\circ} \mathrm{Cd}\right]}\end{array}$ & SE \\
\hline Loess-Cold-Wet & 0.55 & 0.059 & 15 & 2.4 & 243 & 38.2 & 8 & 1.8 & 151 & 27.9 \\
\hline Loess-Cold-Dry & 0.70 & 0.059 & 17 & 2.1 & 145 & 20.6 & 9 & 0.7 & 89 & 14.2 \\
\hline Loess-Warm-Wet & 0.59 & 0.085 & 16 & 2.8 & 335 & 48.8 & 8 & 1.8 & 174 & 30.1 \\
\hline Loess-Warm-Dry & 0.81 & 0.054 & 17 & 1.9 & 131 & 16.3 & 9 & 1.1 & 84 & 13.7 \\
\hline Clay-Cold-Wet & 0.47 & 0.095 & 17 & 3.2 & 258 & 54.7 & 6 & 2.0 & 128 & 32.1 \\
\hline Clay-Cold-Dry & 0.60 & 0.037 & 18 & 2.5 & 143 & 13.9 & 10 & 1.6 & 91 & 9.6 \\
\hline Clay-Warm-Wet & 0.70 & 0.098 & 14 & 2.8 & 258 & 52.4 & 5 & 0.4 & 191 & 8.5 \\
\hline Clay-Warm-Dry & 0.64 & 0.070 & 18 & 2.9 & 132 & 22.5 & 8 & 1.1 & 67 & 8.1 \\
\hline Peat-Cold-Wet & 0.54 & 0.105 & 18 & 3.1 & 267 & 56.4 & 7 & 1.8 & 142 & 27.1 \\
\hline Peat-Cold-Dry & 0.67 & 0.067 & 17 & 2.9 & 181 & 17.2 & 7 & 1.0 & 92 & 8.5 \\
\hline Peat-Warm-Wet & 0.74 & 0.056 & 18 & 2.5 & 331 & 45.4 & 7 & 1.9 & 140 & 34.3 \\
\hline Peat-Warm-Dry & 0.67 & 0.061 & 12 & 2.1 & 110 & 16.3 & 6 & 0.9 & 64 & 7.6 \\
\hline Sand-Cold-Wet & 0.64 & 0.111 & 20 & 2.7 & 320 & 42.9 & 11 & 2.3 & 193 & 34.5 \\
\hline Sand-Cold-Dry & 0.61 & 0.047 & 17 & 2.4 & 109 & 14.3 & 12 & 1.4 & 59 & 7.7 \\
\hline Sand-Warm-Wet & 0.81 & 0.044 & 20 & 2.2 & 375 & 38.2 & 8 & 1.2 & 150 & 20.6 \\
\hline Sand-Warm-Dry & 0.60 & 0.080 & 17 & 2.3 & 104 & 16.1 & 9 & 1.0 & 57 & 6.0 \\
\hline \multicolumn{11}{|l|}{ D. stramonium } \\
\hline Environm. treatment & $E_{\max }$ & SE & $\begin{array}{l}t_{\max } \\
{[\mathrm{d}]}\end{array}$ & SE & $\begin{array}{c}\theta H T_{\max } \\
{\left[\mathrm{MPa}{ }^{\circ} \mathrm{Cd}\right]}\end{array}$ & SE & $\begin{array}{l}t_{50} \\
{[\mathrm{~d}]}\end{array}$ & SE & $\begin{array}{c}\theta H T_{50} \\
{\left[\mathrm{MPa}^{\circ} \mathrm{Cd}\right]}\end{array}$ & SE \\
\hline Loess-Cold-Wet & 0.91 & 0.022 & 17 & 2.4 & 284 & 39.3 & 7 & 0.0 & 119 & 2.0 \\
\hline Loess-Cold-Dry & 0.70 & 0.050 & 20 & 2.5 & 165 & 23.3 & 10 & 0.7 & 90 & 17.1 \\
\hline Loess-Warm-Wet & 0.81 & 0.063 & 17 & 2.9 & 319 & 54.1 & 8 & 0.7 & 146 & 12.5 \\
\hline Loess-Warm-Dry & 0.70 & 0.062 & 20 & 1.8 & 158 & 3.2 & 9 & 0.4 & 67 & 9.8 \\
\hline Clay-Cold-Wet & 0.81 & 0.058 & 16 & 2.1 & 264 & 35.3 & 7 & 0.3 & 132 & 7.9 \\
\hline Clay-Cold-Dry & 0.81 & 0.095 & 20 & 1.8 & 164 & 5.4 & 8 & 0.4 & 79 & 6.5 \\
\hline Clay-Warm-Wet & 0.76 & 0.077 & 16 & 2.7 & 294 & 29.3 & 7 & 0.5 & 137 & 10.0 \\
\hline Clay-Warm-Dry & 0.73 & 0.077 & 17 & 2.6 & 116 & 19.8 & 8 & 0.2 & 65 & 5.2 \\
\hline Peat-Cold-Wet & 0.78 & 0.058 & 22 & 1.4 & 377 & 22.0 & 8 & 0.5 & 146 & 10.5 \\
\hline Peat-Cold-Dry & 0.78 & 0.051 & 16 & 2.8 & 167 & 17.8 & 8 & 0.4 & 103 & 7.7 \\
\hline Peat-Warm-Wet & 0.81 & 0.069 & 17 & 2.6 & 312 & 47.5 & 7 & 0.3 & 140 & 6.3 \\
\hline Peat-Warm-Dry & 0.75 & 0.056 & 15 & 2.2 & 128 & 21.8 & 7 & 07 & 71 & 7.5 \\
\hline Sand-Cold-Wet & 0.66 & 0.059 & 17 & 2.9 & 277 & 47.1 & 9 & 1.3 & 140 & 19.5 \\
\hline Sand-Cold-Dry & 0.37 & 0.052 & 14 & 1.9 & 100 & 16.7 & 10 & 1.5 & 63 & 12.6 \\
\hline Sand-Warm-Wet & 0.86 & 0.037 & 16 & 2.3 & 273 & 44.7 & 7 & 0.0 & 141 & 3.2 \\
\hline Sand-Warm-Dry & 0.50 & 0.042 & 15 & 2.8 & 97 & 20.2 & 11 & 1.6 & 61 & 10.6 \\
\hline \multicolumn{11}{|l|}{ I. xanthiifolia } \\
\hline Environm. treatment & $E_{\max }$ & SE & $\begin{array}{l}t_{\max } \\
{[\mathrm{d}]}\end{array}$ & SE & $\begin{array}{c}\theta H T_{\max } \\
{\left[\mathrm{MPa}^{\circ} \mathrm{Cd}\right]}\end{array}$ & SE & $\begin{array}{l}t_{50} \\
{[\mathrm{~d}]}\end{array}$ & SE & $\begin{array}{c}\theta H T_{50} \\
{\left[\mathrm{MPa}^{\circ} \mathrm{Cd}\right]}\end{array}$ & SE \\
\hline Loess-Cold-Wet & 0.34 & 0.050 & 11 & 0.9 & 190 & 16.7 & 6 & 0.8 & 101 & 13.0 \\
\hline Loess-Cold-Dry & 0.23 & 0.064 & 7 & 1.4 & 72 & 19.2 & 5 & 0.7 & 54 & 7.0 \\
\hline Loess-Warm-Wet & 0.26 & 0.050 & 8 & 0.9 & 134 & 15.0 & 5 & 0.3 & 89 & 7.2 \\
\hline Loess-Warm-Dry & 0.19 & 0.049 & 6 & 1.0 & 63 & 11.8 & 5 & 0.8 & 54 & 9.1 \\
\hline Clay-Cold-Wet & 0.41 & 0.041 & 9 & 1.3 & 164 & 23.3 & 4 & 0.4 & 77 & 7.0 \\
\hline Clay-Cold-Dry & 0.21 & 0.045 & 8 & 1.1 & 84 & 11.4 & 5 & 0.4 & 66 & 3.4 \\
\hline Clay-Warm-Wet & 0.27 & 0.044 & 9 & 2.2 & 170 & 42.1 & 4 & 0.3 & 82 & 6.3 \\
\hline Clay-Warm-Dry & 0.21 & 0.054 & 5 & 0.8 & 53 & 3.8 & 4 & 0.7 & 49 & 5.3 \\
\hline Peat-Cold-Wet & 0.40 & 0.082 & 13 & 2.7 & 221 & 45.4 & 5 & 0.2 & 98 & 3.9 \\
\hline Peat-Cold-Dry & 0.29 & 0.038 & 8 & 0.8 & 105 & 10.5 & 5 & 0.1 & 80 & 3.2 \\
\hline Peat-Warm-Wet & 0.30 & 0.031 & 8 & 1.2 & 150 & 26.2 & 5 & 0.3 & 87 & 8.0 \\
\hline Peat-Warm-Dry & 0.33 & 0.083 & 6 & 1.0 & 64 & 8.5 & 4 & 0.6 & 53 & 7.0 \\
\hline Sand-Cold-Wet & 0.33 & 0.045 & 15 & 3.1 & 238 & 48.9 & 4 & 0.5 & 77 & 9.4 \\
\hline Sand-Cold-Dry & 0.27 & 0.040 & 10 & 1.1 & 58 & 10.5 & 8 & 1.0 & 47 & 6.8 \\
\hline Sand-Warm-Wet & 0.30 & 0.054 & 11 & 0.8 & 142 & 15.9 & 4 & 0.3 & 87 & 7.5 \\
\hline Sand-Warm-Dry & 0.15 & 0.030 & 7 & 2.0 & 53 & 10.5 & 5 & 1.8 & 45 & 9.4 \\
\hline
\end{tabular}


I. xanthiifolia showed a significant positive response of $E_{\max }$ to a higher soil moisture content (Student's t-test, $p<0.0001$ ), especially in the cold temperature treatment, in all four soils. $E_{\max }$ of $I$. xanthiifolia was significantly reduced in the warm temperature treatment (Student's t-test, $p<0.0001$ ). This species achieved the highest final emergence fraction in the clay-cold-wet $(0.41)$ and in the peat-cold-wet $(0.40)$ treatments, and the lowest in the loess-cold-dry (0.19) and sand-warm-dry (0.15) treatments (Tab. 2.3).

\section{Emergence time courses}

The analyses of $t_{\max }$ and $\theta H T_{\max }$ revealed a pronounced reduction of deviance contributed by the random effect year for all three species. Time to final emergence was significantly affected by the soil x moisture interaction in A. theophrasti and by the factor moisture in $D$. stramonium (Tab. 2.4). In all four soil types, the three species needed longer to reach emergence of $50 \%$ of the seeds in dry conditions; for D. stramonium (Student's t-test, $p=$ 0.0033 ) and I. xanthiifolia (Student's t-test, $p=0.0051$ ), this was significant. Patterns of $t_{\text {max }}$ differed from those of $t_{50}$ depending on soil type. An extended $t_{\max }$ was observed under dry conditions in loess and clay soil substrates. In contrast, in sand and peat soils, $t_{\max }$ was significantly extended in the wet treatments.

Table 2.4 Analysis of deviance results for the AFT model after model simplification (/: fixed effect removed to obtain minimum adequate model). The results show the differences in $t_{\max }$ of $A$. theophasti, D. stramonium and I. xanthiifolia under consideration of soil, temperature and moisture treatment.

A. theophrasti

\begin{tabular}{|c|c|c|c|c|c|}
\hline Source & $d f$ & Deviance & Residual $d f$ & $-2 x$ loglikelihood & $p$ \\
\hline Null model & & & 7802 & 46839.8 & \\
\hline Soil (S) & 3 & 3.43613 & 7799 & 46836.3 & $* * *$ \\
\hline Temp. (T) & 1 & 4.79738 & 7797 & 46831.5 & $* * *$ \\
\hline Moist. (M) & 1 & 4.77551 & 7797 & 46826.7 & $* * *$ \\
\hline Frailty (Year) & 1 & 18.9011 & 7797 & 46807.8 & $* * *$ \\
\hline $\mathrm{S} \times \mathrm{T}$ & l & l & l & / & I \\
\hline $\mathrm{S} \times \mathrm{M}$ & 3 & 8.64583 & 7794 & 46799.2 & $* * *$ \\
\hline $\mathrm{T} \times \mathrm{M}$ & 1 & 4.15338 & 7793 & 46795.0 & $* * *$ \\
\hline $\mathrm{S} \times \mathrm{T} \times \mathrm{M}$ & l & I & l & / & / \\
\hline
\end{tabular}

D. stramonium

\begin{tabular}{|c|c|c|c|c|c|}
\hline Source & $d f$ & Deviance & Residual $d f$ & -2 x loglikelihood & $p$ \\
\hline Null model & & & 7595 & 44015.9 & \\
\hline Soil (S) & 3 & 2.29143 & 7592 & 43993.0 & $* * *$ \\
\hline Temp. (T) & 1 & 2.66622 & 7591 & 43990.3 & $* * *$ \\
\hline Moist. (M) & 1 & 7.75465 & 7590 & 43982.6 & $* * *$ \\
\hline Frailty (Year) & 1 & 4.50697 & 7590 & 43982.6 & $* * *$ \\
\hline$S \times T$ & I & l & I & l & I \\
\hline$S \times M$ & 3 & 1.16720 & 7587 & 43970.9 & $* * *$ \\
\hline $\mathrm{T} \times \mathrm{M}$ & 1 & 3.83306 & 7586 & 43967.1 & $* * *$ \\
\hline$S \times T \times M$ & l & l & l & l & l \\
\hline
\end{tabular}




\begin{tabular}{|c|c|c|c|c|c|}
\hline Source & $d f$ & Deviance & Residual df & $-2 x$ loglikelihood & $p$ \\
\hline Null model & & & 11345 & 74863.2 & n.s. \\
\hline Soil (S) & l & I & I & l & l \\
\hline Temp. (T) & 1 & 2.45634 & 11344 & 74860.8 & n.s. \\
\hline Moist. (M) & l & I & I & l & l \\
\hline Frailty (Year) & l & I & I & I & I \\
\hline $\mathrm{S} \times \mathrm{T}$ & l & I & I & l & l \\
\hline $\mathrm{S} \times \mathrm{M}$ & I & I & I & I & I \\
\hline $\mathrm{T} \times \mathrm{M}$ & I & I & I & l & l \\
\hline $\mathrm{S} \times \mathrm{T} \times \mathrm{M}$ & I & 1 & 1 & I & I \\
\hline
\end{tabular}

$\theta H T_{\max }$ for all three species was most distinctly influenced by the moisture treatment (Tab. 2.5). For all three weeds, hydrothermal units were higher under warm-wet and cold-wet than under warm-dry and cold-dry environmental conditions, for both $\theta H T_{\max }$ and $\theta H T_{50}$. xanthiifolia accumulated less hydrothermal units in comparison to A. theophrasti and $D$. stramonium in all of the tested treatments (Tab. 2.2).

Table 2.5 Analysis of deviance results for the AFT model after model simplification. The results show the differences $\theta H T_{\max }$ of $A$. theophasti, D. stramonium and I. xanthiifolia under consideration of soil, temperature and moisture treatment

A. theophrasti

\begin{tabular}{|c|c|c|c|c|c|}
\hline Source & $d f$ & Deviance & Residual $d f$ & $-2 x$ loglikelihood & $p$ \\
\hline Null model & & & 7802 & 82523.1 & \\
\hline Soil (S) & 3 & 50.38559 & 7799 & 82472.7 & $* * *$ \\
\hline Temp. (T) & 1 & 3.070379 & 7798 & 82469.6 & $* * *$ \\
\hline Moist. (M) & 1 & 1707.587 & 7797 & 80762.0 & $* * *$ \\
\hline Frailty (Year) & 1 & 58.20326 & 7797 & 80703.8 & $* * *$ \\
\hline $\mathrm{S} \times \mathrm{T}$ & 3 & 6.295630 & 7794 & 80697.5 & $* * *$ \\
\hline $\mathrm{S} \times \mathrm{M}$ & 3 & 50.80182 & 7791 & 80646.7 & $* * *$ \\
\hline $\mathrm{T} \times \mathrm{M}$ & 1 & 18.51342 & 7789 & 80628.2 & $* * *$ \\
\hline $\mathrm{S} \times \mathrm{T} \times \mathrm{M}$ & 3 & 13.12795 & 7787 & 80615.1 & $* * *$ \\
\hline \multicolumn{6}{|c|}{ D. stramonium } \\
\hline Source & $d f$ & Deviance & Residual $d f$ & $-2 x$ loglikelihood & $p$ \\
\hline Null model & & & 7595 & 77444.7 & \\
\hline Soil (S) & 3 & 63.56699 & 7592 & 77381.2 & $* * *$ \\
\hline Temp. (T) & 1 & 5.146481 & 7591 & 77376.0 & $* * *$ \\
\hline Moist. (M) & 1 & 1284.755 & 7590 & 76091.3 & $* * *$ \\
\hline Frailty (Year) & 1 & 75.89649 & 7589 & 76015.4 & $* * *$ \\
\hline $\mathrm{S} \times \mathrm{T}$ & 3 & 5.208024 & 7586 & 76010.2 & $* * *$ \\
\hline $\mathrm{S} \times \mathrm{M}$ & 3 & 31.89627 & 7583 & 75978.3 & $* * *$ \\
\hline $\mathrm{T} \times \mathrm{M}$ & 1 & 16.48661 & 7582 & 75961.8 & $* * *$ \\
\hline$S \times T \times M$ & 3 & 21.46895 & 7579 & 75940.3 & $* * *$ \\
\hline
\end{tabular}




\begin{tabular}{|c|c|c|c|c|c|}
\hline Source & $d f$ & Deviance & Residual $d f$ & $-2 x$ loglikelihood & $p$ \\
\hline Null model & & & 11345 & 130662.5 & \\
\hline Soil (S) & 3 & 66.09004 & 11342 & 130596.4 & $* * *$ \\
\hline Temp. (T) & 1 & 19.96792 & 11341 & 130576.4 & $* * *$ \\
\hline Moist. (M) & 1 & 2583.906 & 11340 & 127992.5 & $* * *$ \\
\hline Frailty (Year) & 1 & 275.3967 & 11340 & 127717.1 & $* * *$ \\
\hline $\mathrm{S} \times \mathrm{T}$ & 3 & 18.82352 & 11337 & 127698.3 & $* * *$ \\
\hline $\mathrm{S} \times \mathrm{M}$ & 3 & 142.8819 & 11334 & 127555.4 & $* * *$ \\
\hline $\mathrm{T} \times \mathrm{M}$ & 1 & 61.26841 & 11333 & 127494.2 & $* * *$ \\
\hline$S \times T \times M$ & 3 & 16.65225 & 11330 & 127477.5 & *** \\
\hline
\end{tabular}

\section{Emergence time courses versus final emergence fraction}

In dry conditions, $A$. theophrasti and $D$. stramonium needed longer for emergence in clay and loess substrates. For $A$. theophrasti, in the loess substrate this was paralleled by a higher $E_{\max }$; in contrast, in the clay substrate, as well as for D. stramonium in both loess and clay, the $E_{\max }$ in the dry treatments was reduced in comparison to the wet treatments by approx. $10-20 \%$.

In peat, under warm-dry conditions, both $t_{\max }$ as well as $t_{50}$ were shorter than in the other three treatments for all three species. In the peat-warm-dry treatment, the weeds always achieved a higher emergence fraction than when germinated in loess-warm-dry, claywarm-dry or sand-warm-dry, except for A. theophrasti under loess-warm-dry conditions.

In wet treatments in sand and peat substrates, seeds of all species needed longer to complete the emergence process, but they also yielded higher $E_{\max }$.

Higher hydrothermal units lead to a higher final $E_{\max }$ for all three species under most environmental conditions. Only for A. theophrasti grown in loess soil, higher hydrothermal units were not paralleled by a higher $E_{\max }$ (Tab. 2.3).

\section{Emergence probabilities}

In cold-dry and warm-dry conditions the emergence probability was reduced in the sand soil mixture, followed in ascending order by loess, clay and peat. Emergence probability was significantly reduced for $A$. theophrasti $\left(\chi^{2}=1908, p<0.001\right)$, D. stramonium $\left(\chi^{2}=\right.$ $1504, p<0.001)$ and I. xanthiifolia $\left(\chi^{2}=3185, p<0.001\right)$ in sand- warm-dry conditions. The estimated emergence probabilities per $\theta H T$ unit for the weeds and the environmental conditions are visualized in Fig. 2.4. $\theta H T_{50}$ units are included in the graph as horizontal lines per artificial environmental treatment. 
a) Abutilon theophrasti
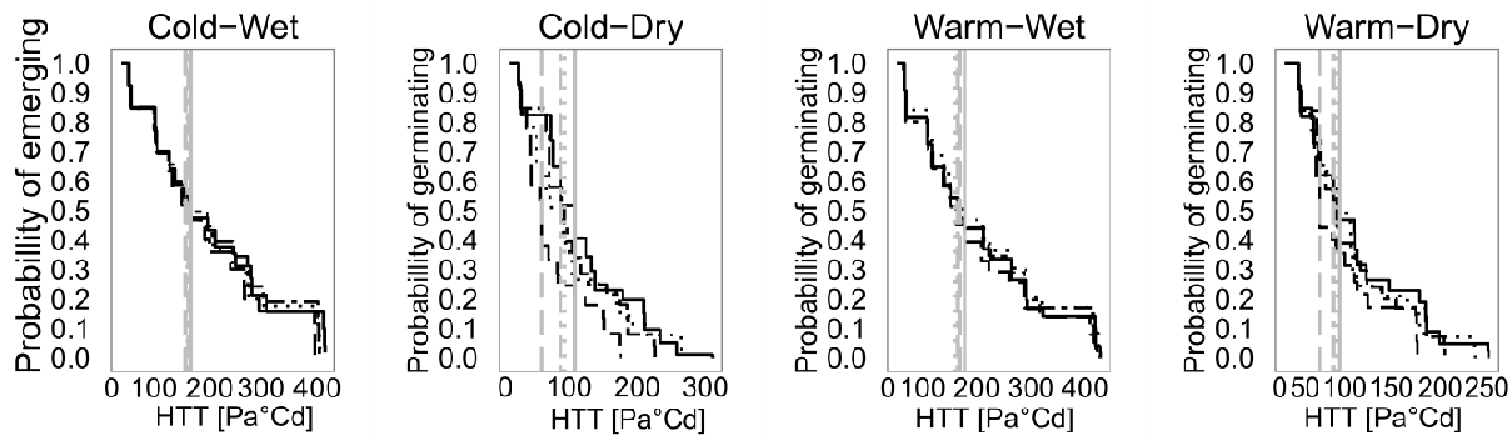

b) Datura stramonium
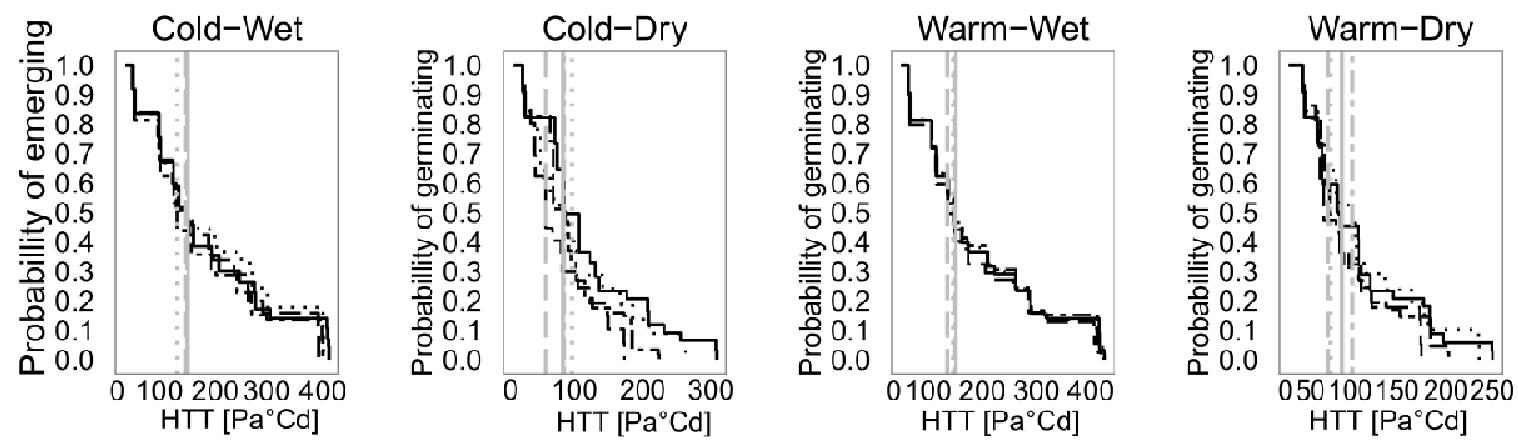

c) Iva xanthiifolia
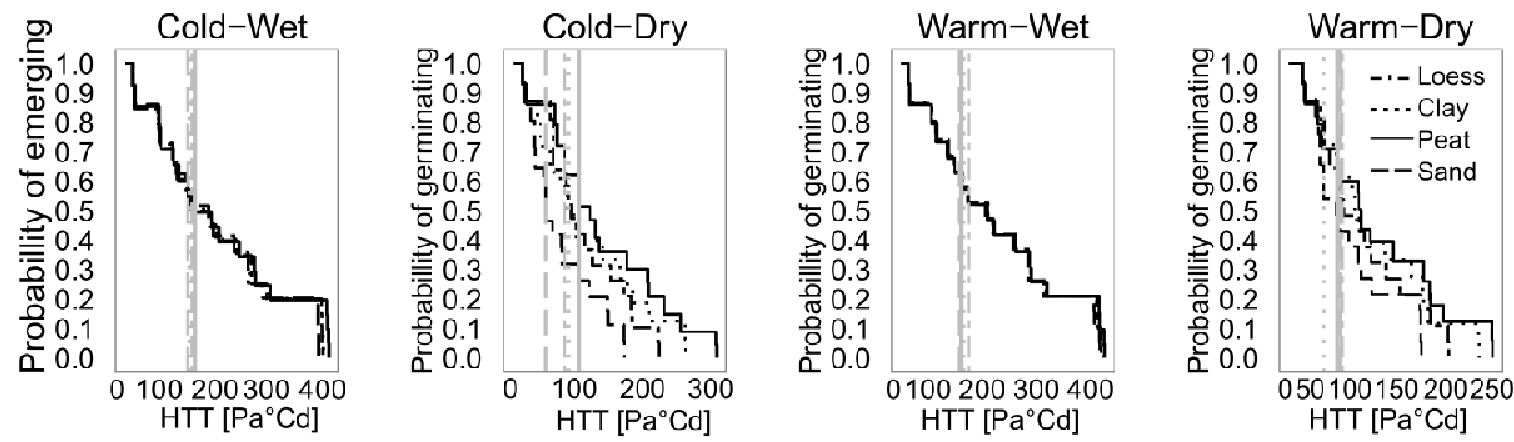

Fig. 2.4 Kaplan-Meier curves of the emergence function of A. theophrasti, D. stramonium and I. xanthiifolia. Curves are shown for the four artificial soil substrates mixtures (loess: twodashed line; clay: dotted line; peat: solid line; sand: longdashed line) per climatic treatment (cold-wet, cold-dry, warm-wet, warm-dry). $\theta H T_{50}$ is vertically lined per artificial environmental treatment. The curves show the probability that the weed seeds will germinate per $\theta H T$ unit. Therefore, the emergence probability has to be 1.0 at $\theta H T=0$, because all seeds are not emerged and have possibility to emerge. 


\section{Discussion}

The aim of the present study was to determine the effect of a range of microsite conditions on the emergence parameters of three weed species which are expected to become more relevant in Central Europe as a consequence of global change.

Our results showed that the emergence of $A$. theophrasti, D. stramonium and I. xanthiifolia responded in idiosyncratic ways to the experimental warming and drought conditions, and that their emergence patterns were significantly influenced by the soil type.

The response of $E_{\max }$ to elevated temperature differed strongly in the tested weed species. In $A$. theophrasti, warming enhanced $E_{\max }$, whereas the opposite was true for $I$. xanthiifolia; in D. stramonium, temperature did not produce a significant effect on this variable. Emergence usually increases linearly with increasing temperature and moisture availability up to an optimum point beyond which it strongly declines (Steinmaus et al., 2000; Alvarado and Bradford, 2002). The observed mean daily air temperatures, both in the cold as well as in the warm treatment were relatively high, with average values of 22 and $25{ }^{\circ} \mathrm{C}$, respectively. For $A$. theophrasti, the warm treatment provided the optimum temperature for emergence, which is between 24 to $30{ }^{\circ} \mathrm{C}$ (Leon et al., 2004). Possibly, for I. xanthiifolia the warm treatment was beyond optimum temperature; at supraoptimal temperatures, $E_{\max }$ is reduced (Guillemin et al., 2013). This may also be support by the results of the germination test, where I. xanthiifolia achieved a higher germination fraction at the $18 / 10^{\circ} \mathrm{C}$, compared to the $30 / 20^{\circ} \mathrm{C}$ temperature setting. The indifferent response of D. stramonium to the temperature treatment may indicate that both temperature levels are within the range of optimal conditions of this species. Independent of temperature treatment (and of moisture), I. xanthiifolia yielded comparatively low values of $E_{\max }$ in this experiment. We cannot provide a clear-cut explanation to this.

In accordance with Biligetu et al. (2011) who proposed that the final emergence fraction decreases with a decrease of water potential, soil moisture had a significant negative effect on $E_{\max }$ of D. stramonium and I. xanthiifolia in most treatment combinations. In contrast, in A. theophrasti moisture did not significantly affect $E_{\max }$. The finding of Kebreab and Murdoch (1999) that seeds are capable of emerging under water stress at optimum temperatures may explain this observation. Notably, although the water potential was reduced to a minimum of the physiological requirements of emerged plants, in the dry treatment, moisture was still sufficient for germination and emergence due to the method of watering by pouring from atop. Seeds were provided for a limited time (day of watering) with a sufficient supply of water.

Our data further point out a significant effect of the soil type, and of the soil x moisture and soil $x$ temperature interactions on emergence parameters of the three weeds. We used the concept of hydro-thermal time units to quantitatively characterise the different emergence conditions prevailing in the individual microsites (Gummerson, 1986; Grundy et al., 2000; Alvarado and Bradford, 2002). Within the same combinations of temperature and moisture 
levels, we found significant differences in $\theta H T$ depending on soils type. In the dry treatments, emergence was higher in peat than in the other soils. Probably, plant available water capacity was highest in the organic soil due to physical soil characteristics: the water edit to the pots was lost faster in sandy soil, due to a lower water holding capacity (Fig. $2.1 b)$. The tested weed species responded in different ways to the various soil conditions in this experiment. Soil effects on emergence were more important in D. stramonium than in the other two species. These findings underpin that it is important to take soil factors and microsites characteristics into account when studying the responses of different plant species to certain environmental variables of interest (e.g. temperature, soil moisture) (Petrů and Tielbörger, 2008; Bullied et al., 2012). Additional experiments are required to establish our approach with grown soils and with a stronger focus on their physical properties.

We aimed to quantitatively characterize the individual emergence conditions prevailing in the different microsites and to determine the range of conditions tolerated for germination by the three weed species. We consider the relationship between $E_{\max }$ and the emergence time course. According to Guillemin et al. (2013) at optimum conditions seeds show a fast emergence coupled with a high emergence fraction. At optimum temperature and water conditions emergence is most rapid, at sub- and supraoptimal temperature and at suboptimal water potential conditions emergence is prevented and emergence fraction decreased (Alvarado and Bradford, 2002). A fast emergence may lead to advantage in competition over resources in a similar way as early emergence, which can, depending on the environment, be beneficial for growth and fecundity (Verdú and Traveset, 2005).

In D. stramonium, we observed a positive correlation between the emergence time courses achieved per environment and the final emergence fraction. In the other two species we did not find a correlation between these two parameters. In A. theophrasti, in the loess-dry environments, a high $E_{\max }$ was coupled with slow emergence $\left(t_{50}\right)$, and in sand-dry environments, the highest $t_{50}$ values were recorded, but emergence fraction was intermediate. We assume that dry environments provide suboptimal, but not unfavourable conditions for this species, as no significant negative impact on emergence fraction was observed. In contrast, in I. xanthiifolia, under sand-warm-dry conditions we observed comparatively fast emergence coupled with a low $E_{\max }$ value. This indicates that emergence conditions were less favourable and were quantitatively characterized with low $\theta H T_{\max }$ value compared to the other tested conditions.

Altogether, we draw two main conclusions from the results of this experiment. Firstly, under predicted future climatic conditions involving reduced precipitation and increased temperatures, the consideration of the soil type may become more important for anticipating the emergence characteristics. Our results indicate that peat substrates may enhance the probability of the studied weeds to emerge under the predicted future climatic conditions, whereas under dry conditions, emergence may be limited in sand.

Secondly, the results indicate an idiosyncratic response of emergence of the tested weeds to altered environmental conditions. Petrů and Tielbörger (2008) have pointed out that 
changing environmental conditions acting upon a plant community will likely lead to adaptation and/or acclimatisation rather than to a simultaneous niche or range shift of all component species. This will in the long run result in shifts of species abundance or in extinction of individual species, and hence cause alterations of community composition (Lloret et al., 2004). Emergence is linked to the suitability of the environment for seedling establishment, and seeds germinate better in environments which are favourable for their persistence (Baskin and Baskin, 2001). Our results hint to a potential advantage of $A$. theophrasti and D. stramonium under future climatic conditions compared to I. xanthiifolia considered in the present experiment. These species appears to tolerate a broader range of environmental conditions as it has a high temperature optimum and to sustain low soil moisture levels for emergence in most soil types.

The results of the present study show general patterns of response to various combinations of environmental factors in the three weed species. However, we recognize that this experiment was conducted with seeds of one population per species only. Because of genetic and phenotypic plasticity within most species, the outcome of this experiment may have differed if using germplasm from other provenance. Intraspecific plasticity may buffer responses, if environmental change is within the physiological tolerance range of the species (Walck et al., 2011). We advise further research with regard to this point.

\section{Acknowledgements}

This study was funded by the Ministry for Science and Culture of Lower Saxony and is a part of Lower Saxony’s Climate Impact research Program (KLIFF). 


\section{References}

AlvarAdo, V. \& BRADFORD, K.J. 2002. A hydrothermal time model explains the cardinal temperatures for seed germination. Plant, Cell \& Environment 25 (8): 1061-1069.

BASKIN, C.C. \& BASKIN, J.M. 2001. Seeds. Ecology, biogeography, and evolution of dormancy and germination. Academic Press, San Diego, Calif.

Biligetu, B., Schellenberg, M.P. \& McLeod, J.G. 2011. The effect of temperature and water potential on seed germination of poly-cross side-oats grama (Bouteloua curtipendula (Michx.) Torr.) population of Canadian prairie. Seed Science and Technology 39 (1): 74-81.

BIOLFLOR 2013. BiolFlor - Search and information system on vascular plants in Germany. URL: http://www2.ufz.de/biolflor/index.jsp; last access date 10.09.2013.

BrÄndle, M., Stadler, J., Klotz, S. \& Brandl, R. 2003. Distributional range size of weedy pklant species is correlated to germination patterns. Ecology 84 (1): 136-144.

Broennimann, O., Treier, U.A., Müller-Schärer, H., Thuiller, W., Peterson, A.T. \& GuISAN, A. 2007. Evidence of climatic niche shift during biological invasion. Ecology Letters 10:701-709.

BROWN, J.H. 1984. On the relatioship between abundance and distribution of a species. American Naturalist 124(2): 255-279.

Bullied, J.W., Bullock, P.R. \& VAn ACKer, R.C. 2012. Modelling Soil Water Retention for Weed Seed Germination Sensitivity to Water Potential. Applied and Environmental Soil Science 2012: 13.

Délye, C., Menchari, Y., Michel, S., Cadet, É. \& Le Corre, V. 2013. A new insight into arable weed adaptive evolution: mutations endowing herbicide resistance also affect germination dynamics and seedling emergence. Annals of Botany.

Donohue, K., Casas, R.R. De, Burghardt, L., Kovach, K. \& Willis, C.G. 2010. Germination, Postgermination Adaptation, and Species Ecological Ranges 41: 293319.

Dorado, J., Sousa, E., Calha, I.M., GonZalez-Andujar, J.L. \& FernandezQuintanilla, C. 2009. Predicting weed emergence in maize crops under two contrasting climatic conditions. Weed Research 49 (3): 251-260.

FAY, P.A. \& Schultz, M.J. 2009. Germination, survival, and growth of grass and forb seedlings: Effects of soil moisture variability. Acta Oecologica 35 (5): 679-684.

Follak, S., Dullinger, S., Kleinbauer, I., Moser, D. \& Essl, F. 2013. Invasion dynamics of three allergenic invasive Asteraceae (Ambrosia trifida, Artemisia annиa, Iva xanthiifolia) in central and eastern Europe. Preslia 85 (1): 41-61.

Gardarin, A., DürR, C. \& COLBACH, N. 2009. Which model species for weed seed bank and emergence studies? A review. Weed Research 49 (2): 117-130. 
Gardarin, A., DÜRr, C. \& COlBACH, N. 2011. Prediction of germination rates of weed species: Relationships between germination speed parameters and species traits. Ecological Modelling 222 (3): 626-636.

Gassó, N., BASnOU, C. \& VilÀ, M. 2010. Predicting plant invaders in the Mediterranean through a weed risk assessment system. Biological Invasions 12 (3): 463-476.

Grime, J.P., Mason, G., Curtis, A.V., Rodman, J. \& Band, S.R. 1981. A Comparative Study of Germination Characteristics in a Local Flora. Journal of Ecology 69 (3): 1017-1059.

Grundy, A.C., PhelPS, K., ReAder, R.J. \& Burston, S. 2000. Modelling the germination of Stellaria media using the concept of hydrothermal time. New Phytologist 148 (3): 433-444.

Guillemin, J.-P., Gardarin, A., Granger, S., Reibel, C., Munier-Jolain, N. \& COLBACH, N. 2013. Assessing potential germination period of weeds with base temperatures and base water potentials. Weed Research 53 (1): 76-87.

Gummerson, R.J. 1986. The Effect of Constant Temperatures and Osmotic Potentials on the Germination of Sugar Beet. Journal of Experimental Botany 37 (6): 729-741.

Hares, M.A. \& NovaK, M.D. 1992. Simulation of Surface Energy Balance and Soil Temperature under Strip Tillage: I. Model Description. Soil Sci. Soc. Am. J 56 (1): 2229.

HEGI, G. 1979. Illustrierte Flora von Mitteleuropa. Band VI, Teil 3. Parey, Berlin, West Germany.

HILLEL, D. 1998. Environmental soil physics. Academic Press, San Diego, CA.

Hirsch, H., Wypior, C., Wehrden, H. von, Wesche, K., Renison, D. \& Hensen, I. 2012. Germination performance of native and non-native Ulmus pumila populations. NeoBiota 15: 53-68.

HoDisAn, N. 2009. Results of the research on the allelopathic effect between the neophyte species, Iva xanthiifolia Nutt. ("Ierboaia") and some agricultural crops. Bulletin UASMV Agriculture 66 (1): 362-369.

Hothorn, T., Bretz, F. \& WestFall, P. 2008. Simultaneous Inference in General Parametric Models. Biometrical Journal 50 (3): 346-363.

Hyvönen, T., Glemnitz, M., Radics, L. \& Hoffmann, J. 2011. Impact of climate and land use type on the distribution of Finnish casual arable weeds in Europe. Weed Research 51 (2): 201-208.

IAEA 2008. International Atomic Energy Agency. Field Estimation of Soil Water Content. A Practical Guide to Methods, Instrumentation and Sensor Technology, Vienna.

Kebreab, E. \& Murdoch, A.J. 1999. Modelling the effects of water stress and temperature on germination rate of Orobanche aegyptiaca seeds. Journal of Experimental Botany 50 (334): 655-664. 
KÖCHY, M. \& TIELBÖRGER, K. 2007. Hydrothermal time model of germination: Parameters for 36 Mediterranean annual species based on a simplified approach. Basic and Applied Ecology 8 (2): 171-182.

KÜHN, I., DURKA, W. \& KLOTZ, S. 2004. BiolFlor - a new plant-trait database as a tool for plant invasion ecology. Diversity and Distributions 10 (5-6): 363-365.

Larsen, S.U., Bailly, C., Côme, D. \& Corbineau, F. 2004. Use of the hydrothermal time model to analyse interacting effects of water and temperature on germination of three grass species. Seed Science Research 14 (01): 35-50.

LEON, R.G., KNAPP, A.D. \& OWEN, M.D.K. 2004. Effect of temperature on the germination of common waterhemp (Amaranthus tuberculatus), giant foxtail (Setaria faberi), and velvetleaf (Abutilon theophrasti). Weed Science 52 (1): 67-73.

Lloret, F., Peñuelas, J. \& Estiarte, M. 2004. Experimental evidence of reduced diversity of seedlings due to climate modification in a Mediterranean-type community. Global Change Biology 10 (2): 248-258.

LodDo, D., MASin, R., OtTO, S. \& Zanin, G. 2012. Estimation of base temperature for Sorghum halepense rhizome sprouting. Weed Research 52 (1): 42-49.

Masin, R., Loddo, D., Benvenuti, S., Zuin, M.C., Macchia, M. \& Zanin, G. 2010. Temperature and Water Potential as Parameters for Modelling Weed Emergence in Central-Northern Italy. Weed Science 58 (3): 216-222.

MCNaIR, J.N., Sunkara, A. \& Frobish, D. 2012. How to analyse seed germination data using statistical time-to-event analysis: non-parametric and semi-parametric methods. Seed Science Research 22 (02): 77-95.

Moseley, C., Panferov, O., Döring, C., Dietrich, J., Haberlandt, U., Ebermann, V., RECHID, D., BEESE, F. \& JACOB, D. 2012. Klimaentwicklung und Klimaszenarien. In: Niedersächsisches Ministerium für Umwelt, Energie und Klimaschutz (ed.) Empfehlung für eine niedersächsische Strategie zur Anpassung an die Folgen des Klimawandels. Regierungskommision Klimaschutz, pp. 18-41.

Myers, M.W., Curran, W.S., VanGessel, M.J., Calvin, D.D., Mortensen, D.A., MajeK, B.A., Karsten, H.D. \& Roth, G.W. 2004. Predicting weed emergence for eight annual species in the northeastern United States. Weed Science 52 (6): 913-919.

NIEDERSÄCHSISCHES MINISTERIUM FÜR UMWELt, ENERGIE UND KLIMASCHUTZ (ed.) 2012. Empfehlung für eine niedersächsische Strategie zur Anpassung an die Folgen des Klimawandels. Regierungskommision Klimaschutz.

ONOFRI, A., Gresta, F. \& TEI, F. 2010. A new method for the analysis of germination and emergence data of weed species. Weed Research 50 (3): 187-198.

Parmesan, C. \& Yohe, G. 2003. A globally coherent fingerprint of climate change impacts across natural systems. Nature 421 (6918): 37-42.

Petrú, M. \& TIElbÖRger, K. 2008. Germination behaviour of annual plants under changing climatic conditions: separating local and regional environmental effects. Oecologia 155 (4): 717-728. 
Pinheiro, J., Bates, D., DebRoy, S., Sarkar, D. \& R Development Core Team 2012. nlme: Linear and Nonlinear Mixed Effects Models. R package version 3.1-104.

R Development CoRe TEAM 2013. R: A Language and Environment for Statistical Computing. URL: http://www.R-project.org; last access date 05.07.2013.

Ridolfi, L., D'Odorico, P., Porporato, A. \& Rodriguez-Iturbe, I. 2003. Stochastic soil moisture dynamics along a hillslope. Journal of Hydrology 272 (1-4): 264-275.

Roman, E.S., MurPhy, S.D. \& Swanton, C.J. 2000. Simulation of Chenopodium album seedling emergence. Weed Science 48 (2): 217-224.

Steinmaus, S.J., Prather, T.S. \& Holt, J.S. 2000. Estimation of base temperatures for nine weed species. Journal of Experimental Botany 51 (343): 275-286.

Therneau, T. \& Lumley, T. 2012. Survival: Survival analysis, including penalised likelihood. R package version 2.36-12.

ThOMAS, C.D. 2010. Climate, climate change and range boundaries. Diversity and Distributions 16 (3): 488-495.

Tutin, T.G., Heywood, V.H., Burges, N.A., Moore, D.M., Valentine, D.H., Walters, S.M. \& WeBB, D.A. (eds.) 1964 ff. Flora Europaea. Cambridge University Press, Cambridge.

VAN WiJK, W.R. (ed.) 1963. Physics of plant environment. North-Holland Pub. Co.; Interscience Publishers, Amsterdam, New York.

Verdú, M. \& TRAVESET, A. 2005. Early emergence enhances plant fitness: A phylogenetically controlled meta-analysis. Ecology 86 (6): 1385-1394.

Walck, J.L., Hidayati, S.N., Dixon, K.W., Thompson, K.E. \& Poschold, P. 2011. Climate change and plant regeneration from seed. Global Change Biology 17 (6): 2145-2161.

WEBER, E. \& GUT, D. 2005. A survey of weeds that are increasingly spreading in Europe. Agronomy for Sustainable Development 25 (1): 109-121.

Wisser, D., Marchenko, S., Talbot, J., Treat, C. \& Frolking, S. 2011. Soil temperature response to 21 st century global warming: the role of and some implications for peat carbon in thawing permafrost soils in North America. Earth System Dynamics 2(1): 121-138.

ZUUR, A.F. 2009. Mixed effects models and extensions in ecology with R. SPRINGER, New York. 


\section{CHAPTER}

\section{Growth responses of three range-expanding weeds to elevated temperature and reduced soil moisture}

Barbara Edler, Laura Breitsameter, Jana Bürger, Horst-Henning Steinmann \&

Johannes Isselstein

This chapter is an article accepted for publisching in the Journal of Plant Diseases and Plant Protection. Edler, B., BÜrger, J., Breitsameter, L., Steinmann, H.-H. \& Isselstein, J. (accepted). Growth responses to elevated temperature and reduced soil moisture during early establishment of three annual weeds in four soil types. 


\section{Abstract}

In the present study, we investigated the effect of prospective future climatic conditions involving increased temperatures and reduced soil moisture during the vegetation period on the growth of three weed species which co-occur in spring crops and are currently spreading in Europe.

Abutilon theophrasti Medik., Datura stramonium L., and Iva xanthiifolia Nutt., were grown together with Zea mays L. in a manipulative greenhouse pot experiment. The artificial fourspecies crop-weed-community was exposed to warming (ambient temperature $+2.5{ }^{\circ} \mathrm{C}$, treatment "warm") and drought (soil moisture content between -0.1 to $-1.5 \mathrm{MPa}$, treatment "dry") versus ambient greenhouse temperature (treatment "cold") and total plant water availability of $-0.0036 \mathrm{MPa}$ (treatment "wet"), in four different substrate mixtures (loess, clay, peat, sand, treatment soil $\left[S_{L}, S_{C}, S_{P}, S_{S}\right]$ ) in an orthogonal procedure approach.

We examined the response of the weed species to different combinations of environmental conditions regarding plant biomass (root, shoot and total), root length, leaf size and root-toshoot ratio and the response of maize regarding shoot biomass. The measured parameters were used as surrogates for plant performance and plasticity. In order to account for intra- and interspecific interaction and/or competition for resources, the mean absolute total aboveground biomass per pot and environmental treatment and the relative aboveground biomass per species and environmental treatment were determined.

Our results showed that the three range-expanding weed species and maize reacted strongly, but in species-specific ways to the tested environmental conditions. Under warm-dry conditions, significant negative effects on aboveground biomass were found for all three weed species and maize. For $A$. theophrasti and $D$. stramonium, we observed a tendency of a higher total biomass in $S_{C}$ and $S_{P}$ soils than in the other soil types under warm-dry conditions. These two species showed a higher plasticity than I. xanthiifolia in all of the tested environmental treatments. $I$. xanthiifolia did not respond to the tested conditions in a consistent way, but positive performance of this species was most strongly related to good moisture supply.

Our results suggest that future climatic conditions may impair the performance of $I$. xanthiifolia. For A. theophrasti and D. stramonium, we deduced tolerance to a wide range of environmental conditions. These two species may benefit from the predicted future climate.

Keywords: artificial warming, plant plasticity, environmental tolerance, velvetleaf, jimson weed, false ragweed 


\section{Introduction}

Empirical evidence underpin that changing climatic conditions affect plant species in various ways. Prominent examples highlight their influence on plant phenology and physiology (Morin and Thuiller, 2009; Walther, 2010), which again result in alterations in distribution, abundance, and community composition (Sommer et al., 2010). For these reasons, the prediction of species responses to environmental change has been in the focus of ecological research during the last decades (e.g. Grime, 1977; Cleland et al., 2007; Bonser et al., 2010; Thomas, 2010). Wiens et al. (2009) have pointed out that range-expanding species are a particular threat for local biodiversity. For early detection of spreading species and for the conception of control and management policies, the estimation of their distribution potential is of prior interest (Broennimann et al., 2007; Hyvönen et al., 2012).

A number of weed species are currently expanding their range in Europe, some of which are native, others are alien or invasive (Weber and Gut, 2005). As a consequence, changes in the European weed flora can be expected for the future. A central question to the investigation of the observed range shifts has been whether changing climatic conditions are the trigger to those spreads.

One possibility to address this question which is pursued by a large number of researchers today is to utilise species distribution modelling. The two most commonly used ecological approaches for distribution modelling are the niche-based and fitness-based one. The niche as a central concept in ecology was first defined by Grinnell in 1917 as all sites where an organism can live (Grinell ,1917; Holt, 2009). Hutchison (1957) subsequently proposed a broadly used new definition of the niche as a set of biotic and abiotic conditions in which a species is able to persist and maintain a stable population size (Wiens and Graham, 2005; Soberón and Nakamura, 2009). He also differentiated between the fundamental and the realized niche with the realized niche being the expression of the fundamental niche affected by species interaction (Hutchinson, 1957; Holt, 2009). Most niche-based distribution models rely on Grinnell's or Hutchinson's concept of a species niche and try to identify the environmental variables that describe species distribution. Fitness-based models, in contrast, are based on Rosenzweig's (1987) specification of a species niche who defined a species niche as the ensemble of traits that allow a species to persist in a particular environment (Rosenzweig, 1987; Chuine, 2010).

Despite their broad use, predictions of models using either of these ecological approaches yield a high potential of inaccuracy (Chuine et al., 2012). To gain additional knowledge of species responses to changing climatic conditions, manipulative experiments offer a promising complement to distribution modelling (Morin and Lechowicz, 2008; Beier et al., 2012). They allow assessing model predictions in view of experimental results and hence contribute to an understanding of the mismatch between predictions and observations (Chuine et al., 2012). The combination of modelling and manipulative experiments will therefore lead to greater precision in predicting the impacts of a changing environment on plant species and ecosystems processes (Chuine et al., 2012).

For this study, we conducted a manipulative experiment based on a modified fitness-based approach for three co-occurring weed species, Abutilon theophrasti (Medic.), Datura 
stramonium (L.) and Iva xanthiifolia (Nutt.). These weeds are known to be highly competitive in spring crops (Sattin et al., 1992; Hodí and Torma, 2000; Efthimiadou et al., 2009), and a high spreading potential is known for $A$. theophrasti and D. stramonium in Mediterranean (Gassó et al., 2010) and for I. xanthiifolia in Central European regions (Follak, 2009). We exposed artificial communities of these three species grown together with maize to various combinations of temperature and soil moisture conditions. Additionally, we considered four soil types with different structural and texture characteristics, of which the specific physical properties, e.g., water holding capacity, thermal conductivity and availability and accessibility of nutrients, have important impact on plant growth (van Wijk, 1963; Hillel, 1998). In this way we aimed at creating a variety of possible niches.

In order to assess the impact of various environmental conditions on the growth of the weeds, we measured several aboveground and belowground parameters which are considered as adaptive. The aim of this study was to address the following questions. (i) How do growthrelated parameters respond to an alteration of temperature and soil moisture conditions? (ii) Do above and below ground parameters respond in a different way? (iii) How does the soil type, as a determinant of soil resource availability, influence plant responses to these conditions? Based on these findings, we aimed at deducing answers to the question (vi) Which weed species may acclimate better to predicted future climatic conditions and therefore further increase in distribution?

\section{Materials and Methods}

\section{Experimental design}

For this study, a greenhouse pot experiment was conducted at the Centre for Biodiversity and Sustainable Land Use in Göttingen, Lower Saxony, Germany, in the years 2010 and 2011. Three weed species, Abutilon theophrasti (Medic.), Datura stramonium (L.) and Iva xanthiifolia (Nutt.) (Tab. 3.1) and maize (variety Fernandez S250, KWS Saat AG, Einbeck, Germany) were cultivated together under all possible combinations of two temperature levels ("cold" and "warm") and two soil moisture levels ("wet" and "dry") in four soil substrate mixtures (treatment soil: loess, clay, peat and sand), in an orthogonal procedure approach (Fig. 3.1). The resulting 16 environmental treatments were replicated 4 times in a completely randomized block design. The experimental design hence comprised a total of 64 pots. Two replications in time were achieved by conducting the experiment in the identical way in two consecutive years. 


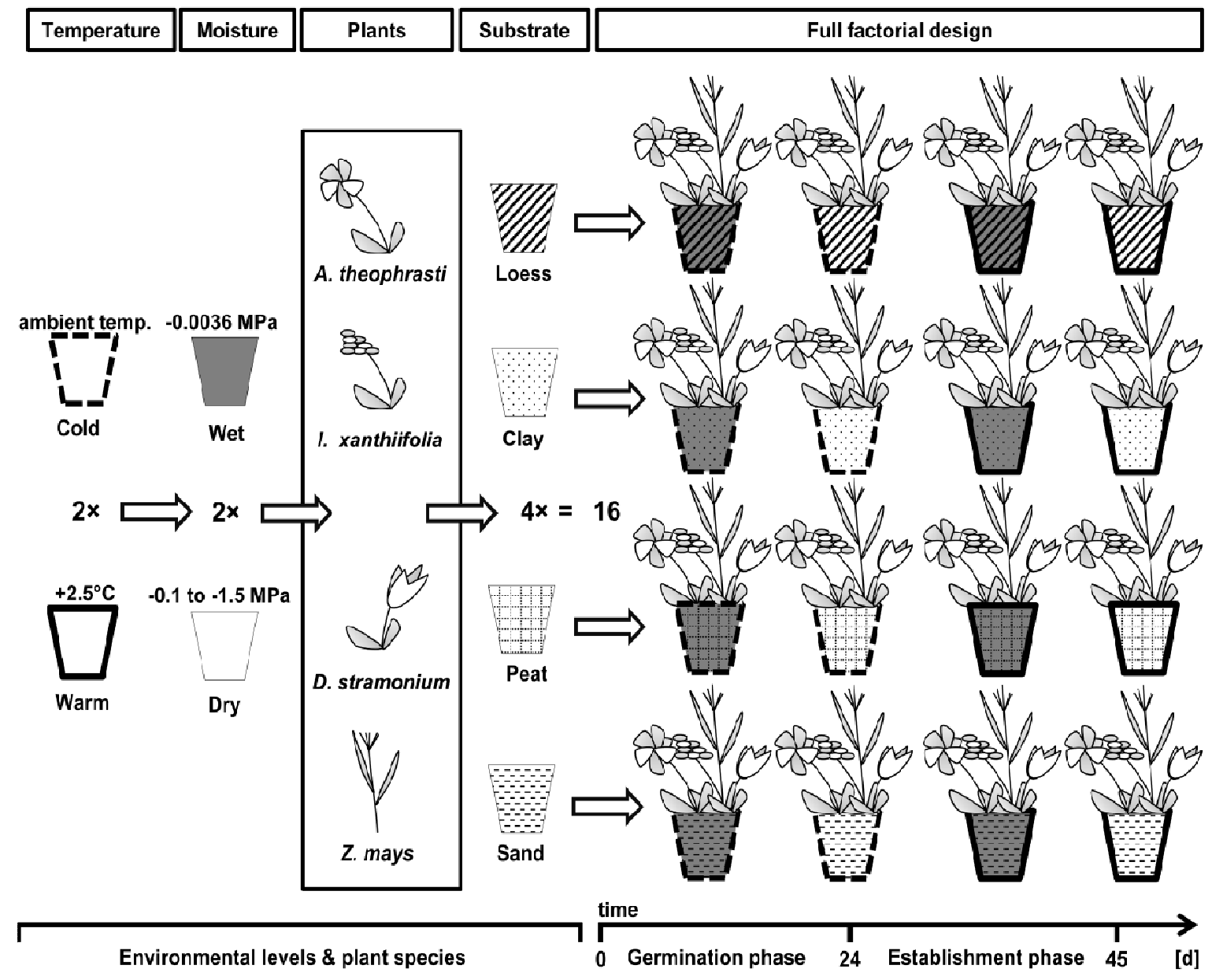

Fig. 3.1 Experimental design depicting the manipulated environmental factors and the main experimental phases. 
Table 3.1 Floristic region, seed source and additional information on the weed species used

\begin{tabular}{|c|c|c|c|}
\hline Aspects & Abutilon theoprasti & Datura stramonium & Iva xanthiifolia \\
\hline Picture $^{1}$ & & & \\
\hline Family $^{2,4}$ & Malvaceae & Solanaceae & Asteraceae \\
\hline $\begin{array}{l}\text { Spread } \\
\text { potential }^{2}\end{array}$ & 2.08 & 2.07 & 2.5 \\
\hline Weediness $^{2}$ & 2.15 & 2 & 1.5 \\
\hline Status ${ }^{3,4}$ & $\begin{array}{l}\text { Archaeophyte, } \\
\text { or pre } 1500 \text { alien }\end{array}$ & $\begin{array}{c}\text { Neophyte, } \\
\text { or post } 1500 \text { alien }\end{array}$ & $\begin{array}{c}\text { Neophyte, } \\
\text { or post } 1500 \text { alien }\end{array}$ \\
\hline Life $\operatorname{span}^{4}$ & annual & annual & annual \\
\hline $\begin{array}{l}\text { Introduction } \\
\text { mode }^{4}\end{array}$ & seed contaminant & $\begin{array}{l}\text { escaped crop and } \\
\text { timber plant }\end{array}$ & contaminant \\
\hline $\begin{array}{l}\text { Time of first } \\
\text { naturalization } \\
\text { in } \mathrm{GER}^{4}\end{array}$ & / & 1584 & 1860 \\
\hline $\begin{array}{l}\text { Ecological } \\
\text { strategy }\end{array}$ & competitor/ruderal & competitor/ruderal & competitor/ruderal \\
\hline $\begin{array}{l}\text { Floristic region } \\
\& \text { status }^{4}\end{array}$ & $\begin{array}{c}\text { Asia \& Europe/natural } \\
\text { range }\end{array}$ & America/natural range & America/natural range \\
\hline Sociology ${ }^{4}$ & $\begin{array}{c}\text { Class: Sisymbrietea } \\
\text { officinalis }\end{array}$ & $\begin{array}{c}\text { Class: Sisymbrietea } \\
\text { officinalis }\end{array}$ & $\begin{array}{c}\text { Class: Sisymbrietea } \\
\text { officinalis }\end{array}$ \\
\hline $\begin{array}{l}\text { Additional } \\
\text { information \& } \\
\text { occurrence site }\end{array}$ & $\begin{array}{l}\text { Height: } 50-100 \mathrm{~cm}^{6} \\
\text { Leaves: up to } 15 \mathrm{~cm}^{6} \\
\text { Cultivated ground and } \\
\text { waste places }\end{array}$ & $\begin{array}{c}\text { Height: } 50-200 \mathrm{~cm}^{6} \\
\text { Leaves: } 5-18 \mathrm{x} 4-15 \\
\mathrm{~cm}^{6} \\
\text { Cultivated ground, } \\
\text { waste places and other } \\
\text { open habitats }{ }^{6} \\
\text { Thermophile } \\
\text { Prefers nitrogen rich } \\
\text { soils }^{5}\end{array}$ & $\begin{array}{l}\text { Height: up to } 200 \mathrm{~cm}^{6} \\
\text { Leaves: } 7-30 \mathrm{~cm}^{6} \\
\text { Cultivated ground, } \\
\text { railway-lines and } \\
\text { waste places }{ }^{6} \\
\text { Thermophile } \\
\text { Prefers humid, but well } \\
\text { drained fertile sandy, } \\
\text { respectively stony } \\
\text { soils }\end{array}$ \\
\hline $\begin{array}{l}\text { Invasive/other } \\
\text { continents }\end{array}$ & Yes & Yes & No \\
\hline $\begin{array}{l}\text { Seed source } \\
\text { (crop year) }\end{array}$ & $\begin{array}{l}\text { Experimental botanical } \\
\text { garden, University of } \\
\text { Göttingen (2009) }\end{array}$ & $\begin{array}{c}\text { Experimental } \\
\text { botanical garden, } \\
\text { University of } \\
\text { Göttingen (2009) } \\
\end{array}$ & $\begin{array}{l}\text { Botanical garden, } \\
\text { University of Leipzig } \\
\text { (2009) }\end{array}$ \\
\hline
\end{tabular}

${ }^{1}$ Edler (2011), ${ }^{2}$ Weber and Gut (2005) [(1 min - 3 max)], ${ }^{3}$ FloraWeb (2013), ${ }^{4}$ BiolFlor (2013), ${ }^{5}$ Hegi (1935 ff), ${ }^{6}$ Tutin et al. (1964 ff.)

The four soil substrates mixtures were individually prepared for the experiment. Each consisted of 50\% commonly used greenhouse soil and $50 \%$ loess (loess minerals), clay (clay minerals), peat (pure "fibrous peat") or sand (graded quarzsand), respectively. Using soil mixtures rather 
than native soils facilitated handling, for instance reduced puddling. The four soil substrate mixtures were analysed for their physical and chemical properties, including the maximum dry density $\left[\mathrm{g} / \mathrm{cm}^{3}\right]$ and the soil moisture content (Vol.-\%) (details in Tab. 3.2). The average pHvalue was 6.5-7.2 for all soil substrate mixtures. Sixteen pots each were filled with $1900 \mathrm{~g}$ loess $\left[S_{L}\right], 1770 \mathrm{~g}$ clayey $\left[S_{C}\right], 900 \mathrm{~g}$ peaty $\left[S_{P}\right]$ or $2300 \mathrm{~g}$ sandy $\left[S_{S}\right]$ substrate mixture, respectively.

Table 3.2: Physical and chemical soil properties analysis for the used loess, clay, peat and sand substrate mixtures

\begin{tabular}{|c|c|c|c|c|c|c|c|c|}
\hline \multirow[b]{2}{*}{ 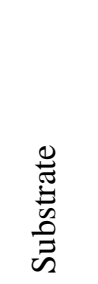 } & \multicolumn{5}{|c|}{ Chemical soil properties } & \multicolumn{3}{|c|}{ Physical soil properties } \\
\hline & $\mathrm{pH}$ & $\begin{array}{c}\mathrm{mg} \\
(\mathrm{C}) / \mathrm{g} \\
(\text { d. m.)* }\end{array}$ & $\begin{array}{c}\mathrm{mg} \\
(\mathrm{N}) / \mathrm{g} \\
\text { (d. m.) }\end{array}$ & $\begin{array}{c}\mathrm{mg} \\
(\mathrm{P}) / \mathrm{g} \\
\text { (d. m.) }\end{array}$ & $\begin{array}{c}\mathrm{mg} \\
(\mathrm{K}) / \mathrm{g} \\
\text { (d. m.) }\end{array}$ & $\begin{array}{l}\text { treatment } \\
\text { "wet" } \\
\text { moist.cont. } \\
\text { (Vol.-\%) }\end{array}$ & $\begin{array}{l}\text { treatment } \\
\text { "dry" } \\
\text { moist. cont. } \\
\text { (Vol.-\%) }\end{array}$ & $\begin{array}{c}\text { dry } \\
\text { density } \\
\left(\mathrm{g} / \mathrm{cm}^{3}\right)\end{array}$ \\
\hline Loess & 7.2 & 60 & 1.3 & 0.5 & 5.8 & 18.4 & 9.1 & 0.633 \\
\hline Clay & 7 & 78 & 1.6 & 0.8 & 13.7 & 20.4 & 9.9 & 0.59 \\
\hline Peat & 6.5 & 295 & 0.7 & 0.7 & 6.7 & 22.7 & 11.4 & 0.3 \\
\hline Sand & 6.7 & 31 & 0.4 & 0.4 & 5.7 & 15 & 7.6 & 0.766 \\
\hline
\end{tabular}

*d. m. dry matter

For the temperature treatment, half of the pots $(N=32)$ were positioned in a vegetation hall (temperature level "cold"), and the other half were placed on a greenhouse table equipped with heater mats and sand as a buffer between the pots and the heating coils (temperature level "warm"). Between the cold and the warm treatment a temperature difference of approximately $+2.5^{\circ} \mathrm{C}$ was established. The ambient greenhouse air temperature and the heated greenhouse air temperature were measured permanently with temperature loggers, placed in white boxes, $5 \mathrm{~cm}$ above the soil surface. Temperature records showed that the mean daily surface temperature of the "warm" treatment was $24.9 \pm 3.7^{\circ} \mathrm{C}$ in 2010 and $25.9 \pm 4.6^{\circ} \mathrm{C}$ in 2011 . For the "cold" treatment, we recorded a mean daily surface temperature of $22.5 \pm 3.9^{\circ} \mathrm{C}$ in 2010 and of $23.6 \pm$ $5.7^{\circ} \mathrm{C}$ in 2011. Between the two treatment levels, we hence obtained a mean temperature difference of $2.4 \pm 0.2^{\circ} \mathrm{C}$ in 2010 and of $2.3 \pm 1.1^{\circ} \mathrm{C}$ in 2011 .

Soil moisture content was adjusted one week before the start of the experiment. For 4 pots per temperature treatment and soil substrate mixture we simulated drought conditions (altogether $N=32$ ), by keeping the soil moisture content between -0.1 to $-1.5 \mathrm{MPa}$ (moisture level "dry"). For the other half of the pots (altogether $N=32$ ), plant available moisture content was kept at $0.0036 \mathrm{MPa}$ (moisture level "wet"). To this point, three times a week at the beginning (until three weeks after sowing) and twice a week at the end of the experiment (from week three to six after sowing), each pot was weighed and watered by pouring from atop according to the difference to target weight. The amount of water added was calculated based on the total amount of soil water required to obtain the target moisture content, which had been assessed prior to the start of the experiment for each soil substrate mixture and moisture content 
treatment without the influence of plants and temperature. The required soil water content levels were: loess/wet $550 \mathrm{ml}$, loess/dry $275 \mathrm{ml}$, clay/wet $610 \mathrm{ml}$ and clay/dry $300 \mathrm{ml}$, peat/wet $680 \mathrm{ml}$, peat/dry $340 \mathrm{ml}$, and sand/wet $450 \mathrm{ml}$, sand/dry $230 \mathrm{ml}$. To reassess the supplied water quantity per artificial environment we accumulated the water amount per watering point over time (Fig.3.2). The supplied amount of water was significant influenced by the moisture treatment (Fisher's $F$-test, $\mathrm{p}<0.001$ ) and also significantly affected by the temperature treatment and the soil substrate type.

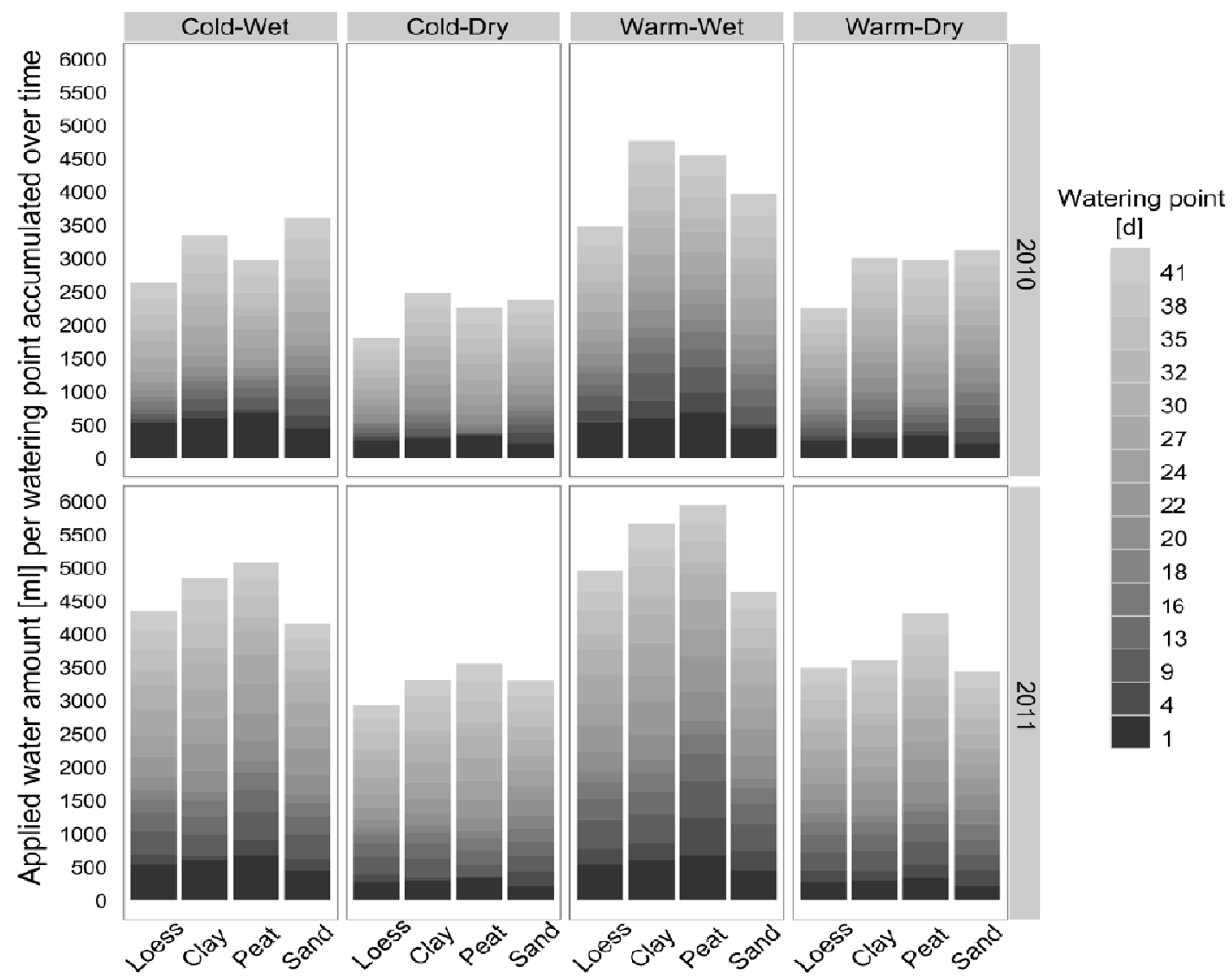

Fig. 3.2 Supplied water amount [ml] per environmental treatment condition and per watering point, accumulated over time and displayed per replication of year.

The temperature and soil moisture levels in this experiment were devised following Moseley et al. (2012) whose climate scenario predicted a warming of up to $2.5 \mathrm{~K}$ by 2100 combined with a decline of annual mean precipitation in the summer months. Temperatures in the "warm" treatment were quite high (daily mean temperature of $\sim 24^{\circ} \mathrm{C}$ ), and soil moisture in the "dry" treatment was temporary less than $-1.5 \mathrm{MPa}$ and hence below the physiological permanent wilting point of plants. The dry treatment level was meant to simulate drought period peaks rather than commonly occurring moisture situations during a growing season. The warm-dry climatic treatment was devised to generate severe stress for the plants. The purpose of reducing the soil moisture content towards the wilting point (treatment "dry"), was to drive the plants towards the limits of their environmental tolerance. Because of genetic and phenotypic 
plasticity within each population, merely in extreme environments, at the edges of the physiological optimum of a species, stress causes measurable responses (Woodward and Williams, 1987; Primack and Kang, 1989). Even if the environment changes substantially, it still may be in the physiological optimum of a species. Hence, only experiments simulating environmental extremes [extreme cold, heat or drought (Thomas, 2010)] appear to be suitable for predicting morphological and distributional change of plants (Chapin III et al., 1993).

Each pot was sown with a fixed number of seeds of $A$. theophrasti $(N=10), D$. stramonium $(N=10)$ and I. xanthiifolia $(N=12)$ and Zea mays $(N=2)$. Number of seeds was chosen after a pre germination test, where the germination capacity and rate per species had been determined (data not shown). The three weed species all belong to the sociological class of Sisymbrietea officinalis (Tab. 3.1) and are associated with spring crops, e.g. maize, sugar beet or sunflower. The reason of joint cultivation and together with maize was to mimic a field-like growing situation with intra- and interspecific interaction and competition over resources, which would reflect an artificially realized, but realistic niche in different environmental conditions. Plants were not fertilized during the experimental study.

\section{Sampling}

The data sampling within the experimental study was divided into two periods: the germination phase and the establishment phase. Within the former (first 24 days after sowing), the emergence pattern was monitored (data not shown). After the germination phase, plants were manually thinned to 5 individuals of the same age per weed species and pot in order to achieve a homogeneous plant density.

We used a number of plant parameters as surrogates for individual plant performance, following Violle and Jiang (2009). In addition, we distinguished between above and belowground plant parameter response, because there is some evidence that environmental change has a larger influence on aboveground parts of the plant (Davis, 2006).

Forty-five days after sowing (end of the establishment phase) and hence before pot size would limit root growth in the weed species, the entire plants were destructively harvested. Roots were cleaned of soil substrate mixture by manual washing in a washing basin. Four entire plants per weed species and the two entire maize plants per pot were separated from one other. Hence, an overall of 1792 plants, or 32 individuals per weed species and 16 individuals of maize were obtained for each combination of environmental conditions (species x 4 replicates $\mathrm{x} 2$ years). Due to drop out problems, the targeted amount of 32 individuals per species sometimes could not be harvested. For this reason, the number of individuals per species and environmental treatment which were used for analysis are displayed in the figures.

From each individual plant, the shoot was clipped off the root. In maize, roots and leaves were not considered for any further observation, because roots already showed signs of spatial limitation caused by the pot size, and leaves were too large to process. In the weed species, the roots and the third leaf from the top of each plant were scanned using a CanonScan 42000F scanner (Canon Inc., Japan) and the images were analysed with WinRHIZOpro (Regents Instruments Inc., USA) to measure root length [cm] and projected leaf area $\left[\mathrm{mm}^{2}\right]$. We selected the third youngest leaf following a recommendation by Cornelissen et al. (2003) who suggested 
measuring a relatively young but fully expanded and hardened leaf. After clipping and scanning, the sampled plant parts were dried for $48 \mathrm{~h}$ at $70{ }^{\circ} \mathrm{C}$ in a drying oven. Root and shoot dry biomass were determined by weighing and added to obtain total biomass. Based on these, we calculated the shoot-to-root ratio for each species and treatment. Additionally, the shoot biomasses of all four species were summed up to obtain the total aboveground biomass per pot and per environmental treatment [g] based on which the relative aboveground biomass [\%] per plant species and environmental treatment were determined.

\section{Data analysis}

The data analyses were performed using the software R (R Development Core Team, 2013). We tested the effect of environmental conditions on the plant parameters (shoot, root and total dry biomass, root length, leaf size and root-to-shoot ratio) for each species by calculating a mixed effects model (nlme package; Pinheiro et al., 2012) with soil type, moisture and temperature as fixed effects, and with the repetition (years 2010 and 2011) and the replicates (blocks) as random effects. For model simplification Akaike's information criterion (AIC) and the backward selection elimination of non-significant terms was used as a guide to select the minimal adequate model. The step-function in $\mathrm{R}$ was used for model simplification (Zuur, 2009). All measured traits were log-transformed for analysis and the predicted values were back transformed for graphical presentation. We inspected for normality and homogeneity by visual control of plots of residuals against fitted values. To obtain the metric model quality for the random effects, we calculated the intra-class correlation coefficient $\rho$ (Zuur, 2009). To estimate the differences among the levels of the mixed effects model, a post-hoc multiple comparison of means using Tukey contrasts with a Bonferroni test correction was conducted (multcomp package; Hothorn et al., 2008) for the observed plant parameters (shoot, root and total dry biomass, root length, leaf size and root-to-shoot ratio).

We determined whether the measured aboveground plant parameters were correlated with belowground parameters by calculating Pearson's correlation coefficient $r$ for the relationships between shoot biomass and root biomass, shoot biomass and root length, leaf size and root length, as well as leaf size and root biomass for each weed species per soil substrate.

The amount of water supplied to each pot to establish the target moisture content were analysed by calculating an ANOVA with soil, temperature, moisture and year as fixed effects.

\section{Results}

All measured traits of A. theophrasti, D. stramonium and I. xanthiifolia, and shoot biomass of Z. mays were affected by the applied environmental conditions. However, effects were significant at differing significance levels for the individual species (Tab. 3.3). The random effect year influenced the results in some cases; in these cases, this is mentioned in detail for each trait/species below. Differences between replicates did not account for more than $1 \%$ of the total variance in any case.

Table 3.3 Anova results of three-factorial mixed model after model simplification showing the effects of soil, temperature and moisture content for shoot, root, and total plant biomass, root 
length, leaf size and root-to-shoot ratio of A. theophrasti, D. stramonium, I. xanthiifolia and shoot biomass of $Z$. mays.

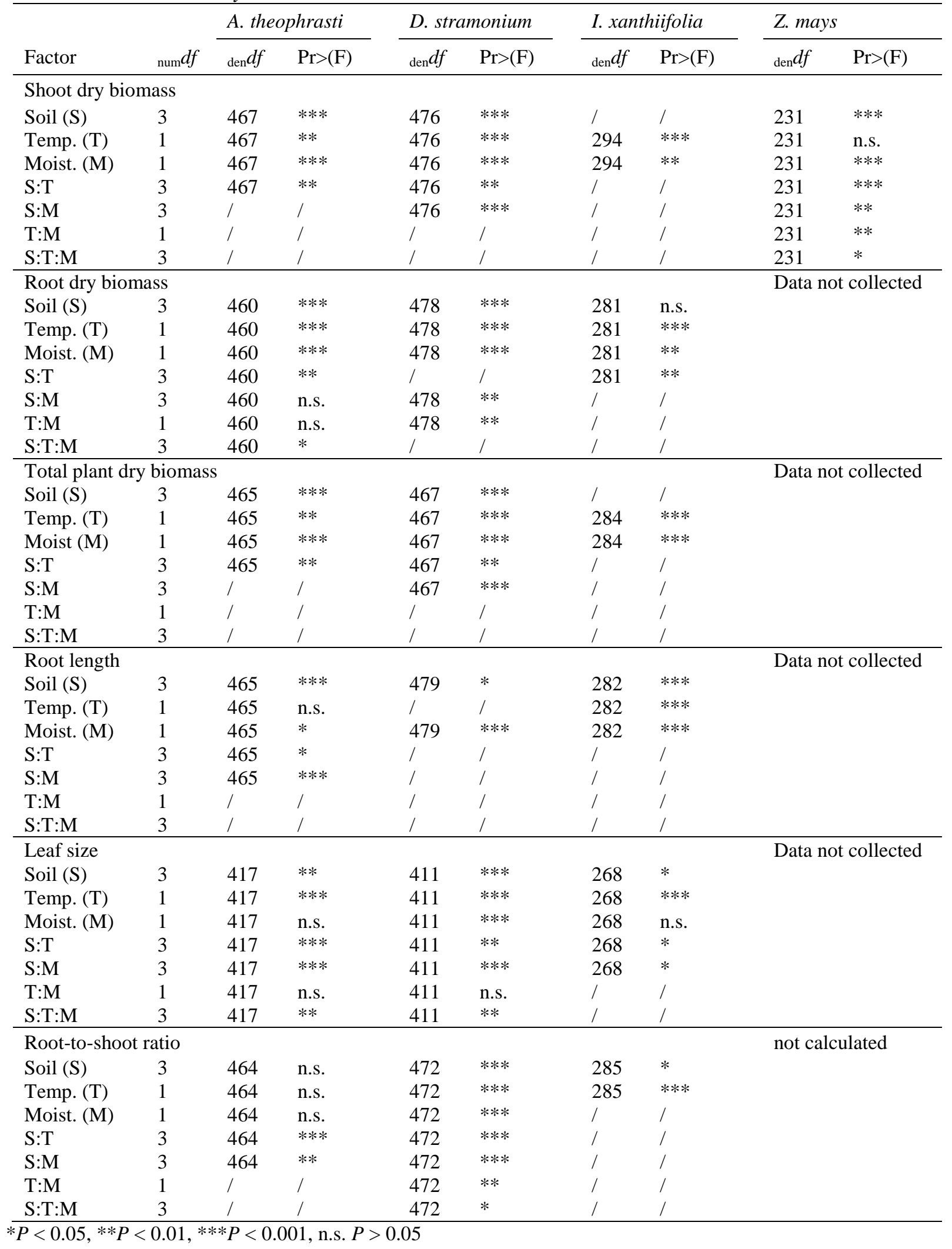


The highest total aboveground biomass was measured in the $S_{C}(7.9 \mathrm{~g})$ and $S_{L}(7.4 \mathrm{~g})$ warm-wet, as well as in $S_{P}(7.6 \mathrm{~g})$ and $S_{S}(7.6 \mathrm{~g})$ cold-wet treatments (Fig. 3.3). In all soil substrate mixtures, total aboveground biomass was lower in the warm-dry treatment than in the cold-wet treatment; this difference was most pronounced in $S_{S}$ and $S_{P}$. Maize always held more than $80 \%$ of the total aboveground biomass in the cold, and more than $88 \%$ in the warm treatments. Aboveground biomass of maize was highest in the $S_{S}$ substrate in all the climatic treatments. The reduction of soil moisture in the cold treatment led to a decline of weed aboveground biomass, which was more severe in $S_{S}$ and $S_{L}$ than in $S_{P}$ and $S_{C}$ substrates.

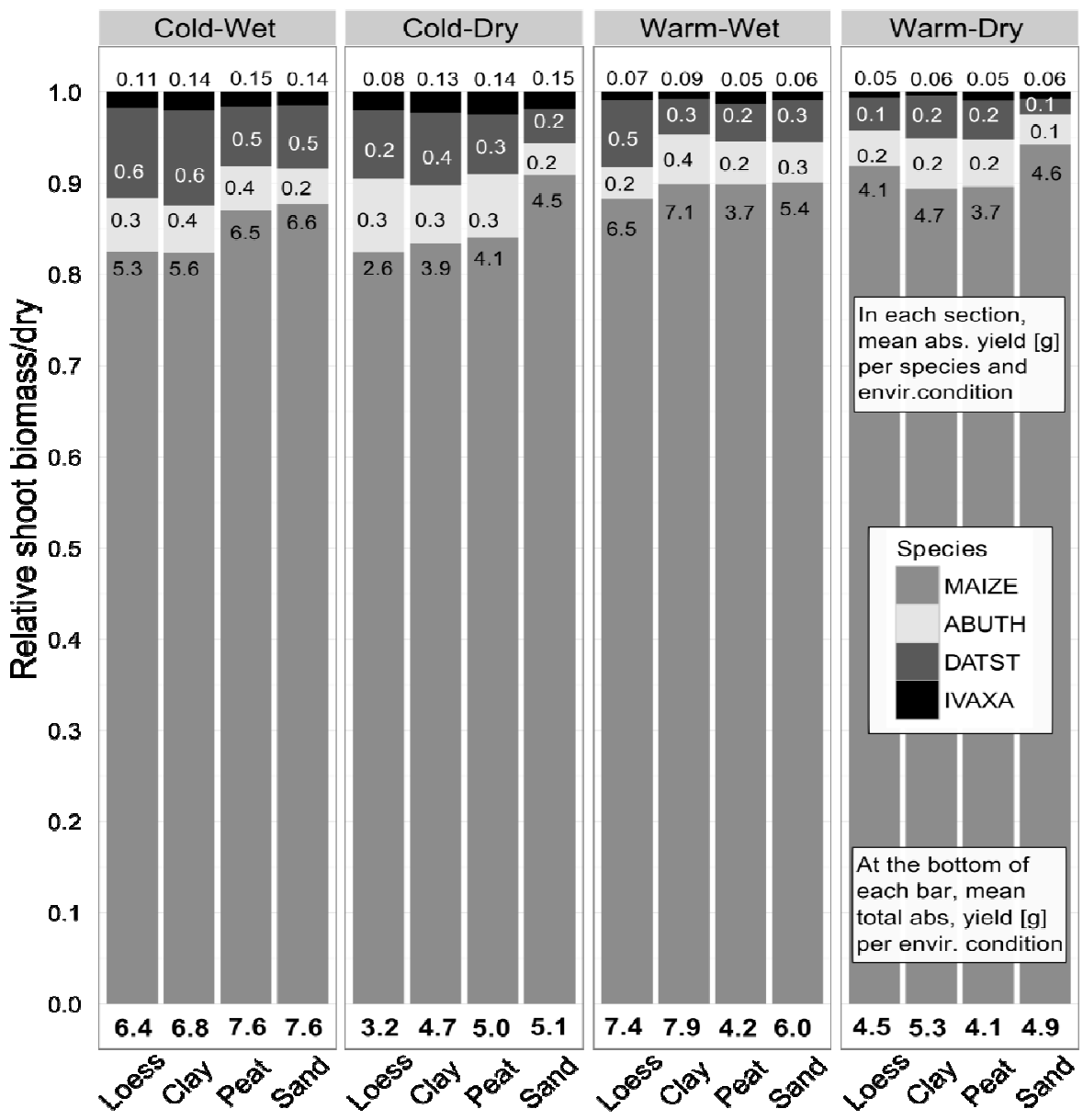

Fig. 3.3 Relative aboveground biomass per environmental treatment and species. Mean values of four replications and two years. The mean total absolute yield $[\mathrm{g}]$ was determined as the sum of dry shoot biomasses of the weeds and of maize, and the mean absolute yield per species [g] was determined as the sum of dry shoot biomasses per weed species, per pot and environmental conditions.

Maize grown in $S_{L}, S_{C}$ or $S_{S}$ showed the highest absolute shoot biomass in the warm-wet, followed by the cold-wet, warm-dry and cold-dry treatment. Absolute shoot biomass of maize was significantly higher in warm growing conditions $(p<0.001)$, except when grown in the $S_{P}$ substrate mixture $(p=0.001)$. In $S_{P}$, shoot biomass of maize decreased from the cold-wet, over the cold-dry, warm-wet to the warm-dry treatment. 


\section{Weed total plant biomass}

Total plant biomass decreased from the cold-wet, over the warm-wet and cold-dry to the warmdry treatment for $A$. theophrasti and D. stramonium. A. theophrasti produced the highest total plant biomass in the $S_{P}$ cold-wet treatment; $D$. stramonium yielded the highest total biomass in the $S_{L}$ cold-wet treatment. I. xanthiifolia also developed the highest total plant biomass under cold-wet conditions. In the warm treatment, A. theophrasti and D. stramonium achieved a significantly lower total plant biomass in $S_{L}$ and $S_{S}$ than in $S_{C}$ and $S_{P}$ substrates.

\section{Weed shoot biomass}

Shoot biomass of the three weed species was significantly lower under warm-dry conditions than in the cold-wet treatment in all of the soil substrate mixtures (Fig. 3.4). For I. xanthiifolia, a decrease in shoot biomass was measured in the order of the treatments from cold-wet, over cold-dry, warm-wet to the warm-dry treatment, with no significant differences among soil substrate mixtures. Within identical soil treatments, shoot biomass of this species in the coldwet environment was at least twice that in the warm-dry environment. The random effect year accounted for $11 \%$ of the total variance in shoot biomass for I. xanthiifolia.

\begin{tabular}{l|l|l|l|} 
Cold-Wet & Cold-Dry & Warm-Wet & Warm-Dry
\end{tabular}
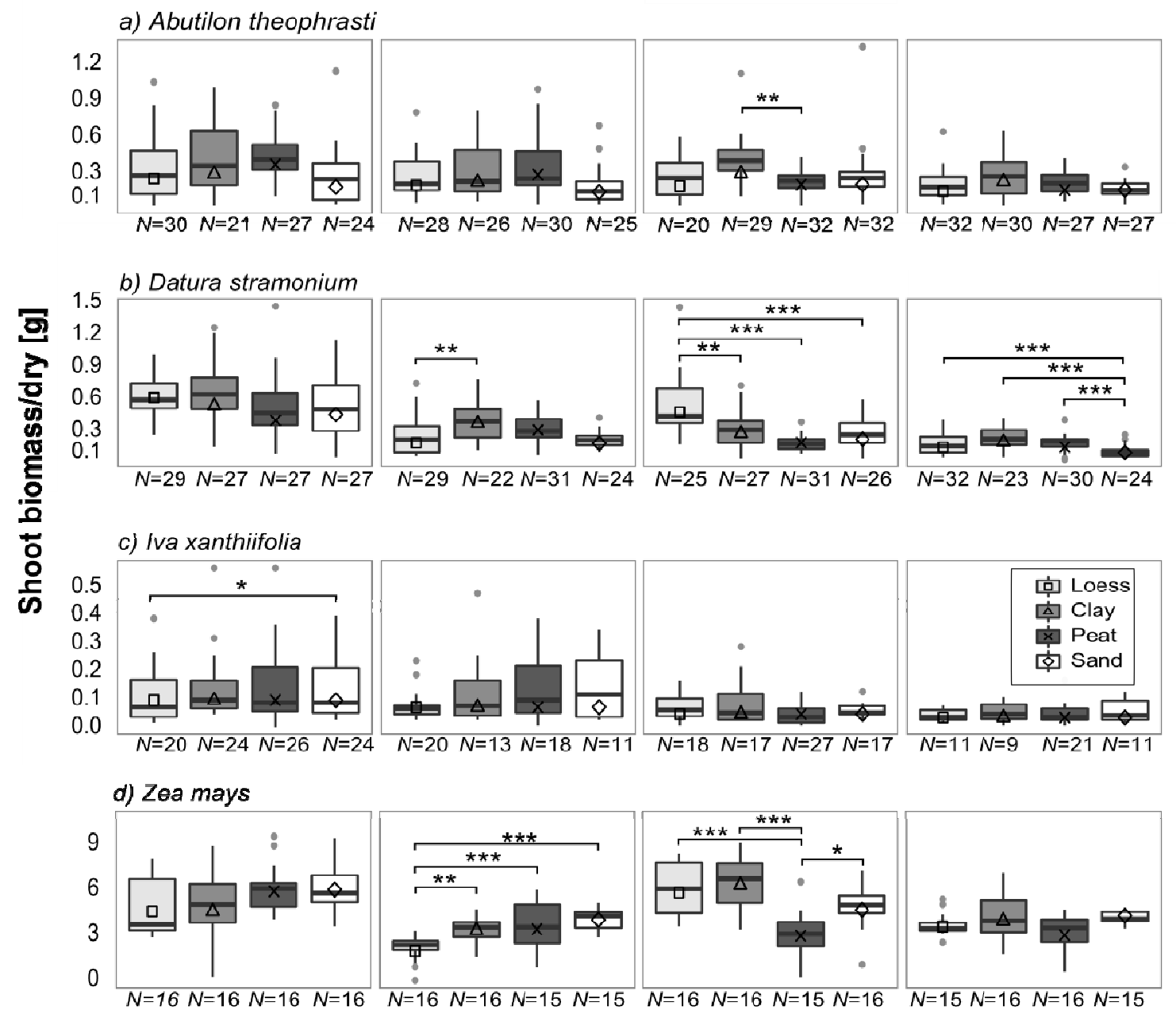

Fig. 3.4 Shoot (dry) biomasses [g] of three weed species and maize, grown in four soil types and at different combinations of climatic conditions. Boxes indicate quartiles with median 
marked as a horizontal line; points are outliers. Fitted values (back transformed) provided by the mixed model are incorporated as signs ( $\square$-loess, $\triangle$-clay, $\times$-peat, $\diamond$-sand) in the graph. The number of harvested plants $(N)$ is given under each boxplot. Stars indicate significant differences among levels per comparison pair (multiple post-hoc test comparison of means; *** $P<0.001 ; * * P<0.01 ; * P<0.05)$.

For A. theophrasti and D. stramonium, the soil type had a significant effect on shoot biomass. Values of this parameter showed a similar pattern as for I. xanthiifolia in the $S_{C}$ and $S_{P}$ growing medium. Shoot biomass decreased from the cold-wet, over the cold-dry and warm-wet to the warm-dry treatment. The order was different in the $S_{S}$ and $S_{L}$ substrate mixtures. Shoot biomass decreased form cold-wet over warm-wet, cold-dry to warm-dry treatment.

\section{Leaf size}

In warm-dry conditions, $A$. theophrasti $(p=0.0009)$ and D. stramonium $(p=0.04)$ had larger leaves in the $S_{P}$ than in the other substrates. In contrast, in I. xanthiifolia, leaf size was significantly lowest in the $S_{P}$ substrate. The random effect year accounted for $7 \%$ of the variance in leaf size in each of the weed species.

\section{Weed root traits}

Root biomass was significantly reduced in A. theophrasti and I. xanthiifolia in the warm compared to the cold treatment and in $S_{P}$ compared to the other soil types. There was a positive effect of $S_{C}$ on the root biomass of A. theophrasti $(p=0.009)$ and I. xanthiifolia $(p=0.01)$, and a significant negative effect of $S_{S}$ on root biomass of $D$. stramonium.

Root length was significantly reduced in the dry compared to the wet treatment for $D$. stramonium, I. xanthiifolia and A. theophrasti. Temperature did not influence the root length of A. theophrasti and D. stramonium significantly, but had a highly significant negative effect on this parameter in I. xanthiifolia. $S_{P}$ had a significant positive effect on the root length for all three weeds; the same was observed for the $S_{C}$ for A. theophrasti and D. stramonium. The random effect year accounted for $52 \%$ of the variance in root length in I. xanthiifolia.

\section{Root-to-shoot ratio}

The root-to-shoot ratio did not show a consistent pattern for the three weeds. In A. theophrasti, in the dry $S_{S}$ treatment it was significantly higher $(p=0.009)$ than in the other treatments. $D$. stramonium showed a reduced root-to-shoot ratio only under $S_{C}$ warm-dry $(p=0.04)$ conditions; a marginally higher value was observed in $S_{S}$ and $S_{P}$ warm-dry conditions. In I. xanthiifolia, root-to-shoot ratio was significantly higher in the warm temperature treatment $(p=0.000)$, whereas soil moisture content did not have a significant influence on this parameter.

\section{Correlation of aboveground and belowground traits}

There was a significant positive correlation between shoot and root traits in most cases (Fig. 3.5). Only for D. stramonium (Pearson $r_{(N=20)}=-0.45, p=0.037$ ) and I. xanthiifolia (Pearson 
$\left.r_{(N=23)}=-0.41, p=0.042\right)$, there was a significant negative correlation between leaf area and root length in the $S_{S}$ warm-dry conditions.
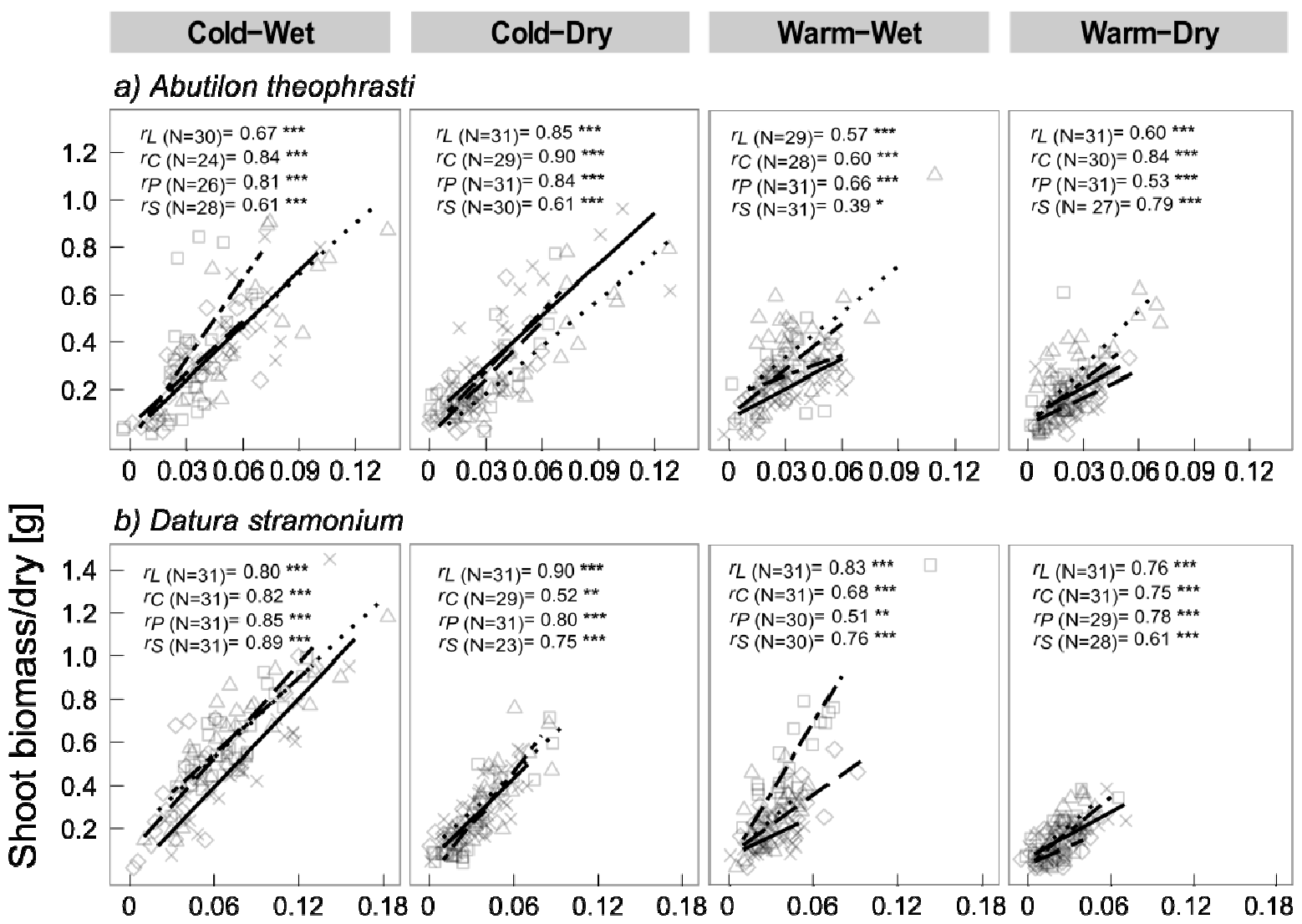

c) Iva xanthiifolia

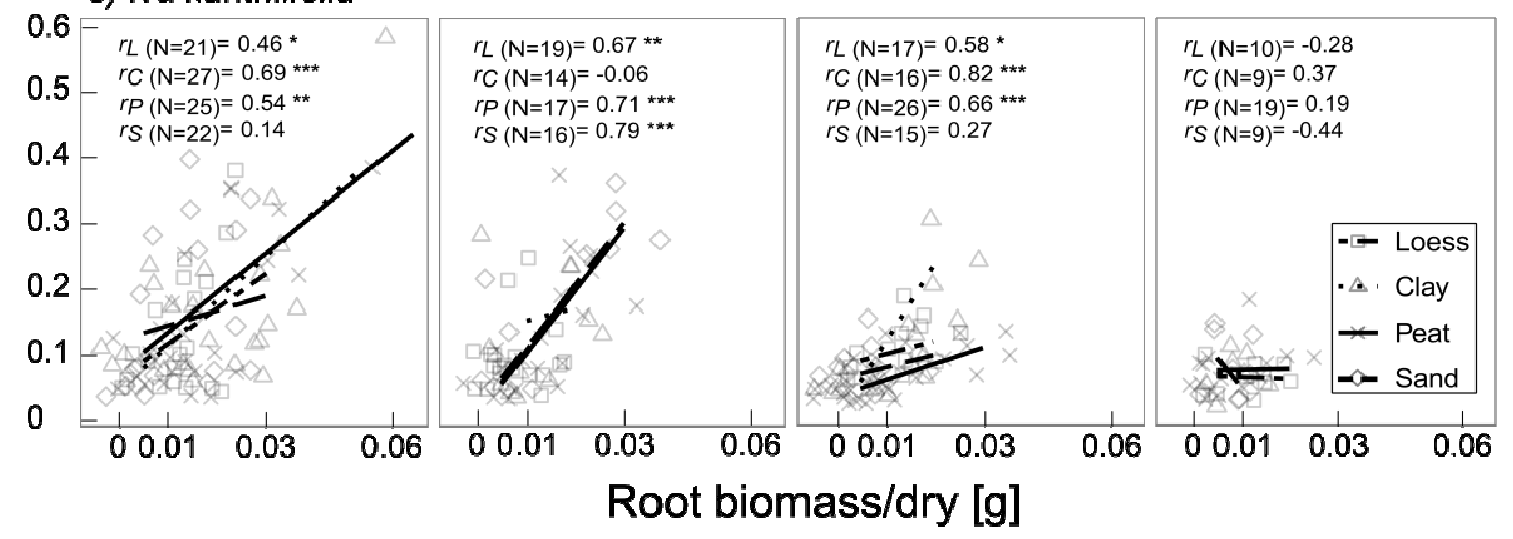

Fig. 3.5 Relationship of shoot biomass to root biomass of A. theophrasti, D. stramonium and $I$. xanthiifolia at each environmental treatment. In each panel, Pearson's correlation coefficient per soil substrate mixture $\left(r_{\mathrm{L}}, r_{\mathrm{C}}, r_{\mathrm{P}} \& r_{\mathrm{S}}\right)$ and the statistical significance of the correlation are shown. 


\section{Discussion}

We conducted the present study in order to examine the effects of elevated temperature and reduced soil moisture on vegetative traits of three weed species. We additionally used four different soil types in order to study the importance of soil properties for the impact of altered environmental conditions on the plants. The results of the experiment were intended to allow an estimation of how future climatic conditions may impact on the performance of the studied weeds.

Our data show that parameters of the studied species responded strongly, and in species-specific ways to the applied temperature and moisture treatments. In general, higher temperatures and water limitation caused a decrease of total biomass in the three weed species. Abutilon theophrasti, and to an even higher extent $D$. stramonium showed significant alterations of the values of leaf size and root length in response to the climatic treatments and as a consequence of the treatment interactions with different soil types. Iva xanthiifolia always reacted in a slightly different way than the other two species to the applied treatments, showing no soil effects for shoot, root and total biomass allocation. This weed also developed the smallest rootto-shoot ratio in sandy soil, D. stramonium, in contrast, the largest. Plant responses are strongly mediated by changes in resource availability and accessibility (Chapin III et al., 1993). It has frequently been shown that unfavourable conditions of water and nutrient supply have a heavier negative impact on aboveground than on belowground plant parts, because plants will allocate more strongly in the roots to maximize soil resource acquisition (Chapin III et al., 1993; Crawley, 1997; Davis, 2006). Under changing climatic conditions, deep rooting may be crucial for plants to survive during dry periods (Chapin III et al., 2003). Besides, advanced rooting can indicate a higher desiccation resistance (de Kron and Visser, 1997). Root-to-shoot ratio appears to be mainly governed by a functional balance between water uptake by the root and photosynthesis by the shoot. The functional balance is shifted if moisture availability decreases (Taiz and Zeiger, 2002). In our study we did not observe a change of root-to-shoot-ratio. This may be explained by the fact that we only monitored the establishment stage of these weeds. The results could have been different, had we continued the experiment until the onset of flowering, because some evidence has been found that competition for assimilates between roots and fruits is stronger during the reproduction phase (Taiz and Zeiger, 2002), or through to the competitive interactions between the species. In our experiment, most correlations between aboveground and belowground traits were positive. If negative correlations were observed, they were not significant in most of the cases, e.g. the correlation between shoot and root biomass (Fig. 3.5). There only was a significantly negative correlation between leaf size and root length for D. stramonium and I. xanthiifolia in $S_{S}$ warm-dry conditions. This finding corresponds to results of other studies, which documented advanced root elongation in sandy soil and reduced aboveground biomass under stressful conditions (Crawley, 1997; Davis, 2006). Our results hint at a higher capacity of $A$. theophrasti and D. stramonium compared to I. xanthiifolia to adapt to alterations of environmental conditions. This is further underpinned by the observation that $I$. xanthiifolia suffered a higher rate of loss than the other two species; particularly in the warm- 
dry treatment, merely $40 \%$ of the plants survived to the end of the experiment, which is a total of 45 days. Similarities could be observed for $I$. xanthiifolia in reduced emergence characteristics in the warm-dry treatment (see thesis chapter 2).

Our findings also highlight that species which are known to have comparable ecological niches under present conditions - in this case, all three weed species are described as thermophile ruderal competitors - may show largely varying performance under conditions of severe stress. The warm-dry treatment of this experiment was devised to generate such conditions. The effectiveness of the treatment with regard to this aspect was indicated by the significant reduction of total plant biomass in the warm-dry compared to the cold-wet treatment. The idiosyncratic response of the three tested species emphasises the need for empirical experiments like the present study for estimating the impact of altered environmental conditions on the composition and structure of established plant communities.

The factor soil type and its interactions with temperature and moisture also had significant effect on plant parameters. We generally observed a moderate trend of better growing performance in $S_{C}$ and $S_{P}$ substrates under temperature and moisture stress, at least for $A$. theophrasti and D. stramonium. This may be explained by the physical characteristics of the soils. Although in sum the same water consumption was recorded for the four soil treatments over time (Fig. 3.2), the loess and sandy soils dried faster in each treatment level. In view of a prospective climate change, these soil characteristics may become more relevant. Soil types with a low water holding capacity - coarse soils like sand and loam - will dry faster under conditions of low precipitation and therefore potentially produce stronger stress than soils with a high water holding capacity - like clays and soils with a large amount of organic matter -, because dry soil prevents mass flow and diffusion of nutrients (Pregitzer and King, 2005). Under conditions of good moisture supply, water and nutrient availability are higher in loamy substrates and hence growing conditions for plants are better (Hillel, 1998). However, in waterlimited conditions, the clay-humus complexes in the $S_{C}$ substrate and the higher concentration of organic matter in the $S_{P}$ substrate mixture may have caused a higher water availability coupled with a good nutrient supply. This may have created more favourable growing conditions under dry conditions compared to well drained loess and sandy soils.

The experiment was conducted with a man-made crop-weed community, because we intended to study possible realized plant niches occurring in the agricultural system. Whenever several species co-exist, biotic interactions affect plant performance and benefit some species while impeding others due to changes in the competitive balance (Chapin III et al., 1993; Hirzel and Le Lay, 2008). For this reason, we cannot disentangle to which extent the observed alterations of performance of the weed species were either mediated directly by the experimental treatment or to which extent they instead affected by an altered competitive ability of the maize plants and hence presented merely indirect consequences of the treatments. However, as the treatments were not nutrient-limited during the duration of the experiment, we assume that differences in biomass production of the individual species were not a consequence of resource depletion by those species which were most adaptive to the treatment conditions, but that they actually reflected the performance of the species as caused by the experimental environment. 
Our results showed that the $S_{S}$ substrate had a positive effect on the aboveground biomass of maize in all climatic treatments. Particularly under warm-dry and $S_{S}$ conditions, $Z$. mays was favoured and held more than $92 \%$ of the total aboveground biomass. In contrast, the cold-wet treatment was beneficial for the weeds in all soil types. The increased performance of $Z$. mays as a $\mathrm{C} 4$ plant in the warm temperature treatment may be explained by the photosynthetic pathway of $\mathrm{C} 4$ plants which makes them better adjusted to high temperatures and drought stress than C3 plants (Chuine et al., 2012). Iva xanthiifolia apparently was not able to compete for resources with the other two weed species and maize successfully, in none of our experimental treatments.

Altogether, our results suggest that $A$. theophrasti and $D$. stramonium feature a wide environmental tolerance range. They showed higher plant performance and plasticity with regard to all sampled traits and in all treatment levels, in contrast to I. xanthiifolia, where plant performance was strongly related to moisture supply and colder temperatures. Hence, because of their plasticity $A$. theophrasti and D. stramonium may acclimate better to new climatic conditions. These weed species may be favoured by the predicted future climatic conditions and - given favourable conditions of dispersal - might increase their distributional range.

\section{Acknowledgements}

The study is part of Lower Saxony's Climate Impact research Program (KLIFF) and was funded by the Ministry for Science and Culture of Lower Saxony, Germany. This financial support is gratefully acknowledged. The authors are also most thankful to Martin Potthoff (soil biology), Johannes Glauninger (weed biology) and Lena Ulber (statistics) for their additional advice. 


\section{References}

ACKERLY, D.D. 2009. Conservatism and diversification of plant functional traits: Evolutionary rates versus phylogenetic signal. Proceedings of the National Academy of Sciences of the United States of America 106:19699-19706.

Beier, C., Beierkuhnlein, C., Wohlgemuth, T., Penuelas, J., Emmett, B., KöRner, Ch., DE Boeck, H., Christensen, J.H., Leunzinger, S., Janssens, I.A. \& Hansen, K. 2012. Precipitation manipulation experiments -challenges and recommendations for the future. Ecological Letters 15: 899-911.

BIOLFLOR 2013. BiolFlor - search and information system on vascular plants in Germany. URL: http://www2.ufz.de/biolflor/index; last access date 10.09.2013.

Bonser, S.P., LADD, B., MonRo, K., HALl, M.D. \& Forster, M.A. 2010. The adaptive value of functional and life-history traits across fertility treatments in an annual plant. Annals of Botany.

Broennimann, O., Treier, U.A., Müller-Schärer, H., Thuiller, W., Peterson, A.T. \& GuISAN, A. 2007. Evidence of climatic niche shift during biological invasion. Ecology Letters 10:701-709.

Chapin, F.S., III, Rincon, E. \& Huante, P. 1993. Environmental responses of plants and ecosystems as predictors of the impact of global change. Journal of Biosciences: 515-524.

CHAPIN, F.S. III 2003. Effects of plant traits on ecosystems and regional processes: a conceptual framework for predicting the consequences of global change. Annals of Botany 91:455-463.

Chuine, I. 2010 Why does phenology drive species distribution? Philosophical Transactions of the Royal Society B: Biological Sciences 365:3149-3160.

Chuine, I., Morin, X., Sonié, L., Collin, C., Fabreguettes, J., Degueldre, D., Salager, J. \& RoY, J. 2012. Climate change might increase the invasion potential of the alien C4 grass Setaria parviflora (Poaceae) in the Mediterranean Basin. Diversity and Distributions 18:661-672.

Cleland, E.E., Chuine, I., Menzel, A., Mooney, H.A. \& Schwartz, M.D. 2007 Shifting plant phenology in response to global change. Trends in Ecology \& Evolution 22:357-365.

Cornelissen, J.H.C., Lavorel, S., Garnier, E., Díaz, S., Buchmann, N., Gurvich, H.D., Reich, P.B., Steegeter, H., Morgan, H.D., van der Heidden, M.G.A., Pausas, J.G. \& PoORTER, H. 2003 A handbook of protocols for standardised and easy measurement of plant functional traits worldwide. Australian Journal of Botany 51:335-380.

CRAWLEY, M.J. 1997 Plant ecology, 2nd. Blackwell Science, Oxford [etc.].

DAVIS, W.J. 2006. Responses of plant growth and functioning to changes in water supply in a changing climate. In: Morison JIL, Morecroft MD (eds) Plant growth and climate change: Blackwell Pub., Oxford, pp 97-145. 
Efthimiadou, A.P., Karkanis, A.C., Bilalis, D.J. \& Efthimiadis, P. 2009. Review: The phenomenon of crop-weed competition; a problem or a key for sustainable weed management? Food, Agriculture \& Environment 7:861-868.

ELLENBERG, H. 1950. Unkrautgemeinschaften als Zeiger für Klima und Boden. Grundlagen und Anwendungen einer Ökologie der Pflazengemeinschaften für Landwirte Gärtner, Bodenkundler und Biologen. Eugen Ulmer, Stuttgart.

FloRAWEB. 2013. FloraWeb- Daten und Informationen zu Wildpflanzen und zur Vegetation Deutschlands. www.floraweb.de; last access date 10.09.2013.

FOLLAK, S. 2009. Vorkommen und potenzielle Verbreitung des Rispenkrauts (Iva xanthiifolia) in Österreich. Botanica Helvetica 119:7-12.

Gassó, N., Basnou, C. \& VilÀ, M. 2010. Predicting plant invaders in the Mediterranean through a weed risk assessment system. Biological Invasions 12:463-476.

GRIME, J.P. 1977. Evidence for existence of 3 primary strategies in plants and its relevance to ecological and evolutionary theory. American Naturalist 111:1169-1194.

GRINELL, J. 1917. The niche-relationships of the California Thrasher. Auk 34:427-433.

HEGI, G. 1935 ff. Illustrierte Flora von Mitteleuropa. München.

HiLlel, D. 1998. Environmental soil physics. Academic Press, San Diego, CA.

HiRzEL, A.H. \& LE LAY, G. 2008 Habitat suitability modelling and niche theory. Journal of Applied Ecology 45:1372-1381.

HóDI, L. \& TORMA, M. 2000. Efficacy of some herbicide active ingredients on Iva xanthiifolia Nutt. in laboratory trials. Journal of Plant Diseases and Protection: 603-605.

Holt, R.D. 2009. Bringing the Hutchinsonian niche to the 21st century: Ecological and evolutionary perspectives. PNAS 106:19659-19665.

Hothorn, T., Bretz, F. \& WestFall, P. 2008. Simultaneous Inference in General Parametric Models. Biometrical Journal 50:346-363.

Hutchinson, G.E. 1957. "Concluding remarks". Cold Spring Harbor Symposia on Quantitative Biology 22:415-427.

Hyvönen, T., Luota, M. \& Uotila, P. 2012. Assessment of weed establishment risk in a changing European climate. Agriculture and Food Science 21: 348-360.

International SeEd Testing Association, (ISTA). 2005. International rules for seed testing edition 2005, Bassersdorf CH-Switzerland.

KroON DE, H. \& VISSER, E.J.W. 2003. Root ecology. Springer, Berlin, New York.

MoreCroft, M.D. \& PATERSON, J.S. 2006. Effects of temperature and precipitation changes on plant communities. In: Morison JIL, Morecroft MD (eds) Plant growth and climate change: Blackwell Pub., Oxford, pp 147-163.

Morin, X., LeCHOwICZ, M.J. 2008. Contemporary perspectives on the niche that can improve models of species range shifts under climate change. Biology Letters 4:573-576.

Morin, X., Thuiller, W. 2009. Comparing niche- and process-based models to reduce prediction uncertainty in species range shifts under climate change. Ecology 90:1301-1313. 
Moseley, C., Panferov, O., Döring. C., Dietrich. J., Haberlandt, U., Ebermann, V., RECHID, D., BEESE, F. \& JACOB, D. 2012. Klimaentwicklung und Klimaszenarien. In: Niedersächsisches Ministerium für Umwelt, Energie und Klimaschutz (ed) Empfehlung für eine niedersächsische Strategie zur Anpassung an die Folgen des Klimawandels. Regierungskommision Klimaschutz, pp 18-41.

Picotte, J.J., Rosenthal, D.M., Rhode, J.M. \& Cruzan, M.B. 2007. Plastic responses to temporal variation in moisture availability: consequences for water use efficiency and plant performance. Oecologia 153:821-832.

Pinheiro, J., Bates, D., Debroy, S., Sarkar, D. \& R Development Core Team. 2012. nlme: Linear and Nonlinear Mixed Effects Models. R package version 3.1-104.

PotT, R. \& HüPPE, J. (eds). 2007. Spezielle Geobotanik. Pflanze - Klima - Boden, 1st edn. Springer, Berlin.

PREgitZER, K.S. \& KING, J.S. 2005. Effects of soil temperature on nutrient uptake. In: BassiriRad H (ed) Nutrient Acquisition by Plants: Springer-Verlag Berlin Heidelberg, New York, pp 277-310.

PRIMACK, R. \& KANG, H. 1989. Measuring fitness and natural selection in wild plant populations. Annual Review of Ecology and Systematics 20:367-396.

R Development Core Team. 2013 R: A Language and Environment for Statistical Computing, Vienna, Austria. http://www.R-project.org.

Rosenzweig, C. \& Hillel, D. 2000. Soils and global climate change: Challenges and opportunities. Soil Science 165:47-56.

RosenZWEIG, M.L. 1987. Habitat selection as a source of biological diversity. Evolution Ecology1:315-330.

SAtTin, M., Zanin, G. \& BerTI, A. 1992. Case history for weed competition/population ecology: velvetleaf (Abutilon theophrasti) in corn (Zea mays). Weed technology: a journal of the Weed Science Society of America 6:213-219.

SiLvertown, J. 2004. Plant coexistence and the niche. Trends Ecological Evolution 19:605611.

Soberón, J. \& NAKAmura, M. 2009. Niches and distributional areas: Concepts, methods, and assumptions. Proceedings of the National Academy of Sciences 106:19644-19650.

Sommer, J.H., Kreft, H., Kier, G., Jetz, W., Mutke, J. \& Barthlott, W. 2010. Projected impacts of climate change on regional capacities or global plant species richness. Proceedings of the Royal Society B: Biological Sciences: rspb.2010.0120v1-rspb20100120.

TAIZ ,L. \& ZEIGER, E. 2002. Plant physiology, 3rd. Sinauer Associates, Sunderland, Mass

THOmAS, C.D. 2010. Climate, climate change and range boundaries. Diversity and Distributions 16:488-495.

Tutin, T.G., Heywood, V.H., Burges, N.A., Moore, D.M., Valentine, D.H., Walters, S.M. \& WebB, D.A. (eds) 1964 ff. Flora Europaea, First paperback printing. Cambridge University Press, Cambridge. 
VAn Grunsven, R.H.A., VAn Der Putten, W., Bezemer, T. \& VeenendaAl, E. 2010. Plantsoil feedback of native and range-expanding plant species is insensitive to temperature. Oecologia 162:1059-1069.

VAN WiJK, W.R. (ed) 1963. Physics of plant environment. North-Holland Pub. Co; Interscience Publishers, Amsterdam, New York.

Violle, C., JiAnG, L. 2009. Towards a trait-based quantification of species niche. Journal of Plant Ecology.

Violle, C., Navas, M., Vile, D., Kazakou, E., Fortunel, C., Hummel, I. \& Garnier, E. 2007. Let the concept of trait be functional! Oikos 116:882-892.

WAlther, G. 2010. Community and ecosystem responses to recent climate change. Philosophical Transactions of the Royal Society B: Biological Sciences 365:2019-2024.

WeBER, E. \& GuT, D. 2005. A survey of weeds that are increasingly spreading in Europe. Agronomy for Sustainable Development 25:109-121.

WIENS, J.J. \& GRAHAM, C.H. 2005. Niche conservatism: Integrating evolution, ecology, and conservation biology. Annual Review of Ecology and Systematics 36:519-539.

Wiens, J.A., Stralberg, D., Jongsomit, D., Howell, C.A. \& Snyder, M.A. 2009. Niches, models, and climate change: Assessing the assumptions and uncertainties. Proceedings of the National Academy of Sciences of the United States of America.

WINRHIZOPRo 2013. Win RHIZOpro- a software for root analysis. Copyright (C (1996-2013) by Regents Instruments Inc., Canada. www.regent.qc.ca.

Woodward, F.I. \& Williams, B.G. 1987. Climate and plant distribution at global and local scales. Plant Ecology 69:189-197.

ZUUR, A.F. 2009. Mixed effects models and extensions in ecology with R. Springer, New York. 


\section{CHAPTER}

4

Implications of climate change, land use, cover type, and soil on habitat suitability and potential distribution for three weeds in Lower Saxony

Barbara Edler, Laura Breitsameter, Jana Bürger \& 


\begin{abstract}
Regional climate model projections for Lower Saxony (northwest Germany) suggest a warming of up to $4 \mathrm{~K}$, stronger pronounced during the winter months, and a decline in precipitation, mainly during the summer months, for the end of this century. As the rate and magnitude of climate change accelerate, an understanding of its consequences for weed species distribution is becoming more and more important, considering the vulnerability of agro-ecosystems to the growth of introduced weed species and shifts within the weed species composition. In recent years a northward spread of weeds has been documented in Europe, and range transformations among damaging weed species may occur. It is necessary to identify potential future areas of risks arising from rangeexpanding species in order to proactively limit their spread and to advise appropriate measures of management.

MaxEnt, a niche-based modelling approach, was used to explore the implications of climate change for the distribution of three range-expanding, competitive, thermophile, ruderal, stress tolerant and annual C3 agricultural weed species, Abutilon theophrasti Medik., Datura stramonium L. and Iva xanthiifolia Nutt. Modelling was based on current environmental habitat suitability for the species as determined for Europe, using data on occurrence, climate, land use, land cover and soil. Models were then projected to the future climate conditions predicted by the fine-scale regional climate model REMO for the period between $2070-2100$.

The MaxEnt models performed better than the random for the three species with an average high test AUC ranging from 0.76 to 0.89 . The analysis predicted that the type and extent of suitable habitats and potential distribution of the damaging weed species may be altered under changing climatic conditions. I. xanthiifolia will suffer a greater loss of suitable habit compared to A. theophrasti, whereas $D$. stramonium may be favoured by climate change. Although all three weeds were selected as species from a same guild, idiosyncratic, spatially heterogeneous responses to changing environmental conditions were estimated by the model.
\end{abstract}

Keywords: MaxEnt, ecological niche modelling, potential species distribution, model transfer in space and time, regional fine-scaled climate model 


\section{Introduction}

Global climate has changed over the last three decades, and this trend is expected to continue in the current century at ever growing rates (Sommer et al., 2010). Based on the IPCC emission scenario A1B of continued rapid growth, the regional fine-scale climate model REMO indicates a mean annual temperature rise of up to $2 \mathrm{~K}$ by 2050 and up to $4 \mathrm{~K}$ by 2100 , pronounced stronger during winter, and a decrease mainly in summer precipitation for northwest Germany (IPCC, 2007; Moseley et al., 2012).

Compelling evidence accrues that climate change is affecting agricultural production systems severely, including weeds (Hulme, 2009; McDonald et al., 2009; Clements and DiTammaso, 2011; Estes et al., 2013). Weed problems in a given area may arise from three basic sources: from the introduction and naturalization of new weedy plant species, from the increasing spread of weed taxa that are already present in the area, and from the evolution of new weed taxa in the area (Weber and Schrader, 2006). Agro-ecosystems are especially sensitive to the growth of introduced weed species and to shifts within weed species composition (Glemnitz et al., 2006). Currently, the spatial range expansion of a number of weed species is being observed (Weber and Gut, 2005). In Europe, particularly a northward spread of weeds has been documented (Glemnitz et al., 2010).

Some of the spreading weeds are known to have a distinct effect on agricultural productivity, because of their high weediness and competitiveness and their limited manageability. In order to anticipate their "damage potential" and to devise cost-effective, strategic measures of their control and management as well as adaptation recommendations, information is required about their suitable habitats and potential distribution under changing climate conditions (Broennimann et al., 2007; Hyvönen et al., 2011; Bradley, 2013).

Species distribution is strongly, but not exclusively coupled to climatic conditions (Woodward, 1987; Hyvönen et al., 2011). There is evidence that climate governs the maximum boundaries of a species' potential distribution (Walther et al., 2002; Hulme, 2009; Peterson et al., 2011). Alterations of temperature and humidity may make a current habitat unsuitable, leading to niche or range transformations (Bradley, 2009; Peterson et al., 2011). Beside climate, other factors like land use, land cover type, and soil parameters are important for the distribution range of plants, especially on a regional or local scale (Pompe et al., 2008; Hyvönen et al., 2011; Stratonovitch et al., 2012).

Despite of significant research effort regarding the environmental drivers of plant distribution on different scales, comparatively little attention has as yet been given to the potential effects of climate change on the distributional range of agricultural weeds, especially with regard to regional scales (McDonalds et al., 2009; Hyvönen et al., 2011; Stratonovitch et al., 2012).

Species niche models can be used to estimate possible consequences of climate change for species distribution. They are also known as bioclimatic envelope models, ecological niche models (ENMs) or species distribution models (SDMs). They are correlative models and are based on the concept of describing the niche of a species as a multidimensional space 
of scenopoetic variables (Peterson et al., 2011). These predictor variables describe the past or current environmental conditions in a study area (e.g., climate, soil, or land use and cover type) and are usually measured at coarse spatial resolution over a large geographic area (Wiens et al., 2009; Franklin et al., 2013). The models use the environmental information of known occurrence sites to describe the current niche of a species. Such models can be used to predict the likelihood of a species' presence across an area of interest under a future climate and to mark the future areas of risk (Elith et al., 2006; Sommer et al., 2010). Areas of risk are characterised by possible weed shifts between recent and future suitable habitats (Bradley, 2009; Peterson et al., 2011).

Here, we used the software MaxEnt, with a maximum entropy approach, to analyse the requirements concerning climate, soil, land use and cover type of three weed species, $A$. theophrasti, D. stramonium and I. xanthiifolia (see Pearson et al., 2004; Pompe et al., 2008). The selected agricultural weed species display a guild or species assemblage of range-expanding, competitive, thermophile, ruderal, stress tolerant and annual C3 weed species, but still differing in their ecological requirements and biogeographic importance.

The modelling included projections of future climate of one regional fine-scale climate model (REMO) to predict suitable habitats for potential distribution of the three species for Lower Saxony (northwest Germany) up to the year 2100. The objective of the modelling was to provide information of possible future weed problems for deriving adaptation recommendations aimed at extension workers and farmers in the region. It complements greenhouse experiments with the same species on plant plasticity reactions for changing environmental conditions.

\section{Material and Methods}

\section{Study species}

This study modelled the future potential distribution or relative habitat suitability of: Abutilon theophrasti Medik. (Malvaceae, commonly known as velvetleaf or china jute, EPPO-Code: ABUTH), Datura stramonium L. (Solanaceae, jimson weed or datura, DATST) and Iva xanthiifolia Nutt. (Asteraceae, false ragweed or burweed mash-elder, IVAXA).

Species were selected due to their problematic impact on the agro-ecosystems in parts of Europe where they are already abundant and each is a management priority in parts of these areas (Weber and Gut, 2005). The three species display an annual life span of a C3 plant and are assigned to the strategy type of competitive ruderal plants (BiolFlor, 2013; based on Kühn et al., 2004). They are known for being highly competitive in spring crops (Sattin et al., 1992; Hodí and Torma, 2000; Efthimiadou et al., 2009). Further concern is given for I. xanthiifolia, due to its impact on human health as a highly allergy inducing plant (Follak et al., 2013).

All three species are native in Lower Saxony (ABUTH archaeophyte, DATST neophyte and IVAXA neophyte), with different current distributional area (Garve, 2007). A. 
theophrasti is assigned to the meriodonal floristic zone of evergreen broad-leaved and coniferous forests, steppes and deserts. Its original floristic region comprises Asia and Europe (BiolFlor, 2013).

D. stramonium was first naturalized in Germany in the year 1584. It is assigned the subtropical floristic zone of winter dry zone with savannahs and dry forests. Its original floristic region is America (BiolFlor, 2013).

I. xanthiifolia was first naturalized in Germany in the year 1860. It is assigned to the meridional, submeridional, southern and northern temperate floristic zones of evergreen broad-leaved and coniferous forests, steppes and deserts, winter dry zone with savannahs and dry forests, Southern temperate zone with summer-green deciduous forests and Northern temperate zone with summer-green deciduous forests. Its original floristic region is America (BiolFlor, 2013).

A. theophrasti and I. xanthiifolia were introduced to Europe as a seed contaminants and D. stramonium as escaped timber and ornamental plants (BiolFlor, 2013). A high spreading potential in Europe is forecasted for these three weed species (Weber and Gut, 2005). A high migration rate has already been observed for $A$. theophrasti and D. stramonium in Mediterranean (Gassó et al., 2010) and for I. xanthiifolia in Central European regions (Follak, 2009). Empirical experiments have indicated a high tolerance of D.stramonium and $A$. theophrasti to environmental stress such as high temperatures and low soil moisture (see thesis Chapter $2 \& 3$ ). Referring to Grime (1977), the three weeds display the ecological strategy type of CSR (competitive, stress-tolerant \& ruderal), which is often found in successful migrants. Species affiliated to this strategy type are highly adaptive to ephemeral habitats that may be created by disturbance (Stratonovitch et al., 2012).

Study area in general, Soil-Climate-Area, Lower Saxony Vegetation Survey, arable area apportionment

The study area of interest comprised the federal states of Lower Saxony $\left(47.624 \mathrm{~km}^{2}\right)$ and Bremen $\left(404 \mathrm{~km}^{2}\right.$ ) in northwest Germany (roughly between $6-12^{\circ} \mathrm{E}$ longitude and 51-54 ${ }^{\circ} \mathrm{N}$ latitude). The area is divided into three natural regions (coast, lowlands and uplands) (Niedersachsen, 2008; Schmiedel et al., 2011). A classification based on common soil and climate conditions for agricultural production divides the area into 10 soil-climate areas as shown in Fig. 4.1 (Roßberg et al., 2007). 


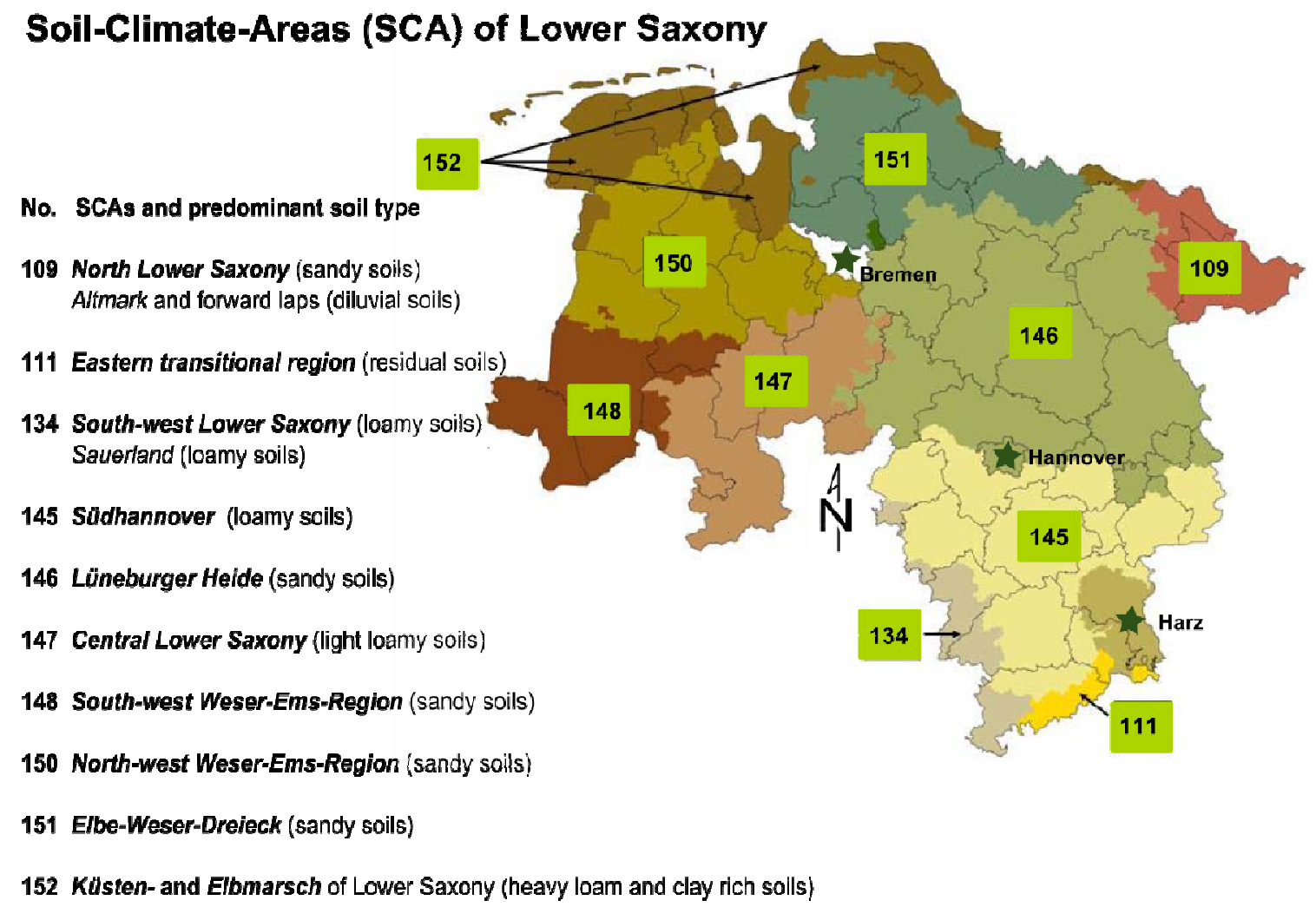

Fig.4.1 Soil-Climate-Areas of Lower Saxony (modified from Roßberg et al., 2007)

The current distribution of A. theophrasti, D. stramonium and I. xanthiifolia in Lower Saxony is included in an inventory of vascular plants compiled from vegetation surveys of the time from 1982 until 2003 (Garve, 2007). This distribution can be understood as the product of the interaction between land use and land cover, soil properties and climate. Figures 4.2-4.4 match the weed species occurrence data (raster data of $5.5 \times 5.5 \mathrm{~km}^{2}$ ) with data of the main crops on arable land.

The occurrence records are largely associated with areas of high summer crop concentration in the south, Central, northwest and northeast of Lower Saxony (145 SCA, eastern parts of $146 \& 150$ SCA 147,151 SCA). This may be caused by an association of the three weed species that mainly establish in spring to spring crops.

A. theophrasti is comparatively frequent in the eastern and south-eastern parts (where it is influenced by subcontinental climate) of Lower Saxony (parts of $145 \& 146$ SCA). It becomes increasingly scarce to the west and the northwest (147, $148 \& 150$ SCA). The species is not present at the East Frisian Islands and in the coastal region (152 SCA) (Fig. 4.2). 


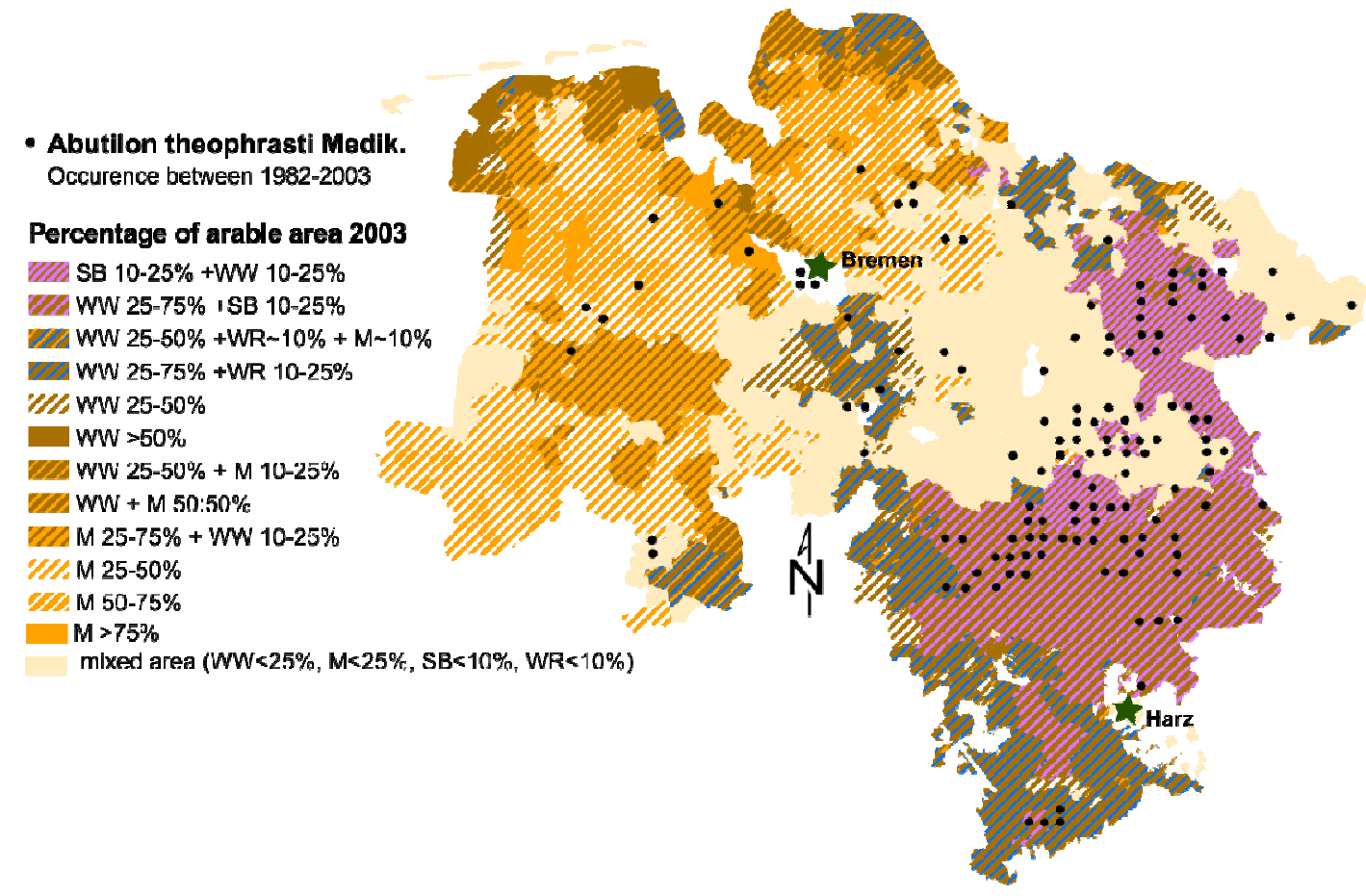

Fig. 4.2 The distribution of $A$. theophrasti Medik. from a series of regional vegetation surveys at an ordinance survey map scale (adapted from Garve, 2007) matched with the arable area apportionment for Lower Saxony from 2003 (SB =sugar beet, WW= winter wheat, $\mathrm{WR}=$ winter oil seed rape, $\mathrm{M}=$ maize).

D. stramonium is frequent in large parts of Lower Saxony. It is less densely distributed only in the very west (148 \& 150 SCA) and near the coast (parts of 152 SCA). The weed is present on the East Frisian Islands (Fig. 4.3).

The current distribution of I. xanthiifolia is marginal. Only two locations of occurrence have been reported in Lower Saxony (Fig. 4.4). 


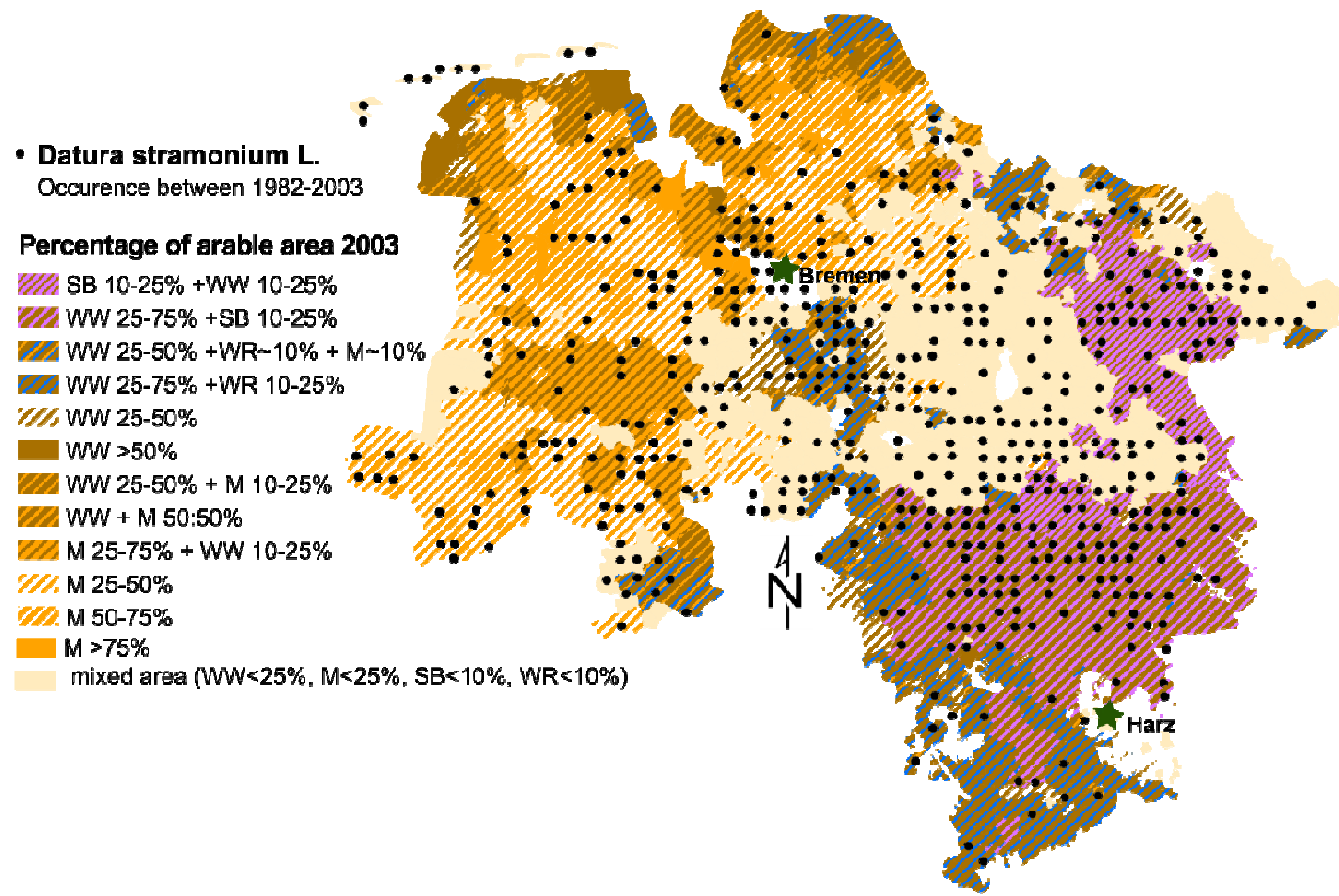

Fig. 4.3 The distribution of $D$. stramonium $\mathrm{L}$. from a series of regional vegetation surveys at an ordinance survey map scale (adapted from Garve, 2007) matched with the arable area apportionment for Lower Saxony from 2003 (SB =sugar beet, WW= winter wheat, WR= winter oil seed rape, $\mathrm{M}=$ maize).

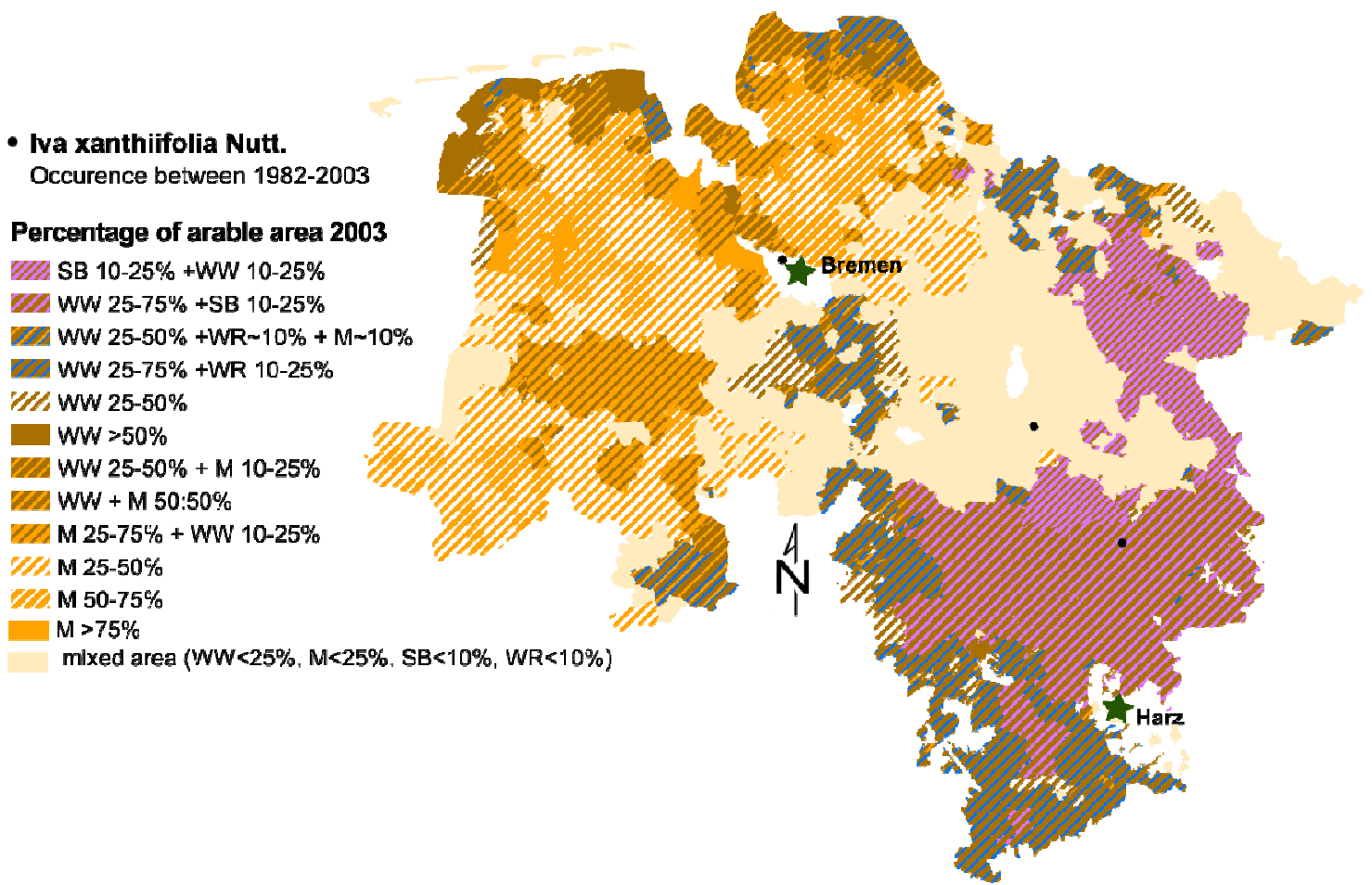

Fig. 4.4 The distribution of I. xanthiifolia Nutt. from a series of regional vegetation surveys at an ordinance survey map scale (adapted from Garve, 2007) matched with the arable area apportionment for Lower Saxony from 2003 (SB =sugar beet, WW= winter wheat, WR= winter oil seed rape, $\mathrm{M}=$ maize). 
Study area and time horizon for the modelling approach

We investigated climate change impacts on weed occurrence for the region of Lower Saxony for the period of 2070-2100. The models were trained on species occurrence and environmental data of Europe in the extent of $-11^{\circ} \mathrm{W}$ until $41^{\circ} \mathrm{E}$ longitude and between $34^{\circ}$ until $70^{\circ} \mathrm{N}$ latitude.

\section{European species occurrence data for modelling approach}

Weed species occurrence data were collected from different international and national databases which were either freely accessible online or available upon personal request (Appendix A). Weed geographic occurrence was entered as point data into a common coordinate system, providing longitude and latitude information. Data were 'cleaned' if errors in the map appeared as recommended by Hijmans and Elith, 2013. We only used occurrence records of the years 1950-2000 with an uncertainty of the coordinates of $<10$ $\mathrm{km}$.

\section{Predictor variables}

Scenopoetic variables that display the variation of environmental parameters determining the ecological niche of a species across the study area were chosen as predictor variables (Peterson et al., 2011; Sheppard, 2013). We focused on climate, soil, land use and land cover information as predictor variables for weed distribution (Appendix B).

\section{Climate data}

Historical climate data were downloaded from the WorldClim database at a resolution of 30 arcseconds (Hijmans et al., 2004). The WorldClim data are derived from measurements of temperature and rainfall from the weather stations across the globe in a time period from 1950-2000 (Hijmans et al., 2005). For our study, based on Thuiller (2003), we chose the set of 19 BIOCLIM variables derived from these measurements for modelling the distribution of the three examined weed species (Appendix B).

\section{Soil}

Data on soil properties was taken from the European soil data base (Van Liedekerke et al., 2006; Panagos, 2006) and included soil texture, organic matter content, and plant available water content (Appendix B).

\section{Land use and land cover}

As previous studies have shown that the quality of species distribution models for arable weeds can be significantly increased when incorporating land use information (Hyvönen et al., 2012), we complemented the climate and soil information with data of land use and cover (Appendix B). This information was downloaded from the International Steering Committee for Global Mapping database (http://www.iscgm.org/). 


\section{Future climate data}

Future climate data originated from the regional climate projection REMO, run UBA, based on the IPCC emission scenario A1B with a reference period from 2070 to 2100. Bias corrected monthly temperature and precipitation data provided by REMO was used to obtain values of the 19 BIOCLIM variables for the reference period for the area of Lower Saxony.

Data layers for all environmental parameters were formatted in a way that they were spatially congruent and had a common resolution of 10 arc-minutes.

Detailed information about gathering data about the study area in general, the soil-climatearea, the Lower Saxony Vegetation Survey, the arable area apportionment, the predictor variables, climate data, the soil data, the land use and land cover data, and the future climate data are described in detail in Bürger et al. (2014).

\section{Model fitting, calibration, evaluation and prediction (transfer)}

To estimate the probability of weed species occurrence and relative habitat suitability we used MaxEnt, a machine learning procedure using the maximum entropy principle to identify the link between distribution points and a set of given environmental variables. MaxEnt is a widely used and robust method for species habitat modelling, utilizing "presence-only" and "background" data in the modelling process (Elith et al., 2010). MaxEnt software is freely available online.

MaxEnt uses background data points to establish the environmental domain of the study, i.e. to characterize the environmental conditions in the study region, whilst the presence data establish under which condition a species is more likely to be present than on average (Philips et al., 2006, Hijmans and Elith, 2013).

The occurrence data showed a distinct sampling bias with a high density in some countries of Europe and very low densities in others. This is frequently the case in occurrence records. We used the target group approach to deal with this issue (Phillips et al., 2009). Occurrence data of 15 arable weeds (including the three studied species) from the study region were randomly sampled, the environmental variables at these locations extracted from raster files and provided to MaxEnt in the so-called svd-format. The sample size was 10.000 for ABUTH and IVAXA, a default number of MaxEnt. Background sample size for DATST was increased to 50.000 data points as the background number should be considerably larger than the presence sample size (which was ca. 10000 for DATST). With this subsampling method it was possible to reduce the sampling bias, but it cannot correct the data for areas that have not been sampled at all (lack of records) and for an inadequate or not existing data sampling (Peterson et al., 2011; Hijmans and Elith, 2013).

The set of predictor variables used for the present modelling approach is relatively small. It was devised in a way to avoid over-fitting by limiting model complexity (Pearson and Dawson, 2003; Philips et al., 2006). 
We calibrated a niche model for each species for the geographic extent of the whole of Europe to incorporate a broad range of environmental conditions (see Pearson and Dawson, 2003). This approach minimizes the risk that, when applied to future climate change scenarios, the model would be used to extrapolate outside the environmental range of the calibration data. This more complete representation of niche estimates may be more representative of the species' potential response.

We used 10-fold cross-validation for testing the model performance and to increase the robustness during the training process.

Accuracy of models was assessed using the area under the receiver-operator curve (AUC). It represents an overall measure of the model's performance across thresholds and is recommended by e.g. Elith et al., 2006 or Thuiller et al., 2009. The interpretation of such presence /background ROCs differs from traditional usage of presence/absence evaluation data and has to be used with caution (Peterson et al., 2011). In unbiased presence/ absence data sets, a high AUC indicates that sites with high predicted suitability values tend to be areas of known presence and locations with lower model prediction values tend to be areas where the species is not known to be present (Hijmans and Elith, 2013). For presence/absence evaluation data sets; AUC values $>0.5$ are generally classed into (1) poor predictions (0.5 to 0.7$)$; (2) reasonable predictions (0.7 to 0.9 ); and (3) very good predictions (>0.9) (see Swets, 1988). In presence/background evaluation data, maximum achievable AUC values depend on the proportional presence of the species and its potential distribution across the study region, such AUC values are species and region-specific (Phillips et al., 2006; Peterson et al., 2011). They are not comparable among species and are generally biased, because different species potential distribution will cover different proportional areas of the study region (Phillips et al., 2006; Peterson et al., 2011; Franklin et al., 2013).

We used the $n-1$ jackknife procedure (jackknife of regularized training gain, jackknife of test gain and jackknife of AUC) and the analysis of variable contribution (percent contribution and permutation importance) to evaluate the relative influence of the different environmental predictor variables (Peterson et al., 2011). To avoid overfitting, variables were eliminated from the models that showed a low contribution and low permutation importance in a first modelling run. Using MaxEnt-generated response curves, we also examined relationships between the habitat suitability and potential distribution and the environmental variables (Elith et al., 2006).

The models thus trained, were projected to the area of Lower Saxony to predict habitat suitability and potential distribution of the three weed species for the period from 2070 to 2100 (Pearson and Dawson, 2003). MaxEnt generates an estimate of relative habitat suitability for the species in a logistic output format with values varying from 0 (lowest suitability) to 1 (highest suitability).

The relative habitat suitability according to the model is visualised for current and future climate conditions with a colour range from blue (relatively unsuitable) to red (relatively suitable conditions). These continuous maps of relative suitability were converted to binary 
maps of potential distribution, to determine potential changes in the future habitat for a species by applying a probability threshold. The choice of this threshold value is critical, because it affects the model parameterisation and output. We used the setting of "10th percentile training presence threshold", which takes account of an error ratio of $10 \%$ of the training data to delimit suitable from unsuitable areas for distribution (Pearson and Dawson, 2003; Franklin et al., 2013).

Data preparation and raster formatting were carried out with $\mathrm{R}$ (version 2.15.2), package raster (version 2.0-41) (Hijmans and van Etten, 2012). Modelling was performed with MaxEnt, version 3.3.3k (Phillips et al., 2006). Detailed information about model fitting, calibration, evaluation and transfer are presented in Bürger et al. (2013).

\section{Results}

Models for the three species performed better than random, with average test AUC values ranging from 0.76 to 0.89 .

\section{A. theophrasti}

The MaxEnt model of $A$. theophrasti had a high goodness-of-fit with an average AUC value of $0.836( \pm 0.0267 \mathrm{SD})$.

The continental climate transect in the south-eastern and eastern areas of Lower Saxony (parts of $146 \& 147 \mathrm{SCA}$ ), with the highest predicted habitat suitability, was quite realistically reproduced by the model (Fig $4.5 \mathrm{a}$ ) and the current predicted suitability areas match quite accurately with the observed occurrence locations in the Lower Saxony Vegetation Survey (Fig. 4.2). 


\section{Abutilon theophrasti}

\section{Predicted current and future habitat suitability}

a.) Current (1950-2000)

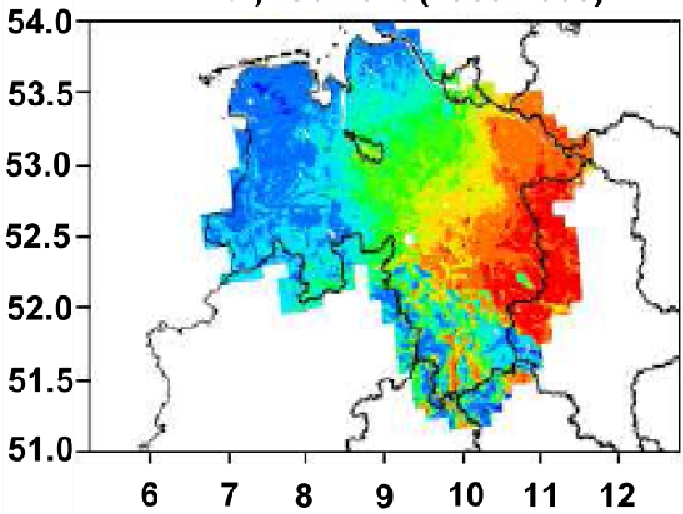

b.) Future (2070-2100)

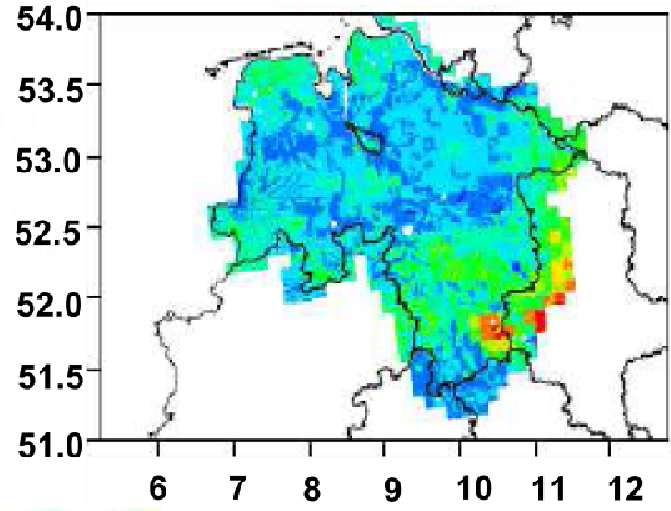

rel. unsuitable rel. suitable

\section{Predicted current and future potential distribution}

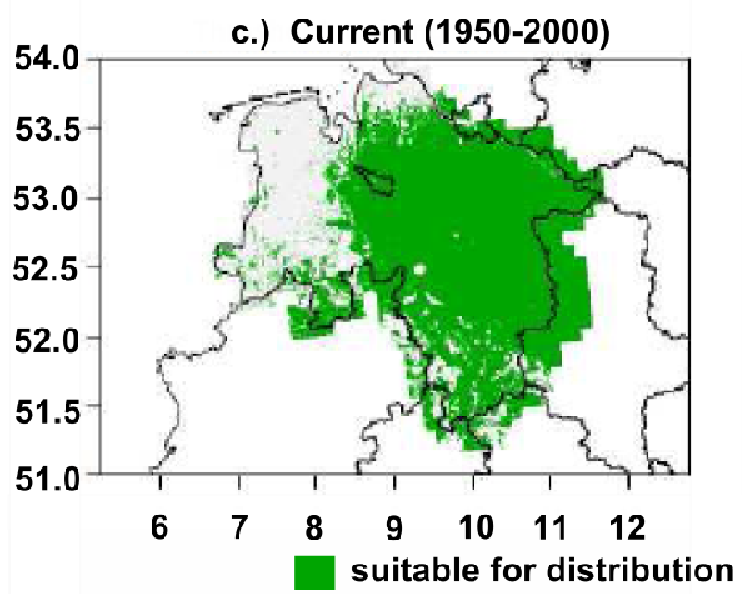

d.) Future (2070-2100)

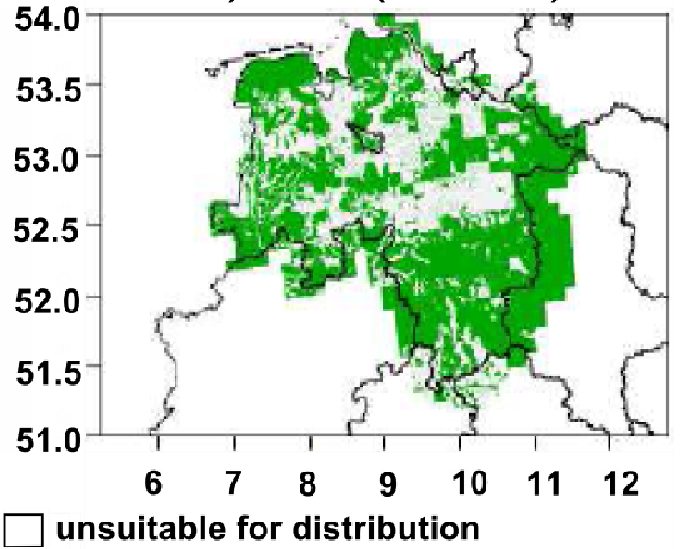

Fig. 4.5 Current $(\mathrm{a}, \mathrm{c})$ and future $(\mathrm{b}, \mathrm{d})$ modelled habitat suitability and potential distribution for $A$. theophrasti in Lower Saxony (northwest Germany).

The current potential distribution of $A$.theophrasti was predicted in the majority of Lower Saxony's areas, with the exception of the western (148 SCA), parts of the north-western (western parts of $150 \mathrm{SCA}$ ), and the coastal area (152 SCA) (Fig. 4.5c).

The environmental variables with the highest gain of importance for the model when used in isolation are the mean temperatures of the driest (Bio09) and warmest (Bio10) quarters. They have the most useful information by themselves to describe A. theophrasti habitat suitability.

The environmental variables that decreased the gain of importance the most, when they were omitted from the model are precipitation of the wettest quarter (Bio17) and annual precipitation (Bio12). They have the most information that was not present in the other variables (Fig 4.6a). These two variables showed also the highest permutation importance 
with $28.3 \%$ for Bio17 and $38.2 \%$ for Bio12. The two top environmental variables for contribution in the MaxEnt model were available soil water content with $37.7 \%$ and land use with $15.4 \%$ (Table 4.1).

Tab. 4.1 Percent contribution of the predictor variables in the MaxEnt models for the three target species; values shown are averages over 10 replicate runs. Variables which contributed less than $1 \%$ to the model in a first run, were removed (indicated by /).

\begin{tabular}{|c|c|c|c|}
\hline & A. theophrasti & D. stramonium & I. xanthiifolia \\
\hline Land use & 15.4 & 49.6 & 14.2 \\
\hline Land cover & 12.2 & l & / \\
\hline Available soil water content (top layer) & 37.7 & & 17.8 \\
\hline Organic $\mathrm{CO}_{2}$ content (top layer) & l & l & 3.6 \\
\hline \multicolumn{4}{|l|}{ Soil texture } \\
\hline Bio01 Annual mean temp. $\left({ }^{\circ} \mathrm{C}\right)$ & 4 & l & / \\
\hline Bio02 Mean diurnal temp. range $\left({ }^{\circ} \mathrm{C}\right)$ & l & l & 11.8 \\
\hline Bio03 Isothermality $(02 \div 07)$ & l & l & / \\
\hline Bio04 Temp. seasonality & / & / & l \\
\hline $\begin{array}{l}\text { Bio05 Max. temp. of warmest month } \\
\left({ }^{\circ} \mathrm{C}\right)\end{array}$ & 2.2 & / & l \\
\hline Bio06 Min. temp. of coldest month $\left({ }^{\circ} \mathrm{C}\right)$ & l & / & 5 \\
\hline Bio07 Temp. annual range $(05-06)\left({ }^{\circ} \mathrm{C}\right)$ & / & 18.2 & l \\
\hline $\begin{array}{l}\text { Bio08 Mean temp. of wettest quarter } \\
\left({ }^{\circ} \mathrm{C}\right)\end{array}$ & / & / & 33.2 \\
\hline Bio09 Mean temp. of driest quarter $\left({ }^{\circ} \mathrm{C}\right)$ & 2.8 & / & l \\
\hline Bio10 Mean temp. of warm. quarter $\left({ }^{\circ} \mathrm{C}\right)$ & 0.1 & 13.6 & I \\
\hline $\begin{array}{l}\text { Bio11 Mean temp. of coldest quarter } \\
\left({ }^{\circ} \mathrm{C}\right)\end{array}$ & / & / & 1.4 \\
\hline Bio12 Annual precipitation (mm) & 4.6 & / & 12.9 \\
\hline $\begin{array}{l}\text { Bio13 Precipitation of wettest week } \\
(\mathrm{mm})\end{array}$ & / & / & / \\
\hline Bio14 Precip. of driest week (mm) & l & 18.6 & / \\
\hline Bio15 Precip. seasonality (C of V) & l & l & l \\
\hline Bio16 Precip. of wettest quarter (mm) & 9.3 & l & l \\
\hline Bio17 Precip. of driest quarter (mm) & 7.4 & l & / \\
\hline Bio18 Precip. of warmest quarter (mm) & 3.4 & / & / \\
\hline Bio19 Precip. of coldest quarter (mm) & l & / & l \\
\hline
\end{tabular}



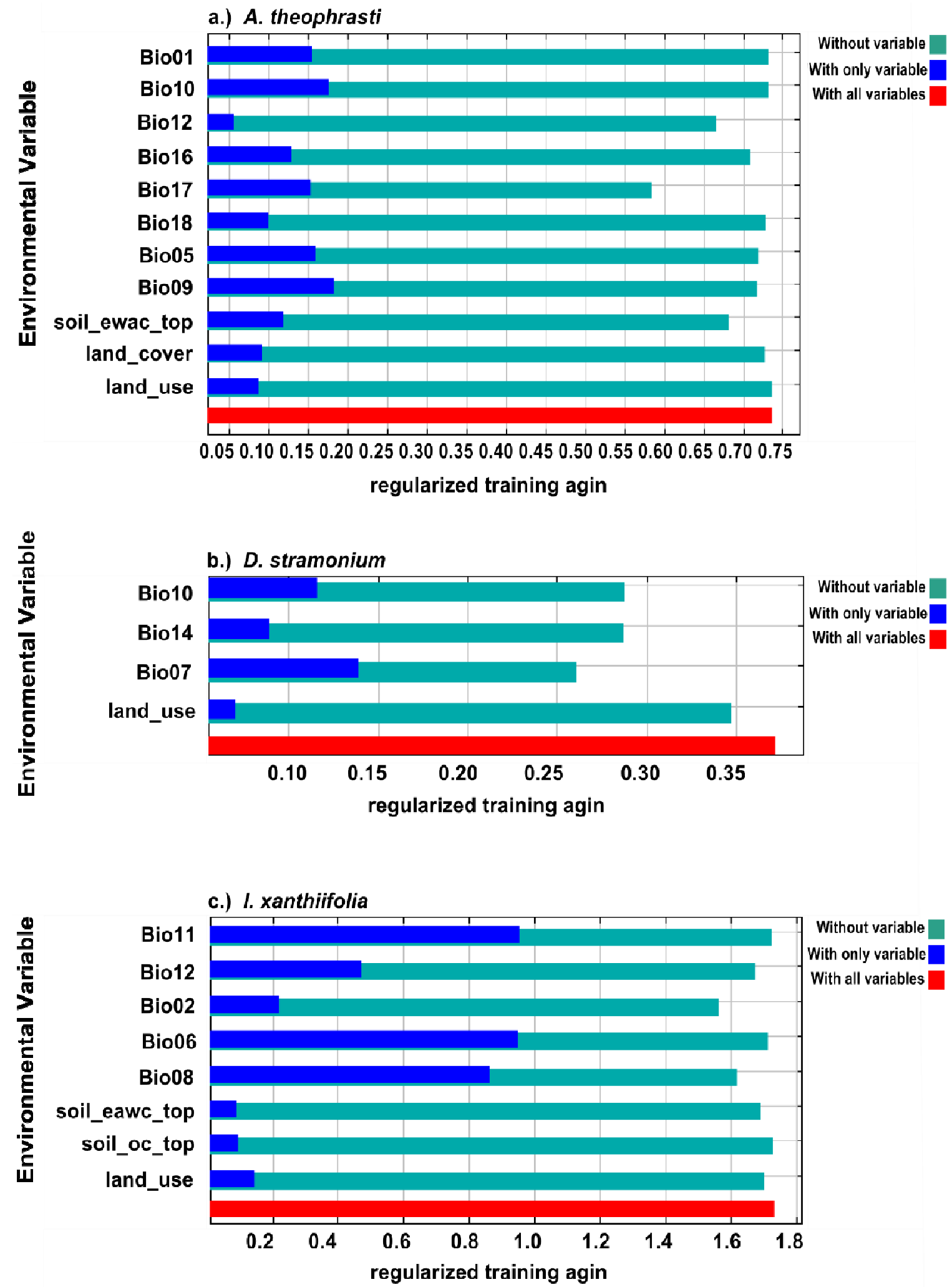

Fig. 4.6 Relative predictive power of different environmental variables based on the jackknife regularized training gain in MaxEnt models for A. theophrasti (a), $D$. stramonium (b) and I. xanthiifolia (c). Values are shown averaged over 10 replicate runs. 
Predictions for Lower Saxony showed a decrease of the area of potential distribution for the period from 2070 to 2100 compared to the reference period. The most pronounced decline of habitat suitability was indicated for some areas in central Lower Saxony (146 \&147 SCA) and particularly for the south-west tip of the federal state (134 SCA). The coastal area (152 SCA) may become more suitable for a potential distribution of $A$. theophrasti (Fig.4.5d).

The relative habitat suitability increased with an increase of the precipitation of the driest quarter (Bio17; bioclimatic profile (bp) based on the occurrence data ranging from 5 to 428 $\mathrm{mm}$ ) and in croplands (land cover class 11) as well as more built-up areas (land use class 2).

Whereas a lower annual precipitation (Bio12; bp ranging from 286 to $2754 \mathrm{~mm}$ ) and an land use class "forest" decreased the habitat suitability of A. theophrasti (Fig. 4.7 a, b).

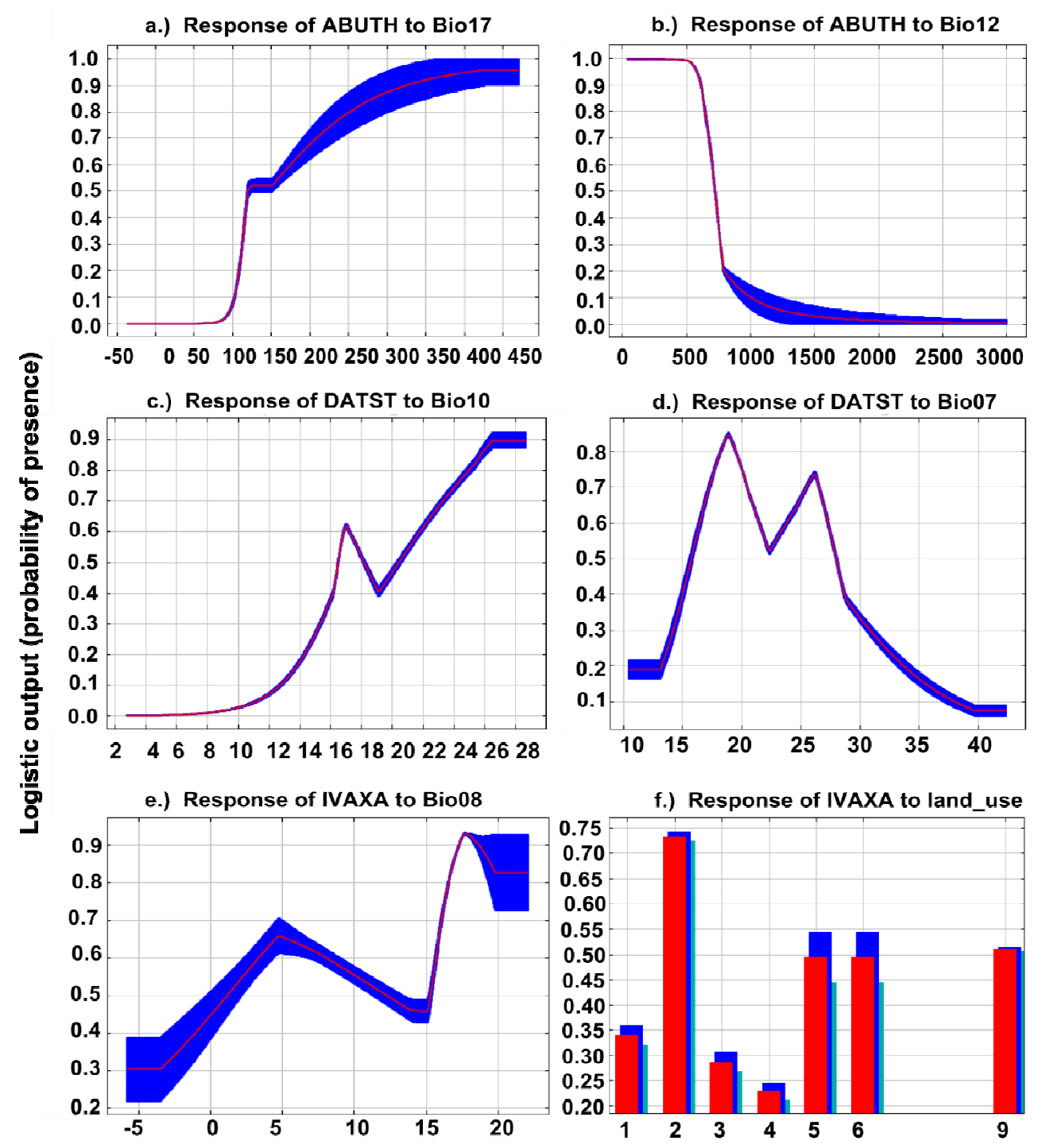

Fig. 4.7 Response curves showing the relationships between the probability of presence of a species and the top two environmental predictors of $A$. theophrasti (a, b), D. stramonium (c, d) and I. xanthiifolia (e, f). Values shown are averaged over 10 replicate runs, margins show \pm SD. 


\section{D. stramonium}

The MaxEnt model for D. stramonium had an AUC of $0.76( \pm 0.0116 \mathrm{SD})$.

The current predicted occurrence of $D$. stramonium in the south-eastern and eastern areas of Lower Saxony (parts of 146 \&147 SCA) with their continental climate influence, was quite realistically reproduced by the model again (Fig 4.8a), with the highest predicted habitat suitability in these areas. The current predicted suitability areas match quite precisely with the the observed occurrence locations in the Lower Saxony Vegetation Survey, except in west (148 SCA), where there is evidence of some under estimation of the modelled environmental habitat suitability (Fig. 4.3).

\section{Datura stramonium}

\section{Predicted current and future habitat suitability}

a.) Current (1950-2000)

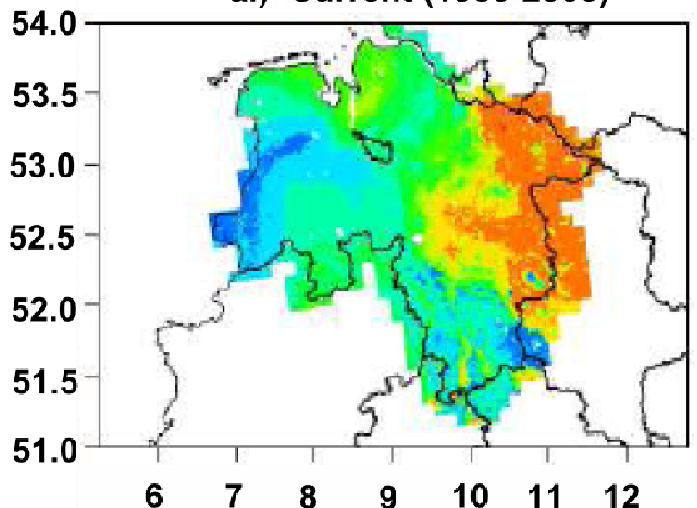

b.) Future (2070-2100)

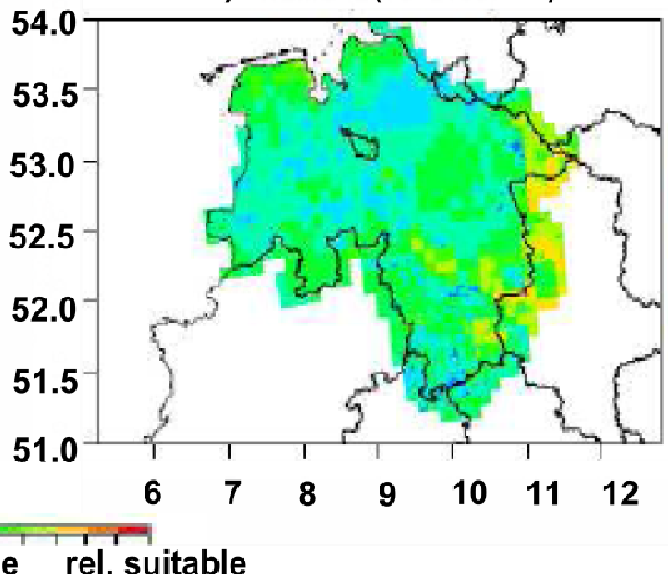

rel. unsuitable rel. suitable

Predicted current and future potential distribution

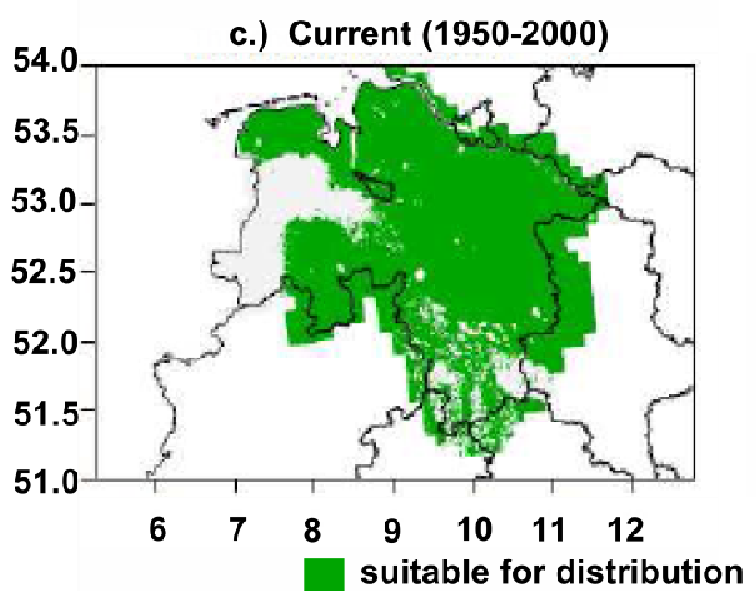

d.) Future (2070-2100)

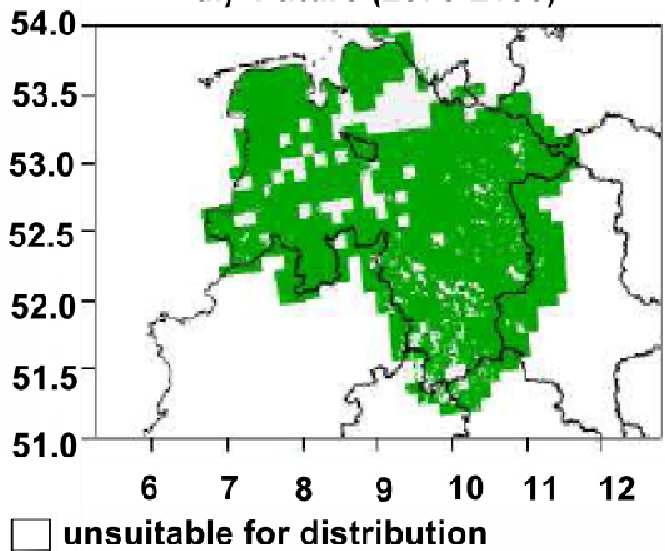

Fig. 4.8 Current $(\mathrm{a}, \mathrm{c})$ and future (b, d) modelled habitat suitability and potential distribution for D. stramonium in Lower Saxony (northwest Germany). 
The current potential distribution of $D$. stramonium was predicted in the majority of Lower Saxony`s areas, with the exception of the west (148 SCA), some patches in the southern parts (134 \& 145 SCA), and the Harz area of Lower Saxony (Fig. 4.8c). The model showed similar patterns of potential distribution in the south of Lower Saxony as obtained for $A$. theophrasti.

The range in annual temperature (Bio07) had higher effects on the habitat suitability of $D$. stramonium relative to other environmental variables. This was evident through a higher training gain for this variable (Fig. 4.6b). This variable also decreased the gain of importance the most, when omitted from the model.

The two top environmental variables for model contribution were land use with $49.6 \%$ and precipitation of the driest month (Bio14) with $18.6 \%$ (Table 4.1).

Predictions for 2100 showed an increase of the potential distribution, mainly in the western and north-western areas of Lower Saxony (147 \& 150 SCA) (Fig. 4.8d).

The relative habitat suitability for $D$. stramonium increased with higher precipitation of the driest month (Bio14; bp ranging from 0 to $125 \mathrm{~mm}$ ). Habitat suitability of $D$. stramonium was highest at a medium range of annual temperature (Bio07; bp ranging from 13.1 to $39.7^{\circ} \mathrm{C}$ ), forest area (land use class 4 ) decreased the habitat suitability for D. stramonium (Fig. 4.7 c,d).

\section{I. xanthiifolia}

The model performance for I. xanthiifolia was better than the random with an AUC of 0.89 $( \pm 0.0332 \mathrm{SD})$. Current highest habitat suitability for I. xanthiifolia was modelled in eastern and south-eastern areas of Lower Saxony (parts of 146 \&147 SCA) (Fig. 4.9 a). The current observed distribution of $I$. xanthiifolia is sparce in Lower Saxony, but the observations of the independent survey of Lower Saxony are also located in the area of highest suitability (Fig. 4.4). 
Iva xanthiifolia

Predicted current and future habitat suitability

a.) Current (1950-2000)

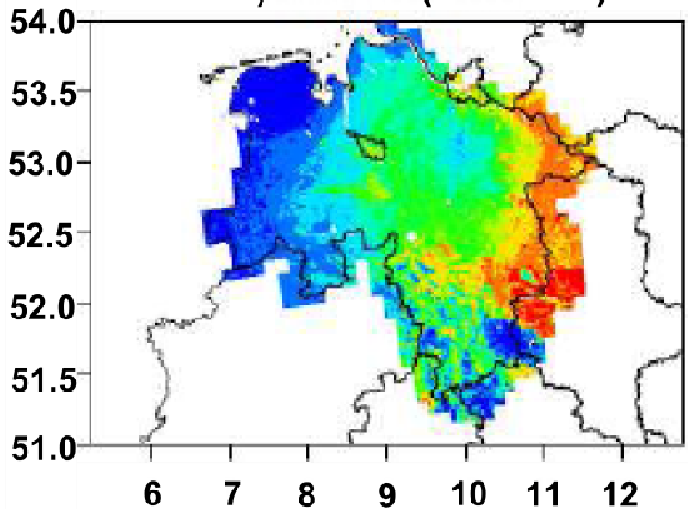

b.) Future (2070-2100)

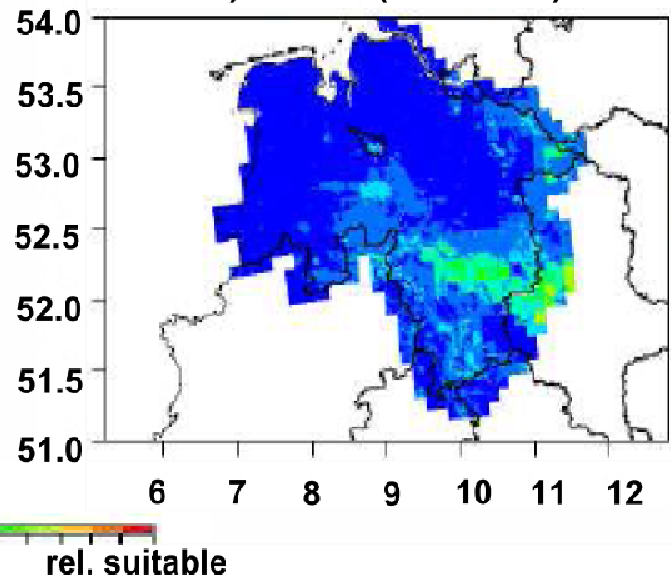

\section{Predicted current and future potential distribution}
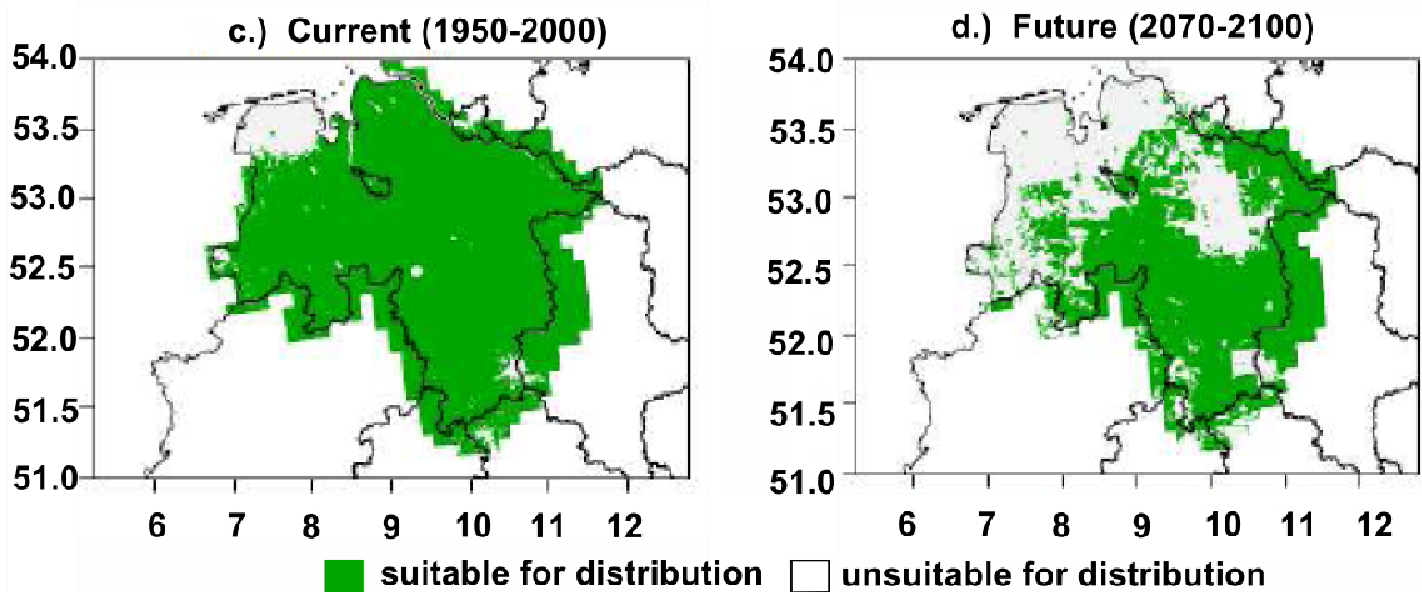

Fig. 4.9 Current $(\mathrm{a}, \mathrm{c})$ and future $(\mathrm{b}, \mathrm{d})$ modelled habitat suitability and potential distribution for I. xanthiifolia in Lower Saxony (northwest Germany).

The current potential distribution of I. xanthiifolia was predicted in the majority of Lower Saxony`s areas, with exception of the coast (parts of 152 SCA) (Fig. 4.9c).

The mean temperature of the coldest quarter (Bio11) and the minimum temperature of the coldest month (Bio06) had a higher training gain than other environmental variables for $I$. xanthiifolia (Fig. 4.6c). They have the most useful information by themselves to describe $I$. xanthiifolia habitat suitability. This was also evident through to the highest permutation importance with 32.7\% for Bio11 and 38.2\% for Bio06.

The environmental variables that decreased the gain of importance the most, when they were omitted from the model are mean diurnal temperature range (Bio02) and the mean temperature of the wettest quarter (Bio08). The two top environmental variables for model contribution were the mean temperature of wettest quarter (Bio08) with 33.2\%, followed by available soil water content with $17.8 \%$ contribution (Table 4.1 ). 
Future predictions for 2100 showed a distribution loss of $30 \%$, mainly in the north (152 SCA) and the west and northwest (148 \&150 SCA), as well as in central parts of Lower Saxony (146 SCA) and around the Harz area (Fig. 4.9d).

The habitat suitability for I. xanthiifolia increased with higher soil water availability, higher organic carbon content, higher mean temperature of the coldest month (Bio06; bp ranging from -21.8 to $8.3^{\circ} \mathrm{C}$ ) and higher mean temperature of the wettest quarter (Bio08; bp ranging from -3.5 to $19.8^{\circ} \mathrm{C}$ ). An increase in the mean temperature of the coldest quarter (Bio11; bp ranging from -15.5-12.4) and forest area (land use class 4) decreased the habitat suitability for I. xanthiifolia (Fig. 4.7 e, f).

\section{Discussion}

\section{The output}

The correlative approach allowed the complex interaction between climate, soil, land use and land cover to be quantified on a regional scale with good model fit (AUC between 0.76 and 0.89 ). Such correlative models based on occurrence data have repeatedly been shown to be a good predictor of occurrence under current, past and future climatic conditions (Elith et al., 2006; Hijmans and Graham, 2006).

The models of habitat suitability for A. theophrasti, D. stramonium and I. xanthiifolia which we trained on a European scale did indeed describe well the current suitable habitats in Lower Saxony, as observed in a plant vegetation survey. This demonstrates the potential of our correlative approach to predict effects of a changing environment on the habitat suitability for these weeds in Lower Saxony.

\section{Suitability change of the species}

In sum, changes in the habitat suitability and potential distribution of the target weed species were spatially heterogeneous and the environmental influences (predictor variables) differed with regard to their relevance for the three tested species.

The environmental habitat suitability of $A$. theophrasti was chiefly, but not exclusively influenced by water availability and precipitation, particularly by the precipitation situation during the summer months. Its potential distribution was predicted to decline in response to lower summer precipitation. In accordance, a minor importance of $A$. theophrasti due to changing climatic condition was estimated by McDonald et al. (2008) for the U.S. Corn Belt too. A. theophrasti was predicted to decrease in areas with sandy and light loamy soils. Coarse soils are physically characterized by a low water holding capacity and hence in general drain easily (Hillel, 1998). The impact of reduced precipitation may be of different extent on a local scale due to variations in soil type and water holding capacity (Stratonovitch et al., 2012). Therefore, the importance of soil features for plant growth may become more pronounced under future environmental constraints (Rosenzweig and Hillel, 2000). 
The increase in future potential distribution of $D$. stramonium was chiefly driven by a positive reaction to the forecasted temperature rise. Future areas of risk may mainly be in parts of west and northwest of Lower Saxony (148 \& 150 SCA). Water supply in general seemed to be less important for the estimated outcome. Areas of habitat gain of D.stramonium are similar to the areas of decrease for A. theophrasti. In lighter soils, owing to more frequent drought stress events, the competitive plant balance may be shifted in favour of deeper rooted plants (Stratonovitch et al., 2012). In a process-based manipulative drought stress and temperature change experiment, an elongation in root length was observed under severe drought and temperature change conditions in sandy soil for $D$. stramonium, but not for A. theophrasti and I. xanthiifolia (see thesis Chapter 3).

The habitat suitability for I. xanthiifolia was chiefly influenced by the temperature regime during winter months. Areas of suitable habitat conditions are predicted to decline strongly, especially in similar parts of Lower Saxony as for A. theophrasti (west, northwest and central parts: 146,148 \&150 SAC). Very low temperatures during the winter season seem to be preferential und could explain the forecasted habitat decline despite of an increase in mean temperature.

For I. xanthiiolia analogue results were obtained in a process-based manipulative drought stress and temperature change experiment in comparison to the modelling approach. In the way, that for I. xanthiifolia a positive plant performance in growth and emergence characteristics was related to cooler temperatures and good water supply. D. stramonium and $A$. theophrasti reacted in the experimental observation with higher plasticity to the environmental stress elicitors (see thesis Chapter 2 and 3). In the experimental approach the influence of seasonality amongst other influencing factors could not be considered. This may explain the difference between the experimental and the model outcomes, with a habitat gain for D. stramonium and a loss for A. theophrasti under future conditions.

\section{Influence of land use and agricultural practices}

However, for all three weed species the models were strongly influenced by land use (which was classified into fairly rough classes like forest, arable land etc.). Follack et al. (2013) analysed the invasion history, spread dynamics and habitat affiliation of $I$. xanthiifolia in Central and Eastern Europe. They found, that land use had a high influence on the current distributional patterns for I. xanthiifolia too. A number of authors have noted that including factors like land use, particularly the cropping structure of arable land, and soil information is very important to improve the accuracy for species distribution models progressively (Pearson and Dawson, 2003; Pompe et al., 2008; Hyvönen et al., 2012).

A change in the cropping structure (e.g., changes of common crops, herbicide usage, earlier drilling or crop rotations), will have an severe effect on the weed population dynamics and the composition assemblages on a field (Weber and Schrader, 2006; Glemnitz et al., 2010; Thomas, 2010; Gevers et al., 2011; Stratonivitch et al., 2013). For Lower Saxony, which has 1.8 million hectares of arable area, a rapid increase of maize area $(46.9 \%)$ has already been observed for a six-year period from 2005 - 2010 (Steinmann and Dobers, 2013). A forecasted arable land use change (e.g., increase in 
proportion of spring crops), will affect the crop- weed interaction, and may lead to amplified opportunities for spring crop weeds, in a similar or larger degree than changes in climate may do (Glemnitz et al., 2010; Gevers et al., 2011; Hyvönen et al., 2011; Stratonovitch et al., 2012).

\section{Uncertainties in modelling}

Despite the recent popularity of ENMs to indicate relative habitat suitability for potential distribution, there is also some restrain to their usage (Wiens et al., 2009). Like all models, ENMs rely on the underlying assumptions and uncertainties, which may make it difficult to interpret the output and to use it for management advice (Peterson et al., 2011; Bradley, 2013). It is impossible to measure all environmental factors that determine a species niche, therefore a careful selection is important. The possibility that unmeasured niche dimensions may account for the observed distribution persists (Pearson et al., 2006; Wiens et al., 2009; Sheppard, 2013).

Making predictions with ecological niche models from occurrence data only is also a poor proxy for species abundance (Bradley, 2013). To describe the realized niche or damaging niche of a species fully, factors need to be taken into account that cause nonequilibrium distributions (McDonald et al., 2009; Stratonovitch et al., 2012). Soberón and Nakamura (2007) describe two major classes of factors that can cause species to inhabit less than their fully suitable distributional areas: dispersal limitations (macrogeographic features like major mountain ranges, or rivers) and biotic interactions (e.g. crop-weed and weed-weed competition, predation, and disturbance through human modification of the environment).

A major challenge to any modelling attempt of future potential or realised distribution is the capacity of weeds to adapt to new conditions, both through phenotypic plasticity and genotypic adaptation (Clementes and DiTommaso, 2011; Stratonovitch et al., 2012). This may lead to an under- estimation of possible shifts in distribution and impact. A possible solution may be to combine correlative and mechanistic modelling approaches (Stratonovitch et al., 2012).

\section{Appropriate management strategies of spreading weeds}

The most cost-effective control method for managing spreading plant and weed species, especially if they become invasive, is early detection, control and eradication before the species attains a large geographic and ecological distribution (Weber and Schrader, 2006; Sheppard, 2013). Therefore, modelling whether a range-expanding plant could find a suitable habitat, or even alter their occurrence ranges in a given area may be useful additional information besides monitoring, for a successful risk assessment (McDonald et al., 2009; Bradley, 2013).

\section{Summary und future tasks}

Our study demonstrates that in specific questions about species' reactions to a changing climate, it is hardly impossible to draw generalised conclusion. Although three quite similar weed species were selected from a guild of range-expanding, thermophile, 
competitive, ruderal, stresstolerant and annual C3 species, our modelling forecasted idiosyncratic distributional responses to changing environmental conditions. Critical ecological niche modelling studies and empirical analysis both indicate that species will often show idiosyncratic responses to changing environmental conditions, so generalities will hold on averages, and not in particular cases (Peterson et al., 2011). This was also accredited by Hyvönen et al. (2012) for 25 arable weed species in a changing European climate.

The results of our ecological niche model study predicted, that there will be moderate to high impacts under future climate scenarios on the distribution of three target weed species in Lower Saxony. I. xanthiifolia will suffer more severe loss of suitable habitat compared to $A$. theophrasti, whereas $D$. stramonium may benefit from climate change.

Here we emphasize, that despite the uncertainties, our niche modelling approach offers a capable tool for estimating suitable habitats and forecasting potential distribution for weed species under explicit fine-scaled climate change scenario as a valuable, educated guess about probable futures (Hijmans and Graham, 2006; Wiens et al., 2009). By knowing the underlying assumptions and uncertainties the output has to be interpreted critically, and may be used with caution to assist in appropriate weed management programmes and adaptation strategies (Pompe et al., 2008; Bradley, 2013). Further research for highaccuracy predictions is absolutely essential.

It will be most promising to move forward joining correlative with mechanistic modelling approaches. To receive more significant results, future modelling could integrate environmental variables that limit abundance (like dispersal factors, disturbance factors, competition factors), estimations or scenarios of future land use change (and land cover change), as well as information on plant adaption and plasticity, especially under future environmental constrains (Hijmans and Graham, 2006; Bradley et al., 2009; Wiens et al., 2009; Stratonovitch et al., 2012).

\section{Acknowledgements}

This study was funded by the Ministry for Science and Culture of Lower Saxony and is a part of Lower Saxony's Climate Impact research Program (KLIFF). The help of Susanne Stein for preparing the arable maps of Lower Saxony is gratefully acknowledged. The Landesbetrieb für Statistik und Kommunikationstechnologie Niedersachsen kindly provided data from the agrar structure survey 2010 as well as the Niedersächsisches Pflanzenarten-Erfassungsprogramm data from the plant survey of Lower Saxony, which are used in this study. 


\section{References}

BIOLFLOR 2013. - Search and information system on vascular plants in Germany. URL: http://www2.ufz.de/biolflor/index.jsp; last access date 10.09.2013.

BRADLEY, B.A. 2009. Regional analysis of the impacts of climate change on cheatgrass invasion shows potential risk and opportunity. Global Change Biology 15 (1).

BRADLEY, B. 2013. Distribution models of invasive plants over-estimate potential impact. Biological Invasions 15 (7): 1417-1429.

Bradley, B.A., Estes, L.D., Hole, D.G., Holness, S., OpPenheimer, M., Turner, W.R., Beukes, H., Schulze, R.E., Tadross, M.A. \& Wilcove, D.S. 2012. Predicting how adaptation to climate change could affect ecological conservation: secondary impacts of shifting agricultural suitability. Diversity and Distributions 18 (5): 425-437.

Broennimann, O., Treier, U.A., Müller-Schärer, H., Thuiller, W., Peterson, A.T. \& GUISAN, A. 2007. Evidence of climatic niche shift during biological invasion. Ecology Letters 10 (8): 701-709.

BÜrger, J., Edler, B., Gerowitt, B. \& Steinmann, H.-H. 2013. Uncertainty in modelling distribution of arable weeds under climate change conditions. European Commission/ BMBF: ECCA European Climate Change Adaptation Conference 2013, 170-171.

BÜRGER, J., EDLER, B., GEROWITT, B. \& STEINMANN, H.-H. 2014. Predicting weed problems in maize cropping by species distribution modelling. 26th German Conference on Weed Biology and Weed Control, Julius-Kühn Archiv 443: 379-386

Clements, D.R. \& DiTommaso, A. 2011. Climate change and weed adaptation: can evolution of invasive plants lead to greater range expansion than forecasted? Weed Research 51 (3): 227-240.

Efthimiadou, A.P., Karkanis, A.C., Bilalis, D.J. \& Efthimiadis, P. 2009. Review: The phenomenon of crop-weed competition; a problem or a key for sustainable weed management? Food, Agriculture \& Environment (JFAE) 7 (2): 861-868.

Elith, J., Graham, C.H., Anderson, R.P., Dudík, M., Ferrier, S., Guisan, A., Hijmans, R.J., Huettmann, F., Leathwick, J.R., Lehmann, A., Li, J., Lohmann, L.G., Loiselle, B.A., Manion, G., Moritz, C., Nakamura, M., NaKazawa, Y., Overton, J.M.M., Peterson, T.A., Phillips, S.J., Richardson, K., Scachetti-Pereira, R., Schapire, R.E., Soberón, J., Williams, S., WisZ, M.S. \& ZimmermanN, N.E. 2006. Novel methods improve prediction of species' distributions from occurrence data. Ecography 29 (2): 129-151.

Elith, J., KeARney, M. \& PhilliPS, S. 2010. The art of modelling range-shifting species. Methods in Ecology and Evolution 1 (4): 330-342. 
ESRI INC. 1996-2006. ArcGis-ArcInfo 9.3.

Estes, L.D., Bradley, B.A., Beukes, H., Hole, D.G., Lau, M., Oppenheimer, M.G., Schulze, R., TAdross, M.A. \& Turner, W.R. 2013. Comparing mechanistic and empirical model projections of crop suitability and productivity: implications for ecological forecasting. Global Ecology and Biogeography 22( 8): 1007-1018.

Follak, S., Dullinger, S., Kleinbauer, I., Moser, D. \& Essl, F. 2013. Invasion dynamics of three allergenic invasive Asteraceae (Ambrosia trifida, Artemisia annua, Iva xanthiifolia) in central and eastern Europe. Preslia 85 (1): 41-61.

FOLLAK, S. 2009. Vorkommen und potenzielle Verbreitung des Rispenkrauts (Iva xanthiifolia) in Österreich. Botanica Helvetica 119: 7-12.

Franklin, J., Davis, F.W., Ikegami, M., Syphard, A.D., Flint, L.E., Flint, A.L. \& HANNAH, L. 2013. Modeling plant species distributions under future climates: how fine scale do climate projections need to be? Global Change Biology 19 (2): 473-483.

GARVE, E. 2007. Verbreitungsatlas der Farn- und Blütenpflanzen in Niedersachsen und Bremen. Naturschutz und Landschaftspflege in Niedersachsen. Niedersächsisches Landesamt für Ökologie, Hannover.

Gassó, N., Basnou, C. \& VilÀ, M. 2010. Predicting plant invaders in the Mediterranean through a weed risk assessment system. Biological Invasions 12 (3): 463-476.

Gevers, J., Høye, T.T., Topping, C.J., Glemnitz, M. \& SchröDer, B. 2011. Biodiversity and the mitigation of climate change through bioenergy: impacts of increased maize cultivation on farmland wildlife. GCB Bioenergy 3 (6): 472-482.

Dengler, J., Jansen, F., Glöckler, F., Peet, R.K., Cáceres, M. de, Chytrý, M., Ewald, J., Oldeland, J., Lopez-Gonzalez, G., FincKh, M., Mucina, L., Rodwell, J.S., Schaminée, J.H.J. \& SPENCER, N. 2011. The Global Index of Vegetation-Plot Databases (GIVD): a new resource for vegetation science. Journal of Vegetation Science 22 (4): 582-597.

GIVD. 2013. Global Index of Vegetation-Plot Databases. URL:http://www.givd.info/559.html; last access date 10.09.2013.

Glemnitz, M., Hyvönen, T., Radics, L., Hoffmann, J. \& Czimber, G. 2010. Weeds in changing climate - a north European perspective. NJF Report 6 (1): 55-57.

Glemnitz, M., Radics, L., Hoffmann, J. \& CzImber, G. 2006. Weed species richness and species composition of different arable field types: a comparative analysis along a climate gradient from south to north Europe. Journal of Plant Diseases and Protection: Special Issue 20: 577-586.

GRIME, J.P. 1977. Evidence for existence of 3 primary strategies in plants and its relevance to ecological and evolutionary theory. American Naturalist 111 (982): 1169-1194. 
HiJMAnS, R.J. \& VAN ETTEN, J. 2012. Raster: Geographic data analysis and modeling. R package version 2.0-41. URL: http://CRAN.R-project.org/package=raster

HiJmans, R.J. \& Elith, J. 2013. Species distribution modeling with R. URL: cran.rproject.org/web/packages/dismo/.../sdm.pdf; last access date 10.09.2013.

Hijmans, R.J., Cameron, S.E., Parra, J.L., Jones, P.G. \& Jarvis, A. 2005. Very high resolution interpolated climate surfaces for global land areas. International Journal of Climatology 25 (15): 1965-1978.

HiJmans, R.J. \& GRAHAM, C.H. 2006. The ability of climate envelope models to predict the effect of climate change on species distributions. Global Change Biology 12 (12): 2272-2281.

HILlEL, D. 1998. Environmental soil physics. Academic Press, San Diego, CA.

Hód, L. \& TORMA, M. 2000. Efficacy of some herbicide active ingredients on Iva xanthiifolia Nutt. in laboratory trials. Journal of Plant Diseases and Protection(Sonderh. 17): 603-605.

Hulme, P.E. 2009. Relative roles of life-form, land use and climate in recent dynamics of alien plant distributions in the British Isles. Weed Research 49 (1): 19-28.

Hyvönen, T., Glemnitz, M., Radics, L. \& HoffmanN, J. 2011. Impact of climate and land use type on the distribution of Finnish casual arable weeds in Europe. Weed Research 51 (2): 201-208.

Hyvönen, T., Luoto, M. \& Uotila, P. 2012. Assesment of weed establishment risk in a chnaging European climate. Agricultural and Food Science (21): 348-360.

IPPC 2007. Climatic Change 2007:. The Physical Science Basis. Contribution of Working Group I to Fourth Assessment Report of The Intergovernmental Panel on Climate Change (IPCC), Cambridge, United Kingdom and New York, NY, USA.

KÜHN, I., DURKA, W., \& KLOTZ, S. 2004. BiolFlor - a new plant-trait database as a tool for plant invasion ecology. Diversity and Distributions 10 (5-6): 363-365.

Liedekerke, M. VAn, Jones, A. \& PAnagos, A. 2006. ESDBv2 Raster Library-a set of rasters derived from the European Soil Database distribution v2. O. CDROM, EUR. European Commission and the European Soil Bureau Network.

McDonald, A., Riha, S., DiTommaso, A. \& DeGaetano, A. 2009. Climate change and the geography of weed damage: Analysis of U.S. maize systems suggests the potential for significant range transformations. Agriculture, Ecosystems \& Environment 130 (34): 131-140.

Moseley, C., Panferov, O., Döring, C., Dietrich, J., Haberlandt, U., Ebermann, V., RECHID, D., BEESE, F. \& JACOB, D. 2012. Klimaentwicklung und Klimaszenarien. In: Niedersächsisches Ministerium für Umwelt, Energie und Klimaschutz (ed.) Empfehlung 
für eine niedersächsische Strategie zur Anpassung an die Folgen des Klimawandels. Regierungskommision Klimaschutz, pp. 18-41.

NIEDERSACHSEN 2008. Zahlen und Fakten. Niedersachsen in Vergleich. Ländervergleich Fläche. Zahlen und Fakten. Niedersachsen in Vergleich. Ländervergleich Fläche. URL: www.niedersachsen.de; last access date 10.09.2013.

NiEDERSÄCHSISCHES MinisteriUM FÜR UMwElT, ENERGIE UND KLIMASCHUTZ (ed.) 2012. Empfehlung für eine niedersächsische Strategie zur Anpassung an die Folgen des Klimawandels. Regierungskommision Klimaschutz.

Panagos, P. 2006. The European soil database. Pan-European in scope, this database provides a consistent view and understanding of the soil we depend upon for living. Geo: International 5 (7): 32-33.

Pearson, R.G. \& Dawson, T.P. 2003. Predicting the impacts of climate change on the distribution of species: are bioclimate envelope models useful? Global Ecology and Biogeography 201312 (5): 361-371.

Pearson, R.G., DAwson, T.P. \& LiU, C. 2004. Modelling species distributions in Britain: a hierarchical integration of climate and land-cover data. Ecography 27 (3): 285-298.

Pearson, R.G., Thuiller, W., Araújo, M.B., Martinez-Meyer, E., Brotons, L., McClean, C., Miles, L., Segurado, P., Dawson, T.P. \& Lees, D.C. 2006. Modelbased uncertainty in species range prediction. Journal of Biogeography 33 (10): 1704-1711.

Peterson, A.T., Soberón, J., Pearson, R.G., Anderson, r.P., Martínez-Meyer, E., NAKAMURA, M. \& ARAÚJO, M.B. 2011. Ecological niches and geographic distributions. Princeton University Press, Princeton, NJ.

Phillips, S.J., Anderson, R.P. \& SchaPIRE, R.E. 2006. Maximum entropy modelling of species geographic distributions. Ecological Modelling (190): 231-259.

Pompe, S., Hanspach, J., Badeck, F., Klotz, S., Thuiller, W. \& Kühn, I. 2008. Climate and land use change impacts on plant distributions in Germany. Climate and land use change impacts on plant distributions in Germany. Biology Letters 4 (5): 564-567.

R Development Core TeAm 2012. R: A Language and Environment for Statistical Computing. URL: http://www.R-project.org.

Rosenzweig, C. \& Hille, D. 2000. Soils and global climate change: Challenges and opportunities. Soil Science 165: 47-56.

Roßberg, D., Michel, V., Graf, R. \& Neukauf, R. 2007. Definition von Boden-KlimaRäumen für die Bundesrepublik Deutschland. Nachrichtenblatt des Deutschen Pflanzenschutzdienstes 59 (7): 151-161. 
SAtTin, M., Zanin, G. \& BerTi, A. 1992. Case history for weed competition/population ecology: velvetleaf (Abutilon theophrasti) in corn (Zea mays). Weed technology : a journal of the Weed Science Society of America 6 (1): 213-219.

Schmiedel, I., Schacherer, A., Hauck, M., Schmidt, M. \& Culmsee, H. 20011. Verbreitungsmuster der Farn- und Blütenpfanzen in Niedersachsen und Bremen unter Berücksichtigung ihres Einbürgerungsstatus und ihrer Gefährdungssituation. Tuexenia 31: 211-226.

SHEPPARD, C.S. 2013. How does selection of climate variables affect predictions of species distributions? A case study of three new weeds in New Zealand. Weed Research 53 (4): 259-268.

Soberón, J. \& NAKAmura, M. 2009. Niches and distributional areas: Concepts, methods, and assumptions. Proceedings of the National Academy of Sciences 106 (Supplement 2): 19644-19650.

Sommer, J.H., Kreft, H., Kier, G., Jetz, W., Mutke, J. \& Barthlott, W. 2010. Projected impacts of climate change on regional capacities for global plant species richness. Proceedings of the Royal Society B: Biological Sciences.

Steinmann, H.-H. \& Dobers, E.S. 2013. Spatio-temporal analysis of crop rotations and crop sequence patterns in Northern Germany: potential implications for plant health and crop protection. Journal of Plant Diseases and Protection 120: 85-94.

Stratonovitch, P., Storkey, J. \& Semenov, M.A. 2012. A process-based approach to modelling impacts of climate change on the damage niche of an agricultural weed. Global Change Biology 18 (6): 2071-2080.

SwETS, J.A. 1988. Measuring the accuracy of diagnostic systems. Science 240 (4857): 1285-1293.

THUILLER, W. 2003. BIOMOD - optimizing predictions of species distributions and projecting potential future shifts under global change. Global Change Biology 9 (10): 1353-1362.

Thuiller, W., Lafourcade, B., Engler, R. \& Araújo, M.B. 2009. BIOMOD - a platform for ensemble forecasting of species distributions. Ecography 32(3): 369-373. URL:

Walther, G.-R., Post, E., Convey, P., Menzel, A., Parmesan, C., Beebee, T.J.C., Fromentin, J.-M., Hoegh-GuldBerg, O. \& BAirlein, F. 2002. Ecological responses to recent climate change. Nature 416 (6879): 389-395.

WEBER, E. \& GUT, D. 2005. A survey of weeds that are increasingly spreading in Europe. Agronomy for Sustainable Development 25: 109-121.

Weber, E. \& Schrader, G. 2006. New weed threats; extent, origins and proper management. Perspectives in Agriculture, Veterinary Science, Nutrition and Natural Resources 47 (1). 
Wiens, J.A., Stralberg, D., Jongsomit, D., Howell, C.A. \& Snyder, M.A. 2009. Niches, models, and climate change: Assessing the assumptions and uncertainties. Proceedings of the National Academy of Sciences.

Woodward, F.I. \& WiLLiams, B.G. 1987. Climate and plant distribution at global and local scales. Plant Ecology 69 (1-3): 189-197. 
Supplementary information (SI)

Appendix A Databases used for species occurrence data on an European extent

\begin{tabular}{|c|c|c|c|}
\hline Data base & Scope & Storage format & Institution and web address \\
\hline $\begin{array}{l}\text { SIVIM } \\
\text { Iberian } \\
\text { Macaronesian } \\
\text { Vegetation } \\
\text { Information } \\
\text { System* }\end{array}$ & $\begin{array}{l}\text { SIVIM is an Iberian and } \\
\text { Macaronesian Vegetation } \\
\text { Information System that aims } \\
\text { to host about } 125.000 \text { relevés } \\
\text { mainly from the Iberian } \\
\text { Peninsula and the Balearic } \\
\text { and Canary Islands. }\end{array}$ & $\begin{array}{l}\text { DB2 } \\
\text { (Express) }\end{array}$ & $\begin{array}{l}\text { Institution: University } \\
\text { Barcelona } \\
\text { URL: http://www.sivim.info }\end{array}$ \\
\hline $\begin{array}{l}\text { Slovak Vegetation } \\
\text { Database* }\end{array}$ & $\begin{array}{l}\text { Almost all phytosociological } \\
\text { relevés from the Slovak } \\
\text { Republic and adjacent areas. } \\
\text { The phytosociological relevés } \\
\text { from the Carpathian region } \\
\text { are also included. }\end{array}$ & TURBOVEG & $\begin{array}{l}\text { Institution: Institute of Botany, } \\
\text { Slovak Academy of Sciences } \\
\text { URL: } \\
\text { http://ibot.sav.sk/cdf/index.html }\end{array}$ \\
\hline $\begin{array}{l}\text { VegItaly } \\
\text { toward an Italian } \\
\text { national vegetation } \\
\text { database* }\end{array}$ & $\begin{array}{l}\text { VegItaly, coordinated by the } \\
\text { SISV, gets together the data } \\
\text { collected by researchers in } \\
\text { Italy resulting from the } \\
\text { different approaches used in } \\
\text { Vegetation Science. }\end{array}$ & PostgreSQL & $\begin{array}{l}\text { Institution: University of Perugia } \\
\text { URL: http://www.vegitaly.it }\end{array}$ \\
\hline $\begin{array}{l}\text { Private database } \\
\text { from Crete (Greece) }\end{array}$ & $\begin{array}{l}\text { Georeferenced plant } \\
\text { occurrence data from Crete. }\end{array}$ & & $\begin{array}{l}\text { Collector: Erwin Bergmeier } \\
\text { Private collection /data upon } \\
\text { request }\end{array}$ \\
\hline $\begin{array}{l}\text { Czech National } \\
\text { Phytosociological } \\
\text { Database* }\end{array}$ & $\begin{array}{l}\text { All phytosociological relevés } \\
\text { and related vegetation plot } \\
\text { records from the Czech } \\
\text { Republic. }\end{array}$ & TURBOVEG & $\begin{array}{l}\text { Institution Masaryk University } \\
\text { URL: } \\
\text { http://www.sci.muni.cz/botany/ve } \\
\text { gsci/dbase.php?lang=cz }\end{array}$ \\
\hline $\begin{array}{l}\text { flora-mv } \\
\text { Floristische } \\
\text { Datenbank und } \\
\text { Herbarien in } \\
\text { Mecklenburg- } \\
\text { Vorpommern* }\end{array}$ & $\begin{array}{l}\text { All phytosociological relevés } \\
\text { and related vegetation plot } \\
\text { records (more than 52.000) } \\
\text { from Mecklenburg- } \\
\text { Vorpommern. }\end{array}$ & TURBOVEG & $\begin{array}{l}\text { Institution: Institut für Botanik } \\
\text { und Landschaftsökologie der } \\
\text { Ernst-Moritz-Arndt-Universität } \\
\text { Greifswald } \\
\text { URL: http://www.flora-mv.de/ }\end{array}$ \\
\hline
\end{tabular}




\begin{tabular}{|c|c|c|c|}
\hline $\begin{array}{l}\text { Vigie-flore } \\
\text { nationwide } \\
\text { monitoring } \\
\text { programme for } \\
\text { common plant } \\
\text { species and plant } \\
\text { communities } \\
\text { France* }\end{array}$ & $\begin{array}{l}\text { Vigie-flore is a French plant } \\
\text { monitoring program to detect } \\
\text { spatial and temporal trends in } \\
\text { the abundance of common } \\
\text { plant species, as well as } \\
\text { change in plant community } \\
\text { composition, with the aim to } \\
\text { identify the drivers. }\end{array}$ & MySQL & $\begin{array}{l}\text { Institution: Tela botanica } \\
\text { URL: http://www.vigie-flore.fr }\end{array}$ \\
\hline $\begin{array}{l}\text { Dutch National } \\
\text { Vegetation } \\
\text { Database* }\end{array}$ & $\begin{array}{l}\text { The database covers all } \\
\text { existing plant communities in } \\
\text { the Netherlands from } 1868(!) \\
\text { up to now. }\end{array}$ & $\begin{array}{l}\text { TURBOVEG } \\
\text { PostgreSQL }\end{array}$ & $\begin{array}{l}\text { Institution: Alterra } \\
\text { URL: } \\
\text { http://www.synbiosys.alterra.nl/lv } \\
\text { d }\end{array}$ \\
\hline $\begin{array}{l}\text { HelNatVeg } \\
\text { Hellenic Natura } \\
2000 \quad \text { Vegetation } \\
\text { Database* }\end{array}$ & $\begin{array}{l}\text { Identification, description and } \\
\text { mapping of habitat types in } \\
\text { Sites of Community } \\
\text { Importance for Nature } \\
\text { Conservation of Greece, } \\
\text { almost } 14000 \text { vegetation } \\
\text { relevés had been carried out } \\
\text { in 1999-2001. }\end{array}$ & TURBOVEG & $\begin{array}{l}\text { Institution: Environmental and } \\
\text { Natural Resources Management, } \\
\text { University of Western Greece } \\
\text { Web address: no details }\end{array}$ \\
\hline $\begin{array}{l}\text { SOPHY } \\
\text { basis of plant socio- } \\
\text { ecology and } \\
\text { phytoclimatology in } \\
\text { France* }\end{array}$ & $\begin{array}{l}\text { Analysis of the environmental } \\
\text { characteristics of flora and } \\
\text { vegetation in France and } \\
\text { characterization of bio- } \\
\text { indicators. }\end{array}$ & $\begin{array}{l}\text { MySQL } \\
\text { Other format text } \\
\text { (MS-DOS) }\end{array}$ & $\begin{array}{l}\text { Institution: Université Louis } \\
\text { Pasteur (ULP) } \\
\text { URL: http://sophy.univ- } \\
\text { cezanne.fr/sophy.htm }\end{array}$ \\
\hline $\begin{array}{l}\text { Global Biodiversity } \\
\text { Information } \\
\text { Facilitiy } \\
\text { (GBIF) } \\
\text { Portal: BioCASE }\end{array}$ & $\begin{array}{l}\text { The database consists of more } \\
\text { than } 4.2 \text { million vegetation } \\
\text { relevés from Germany. }\end{array}$ & / & $\begin{array}{l}\text { Institution: Bundesministerium für } \\
\text { Forschung und Bildung (BfN) } \\
\text { URL: http://search.biocase.de/ }\end{array}$ \\
\hline
\end{tabular}

*GIVD (2013), URL: http://www.givd.info/559.html, accesed on 05.04.2013 based on Dengler et al. (2011) (/no information available) 
Appendix B The current bioclimatic profile of Lower Saxony, includes the environmental variables (land use, land cover, available soil water content, soil organic CO2 content, soil texture and the BIOCLIM set), their disposed classes, their determined frequency of occurrence and units of measurement.

\begin{tabular}{|c|c|c|c|c|c|}
\hline \multicolumn{6}{|l|}{ Land use } \\
\hline class & $\begin{array}{l}1 \\
\text { Mixture }\end{array}$ & $\begin{array}{l}2 \\
\text { Built-up area }\end{array}$ & $\begin{array}{l}3 \\
\text { Grassland/shrub }\end{array}$ & $\begin{array}{l}4 \\
\text { Forest }\end{array}$ & $\begin{array}{l}9 \\
\text { Agricultural area }\end{array}$ \\
\hline frequency & 2486 & 142 & 1 & 135 & 13691 \\
\hline proportion & 0.13 & 0.01 & 0.00 & 0.01 & 0.72 \\
\hline
\end{tabular}

\begin{tabular}{|c|c|c|c|c|c|c|c|}
\hline \multicolumn{8}{|c|}{ Land cover } \\
\hline class & $\begin{array}{l}2 \\
\text { Deciduous } \\
\text { Needleleaf } \\
\text { Forest } \\
\end{array}$ & $\begin{array}{l}3 \\
\text { Deciduous } \\
\text { Broadleaf } \\
\text { Forest } \\
\end{array}$ & $\begin{array}{l}4 \\
\text { Mixed } \\
\text { Forest }\end{array}$ & $\begin{array}{l}9 \\
\text { Grasslands }\end{array}$ & $\begin{array}{l}11 \\
\text { Croplands }\end{array}$ & $\begin{array}{l}12 \\
\text { Urban and } \\
\text { Built-Up }\end{array}$ & $\begin{array}{l}13 \\
\text { Cropland/ } \\
\text { Natural } \\
\text { Mosaic }\end{array}$ \\
\hline frequency & 2 & 21 & 112 & 275 & 12306 & 142 & 3597 \\
\hline proportion & 0.00 & 0.00 & 0.01 & 0.02 & 0.75 & 0.01 & 0.22 \\
\hline
\end{tabular}

\begin{tabular}{|l|l|l|l|l|}
\hline \multicolumn{2}{|l|}{ Available soil water content (top layer) } \\
\hline class & $\begin{array}{l}\text { Low }<100 \mathrm{~mm} \\
\text { frequency }\end{array}$ & $\begin{array}{l}2 \\
\text { medium }\end{array}$ & $\begin{array}{l}3 \\
\text { high }\end{array}$ & $\begin{array}{l}4 \\
\text { very high }>190 \mathrm{~mm}\end{array}$ \\
\hline & 10050 & 2090 & 4159 & 156 \\
\hline & 0.61 & 0.13 & 0.25 & 0.009 \\
\hline
\end{tabular}

\begin{tabular}{|l|l|l|l|l|}
\hline \multicolumn{5}{|l|}{ Soil organic $\mathrm{CO}_{2}$ content (top layer) } \\
\hline class & $\begin{array}{l}\text { High }>6 \% \\
\text { frequency }\end{array}$ & $\begin{array}{l}2 \\
\text { medium }\end{array}$ & $\begin{array}{l}3 \\
\text { low }\end{array}$ & $\begin{array}{l}4 \\
\text { very low }<1 \%\end{array}$ \\
\hline proportion & 0.12 & 155 & 10908 & 3136 \\
\hline
\end{tabular}

\begin{tabular}{|c|c|c|c|c|c|c|}
\hline \multicolumn{7}{|c|}{ Soil texture } \\
\hline class & $\begin{array}{l}0 \\
\text { Coarse } \\
>65 \% \text { sand }\end{array}$ & $\begin{array}{l}1 \\
\text { medium }\end{array}$ & $\begin{array}{l}2 \\
\text { Medium fine }\end{array}$ & $\begin{array}{l}3 \\
\text { Fine } \\
<35 \% \text { clay }\end{array}$ & $\begin{array}{l}4 \\
\text { Very fine } \\
<1 \% \text { sand }\end{array}$ & $\begin{array}{l}8 \\
\text { peat }\end{array}$ \\
\hline frequency & 37 & 11573 & 2434 & 156 & 802 & 1453 \\
\hline proportion & 0.00 & 0.70 & 0.15 & 0.01 & 0.05 & 0.09 \\
\hline
\end{tabular}




\begin{tabular}{|l|l|l|l|}
\hline BIOCLIM & min & mean & max \\
\hline Bio01 Annual mean temperature $\left({ }^{\circ} \mathrm{C}\right)$ & 5.1 & 9.1 & 10.2 \\
\hline Bio02 Mean diurnal temp. range $\left({ }^{\circ} \mathrm{C}\right)$ & 5.2 & 7.6 & 33.2 \\
\hline Bio03 Isothermality (Bio02 $\div$ Bio07 $* 100)$ & 10.2 & 9.7 & 34 \\
\hline Bio04 Temp. seasonality $($ standard deviation $* 100)$ & 5292 & 5533 & 6572 \\
\hline Bio05 Max. temperature of warmest month $\left({ }^{\circ} \mathrm{C}\right)$ & 17.6 & 21.4 & 23.6 \\
\hline Bio06 Min. temperature of coldest month $\left({ }^{\circ} \mathrm{C}\right)$ & -5.5 & -1.2 & -0.1 \\
\hline Bio07 Temperature annual range $\left(\right.$ Bio05-Bio06) $\left({ }^{\circ} \mathrm{C}\right)$ & 20.6 & 22.6 & 26.3 \\
\hline Bio08 Mean temperature of wettest quarter $\left({ }^{\circ} \mathrm{C}\right)$ & -1.2 & 15.9 & 17.7 \\
\hline Bio09 Mean temperature of driest quarter $\left({ }^{\circ} \mathrm{C}\right)$ & -0.3 & 4.7 & 9.9 \\
\hline Bio10 Mean temperature of warmest quarter $\left({ }^{\circ} \mathrm{C}\right)$ & 12.6 & 16.0 & 17.7 \\
\hline Bio11 Mean temperature of coldest quarter $\left({ }^{\circ} \mathrm{C}\right)$ & -2.5 & 2.0 & 2.9 \\
\hline Bio12 Annual precipitation $(\mathrm{mm})$ & 483 & 767 & 1232 \\
\hline Bio13 Precipitation of wettest month $(\mathrm{mm})$ & 60 & 78.8 & 132 \\
\hline Bio14 Precipitation of driest month $(\mathrm{mm})$ & 23 & 45.5 & 84 \\
\hline Bio15 Precipitation seasonality $(\mathrm{C}$ of V) & 11 & 16.2 & 33 \\
\hline Bio16 Precipitation of wettest quarter $(\mathrm{mm})$ & 166 & 224.3 & 364 \\
\hline Bio17 Precipitation of driest quarter $(\mathrm{mm})$ & 78 & 147 & 281 \\
\hline Bio18 Precipitation of warmest quarter $(\mathrm{mm})$ & 166 & 222 & 326 \\
\hline Bio19 Precipitation of coldest quarter $(\mathrm{mm})$ & 78 & 182 & 350 \\
\hline
\end{tabular}




\section{CHAPTER}

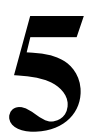

\section{Synthesis}

Environmental change is accelerating as anthropogenic impacts are rising over time (Thomas, 2010). The effects of this change comprise among others modifications of the abundance, physiology, and geographic range of individual plant species, and their interactions with other species (Saavedra et al., 2013). Concern that these environmental alterations may lead to rapid and irreversible changes of local plant communities, especially in agro-ecosystems, which are highly vulnerable, has emphasised the need to understand how weeds respond to these influences in order to anticipate possible future weed problems and to devise management strategies (Glemnitz et al., 2006; McDonald et al., 2009; Bradley, 2012; Weller et al., 2013).

To tackle this complex challenge, scientific investigations needs to span spatial and temporal scales and to integrate various biological levels of organization. Direction and strength of the environmental effect on a weed can, to a certain extent be used to explain and predict potential alterations of the distributional range response of this species (Weller et al., 2013). For those weed species which are pushed to their physiological limits the extent of suitable habitat may decrease, whereas for those, which tolerate changing environmental conditions, e.g. via adaptation or physiological and morphological plasticity, the area providing suitable habitat may expand (Chapin III et al., 1993; Ebeling et al., 2008).

The studies presented within this thesis were assembled for estimating how three species of weeds may respond to changing environmental conditions. Different methodological 
approaches were used, including traditional mechanistic process-based experiments and progressive correlative modelling to take different perspectives on the subject and to allow predictions of the future scenario.

In chapter 2 of this thesis, the effects of changing environmental conditions on the emergence characteristics of Abutilon theophrasti, Datura stramonium and Iva xanthiifolia were analysed. Our results were in discordance to the underlying assumption that these weeds, which had been chosen to represent a guild of thermophile, ruderal, highly competitive, stress-tolerant, range-expanding annual C3 species, would respond in similar ways to the experimental warming and drought conditions. In contrast, they showed strongly idiosyncratic patterns of response to the environmental conditions. However, the emergence pattern of all three species was significantly influenced by the environmental conditions, which is in accordance to our initial assumption. Drought decreased the number of emerged seedlings in most environmental settings, especially when in combination with warmer temperatures and in sandy soils. This finding agrees with other studies which reported that the number of emerged seedling diminished as a consequence of decreased water availability (Lloret et al., 2004). We also decided that for emergence the soil temperature is of higher importance than the air temperature. Not only does soil temperature influence the rate constants of chemical reactions, water content, and nutrient transport in the soil, but it simultaneously affects ion uptake, root growth, and the composition and function of soil microbial communities. There have been several excellent studies of soil temperature effects on root growth and related processes (Pregitzer and King, 2005).

However, in dry conditions, emergence was highest in peat compared to the other soils. One explanation may be that a high content of organic matter in peaty soils, mediating a high water holding capacity (Hillel 1998), may have set more favourable growing conditions in comparison to coarse soils which dried faster at conditions of limited water supply.

However, natural peatlands act as global sinks of atmospheric carbon (C) through the accumulation of organic matter (Bragazza et al., 2013). For peatlands it has been shown that they will quickly respond to the expected warming in this century by losing labile soil organic carbon during dry periods (Ise et al., 2008). Breeuwer et al. (2009) highlighted that changing climatic conditions, especially an increase in warming, promote vascular plant growth (e.g., ericaceous shrubs) in peatlands. Growing condition coupled with vegetation changes are expected in natural peatlands (Breeuwer et al., 2009; Bragazza et al., 2013). Here, our results indicate that the consequences of climatic constraints may strongly deviate in regions of different soil types (Rosenzweig and Hillel, 2000).

Under conditions of warming and good moisture supply, D. stramonium and A. theophrasti had an enhanced emergence fraction in sandy soils, and a shorter time to final emergence was observed in loess and clay soils. The observed enhanced emergence fractions infer that seeds had beneficial settings for growing, in terms of the medium and in combination with moisture supply and temperature conditions. This is in accordance to other studies which 
reported that at optimal growing conditions, seeds show a fast emergence coupled with a high emergence fraction (Guillemin et al., 2013). However, warmer and drier environments provided suboptimal, but not unfavourable conditions for the emergence of A. theophrasti and D. stramonium. In contrast, the results indicated that for I. xanthiifolia the warmer temperature treatment and the reduced water availability were not optimal for emergence. Lloret et al. (2004) emphasised that species with a reduced emergence fraction are more likely to disappear from the community in new climatic conditions, which is correlated to species loss and proportional to species abundance. Therefore, the growth and distribution of I. xanthiifolia may decrease in new climate scenarios of increasing temperature and drought conditions (Chapter 3 and 4).

As one of the first, Hartgerink and Bazzaz (1994) emphasized the importance of the events occurring at the seedling stage for the subsequent fitness of an individual later on. Emergence is especially important for plant adaptation/acclimatisation because, being among the initial life-stage transitions; it sets the initial frame of development and natural selection. The environmental conditions that elicit emergence are those that the seedling must contend with and that will influence seedling survival and the phenotypic expression of post-emergence traits (Donohue et al., 2010). Hartgerink and Bazzaz (1994) suggested that the final biomass of an individual is a function of its starting capital (environmental settings during the emergence stage), the growth rate of the genotype in that environment, the time available for growth and the restriction imposed by the neighbours. In addition, individuals with an early emergence are likely to become dominant and therefore to benefit with regard to competition for resources (Verdú and Traveset, 2005).

In their study, Hartgerink and Bazzaz (1994) describe that stress characteristics which occurred during the emergence stage had a negatively impact on the plants during the establishment stage. In our experiment, as shown in chapter 3, we observed that certain sets of environmental conditions caused a similar stress response patterns concerning both emergence and establishment growth. Altogether, warming and drought had negative effects on the overall plant performance. However, we need to point out that in our experimental approach the stress conditions continued linearly from the emergence to the establishment stage. We hence cannot disentangle, if negative growth effects were the result of unfavourable conditions at the emergence stage or by the conditions at the establishment stage. Future research is needed which involves changes of the environmental conditions, in a way that seedlings which had suboptimal conditions for emergence will be grown later on in an optimal environment to check, if seedling survival and post-emergence traits were influenced by the conditions during emergence.

Laboratory experiments and greenhouse studies are main mechanistic tools to estimate the range of conditions under which a species can emerge, live, and survive. In most cases they have been used to estimate two variables (temperature and moisture) to characterise the niche-matrix of a plant species (Peterson et al., 2011). Here, we have highlighted that they have to be at least complemented with the factor soil. Peat and clay soils provided better growing conditions than sand and loam soils under the same conditions of warming and 
drought, at least for A. theophrasti and D. stramonium. Soil with its physical and chemical properties is inter alia a transmitter of heat and water energy to the plant and can therefore have a severe effect on the current and future weed species distribution (Andreasen and Streibig, 1991; Hillel, 1998).

The design of the experiment presented in chapter 3 used a man-made crop-weed community, consisting of the target weeds and maize, which was chosen as an example of a frequent spring crop. This design was intended to account for the crop-weed and weedweed interactions, which occur under the conditions of the biotically reduced niche. This approach accepts the risk that the net effect of the environmental conditions cannot be separated from the influence of competition. However, it represents the conditions present in actual crop-weed mixtures in the field. Maize as a $\mathrm{C} 4$ plant competing within a group of C3 plants may have had additional advantage in the warming treatment, which is indicated by numerous studies (Hyvönen et al., 2011; Chuine et al., 2012; Stratonovitch et al., 2012). For example, it has been found for grass species, that $C 4$ grasses showed preferences for regions with higher temperatures and lower precipitation compared to $\mathrm{C} 3$ grasses (Pau et al., 2013).

Further, the competitive interaction could be an explication for why we did not observe a different response of the measured aboveground traits in comparison to the belowground traits. Our findings do not confirm the hypothesis of reduced values of aboveground traits (leaf area, biomass) under drier and warmer conditions and a stronger allocation to the belowground parts to maximize soil resource acquisition (Chapin III et al., 1993; Davis, 2006). Especially specific root length is one of the most important parameters with regard to a plant's capacity to acquire nutrients and water under environmental change (Pregitzer and King, 2005). Some studies suggest that in order to estimate the species' individual tolerance to environmental change, one first needs to identify the net effect of the environmental change, specifically the direction of change in the strength of the speciesspecies interaction (Saavedra et al., 2013).

Results of the experimental studies in chapter 2 and 3 indicated that $A$. theophrasti and $D$. stramonium may benefit from the predicted future climate, due to a higher plasticity and a tolerance to a larger range of environmental conditions during the emergence and the establishment stage. We therefore assumed that the geographic range of distribution of these two species may be extended in the future.

We additionally used a maximum entropy modelling approach to predict the relative future habitat suitability for potential distribution of the three investigated weed species as presented in Chapter 4. We finally linked the results of this approach with the data obtained from the empirical experiments in order to obtain a more complete evaluation of the impact of altered environmental conditions on the weeds, because there is increasing evidence of the importance of plasticity and adaptation potential of plants under changing environmental conditions in both natural and agricultural systems (Nicotra et al., 2010; Clementes and DiTommaso, 2011), especially if the intention is to model species distribution with an ecological niche approach. This combined approach has the advantage 
of being based on direct information about the biology of a species (Peterson et al., 2011) and hence contributes to an understanding of the mismatch between modelled predictions and observations (Chuine et al., 2012).

Observed biological parameters could additionally be used in a process-based distribution modelling approach. Process-based distribution models are the major counterpart to correlative distribution models. Predictions of correlative distribution models are usually limited with regard to their biological realism, whereas process-based models rely on a large amount of biological parameters, but can address deficits by explicitly including processes omitted by the correlative approach. Both models have their weakness and their strengths (Dormann et al., 2012). Future developments should more closely link both modelling approaches with each other to make one important step towards improving projections of species distribution and abundance (Estes et al., 2013).

In chapter 4, we demonstrated by using a correlative model (MaxEnt), that there will be moderate to strong impacts on the distributional range (gain and loss of suitable habitat area) of the investigated three weed species in northwest Germany (Bürger et al., 2013). The relevance of certain environmental factors varied with regard to their influence on the three weeds. The model prediction and the experimental findings differed in the case of $A$. theophrasti. The model predicted a decline of potential distribution range and habitat suitability for this species. This is in disagreement with our experimental findings where we estimated a high plasticity and tolerance to a range of environmental conditions for this species, but it is conform to other studies: McDonald et al. (2009) estimated a minor importance of $A$. theophrasti for the end of this century in the U.S. Corn Belt under changing climatic conditions. In contrast, the results of our modelling approach confirmed an increase of the potential distribution range and habitat suitability for D. stramonium and a decrease for I. xanthiifolia in northwest Germany, which agrees with the results of our empirical experiments (Chapter 2 and 3).

Follack et al. (2013) analysed the history of the invasion, spread dynamics and habitat affiliation of I. xanthiifolia in Central and Eastern Europe. He found that climatic factors were of little importance for the current distributional range of I. xanthiifolia, but land use had a significant influence. As mentioned in Chapter 1 (Fig. 1.2) of this thesis, various environmental factors have great influence at different scale levels on the potential distribution, and their impact in combination with processes such as dispersal, disturbance, and competition results in the biotically reduced niche/realized niche of a plant species (Pearson and Dawson, 2003; McDonald et al., 2009). However, these factors do not exclusively explain species distribution. It has been shown by several authors that the contribution of land use to the observed and modelled distribution is of significant importance (Pompe et al., 2008; Hulme, 2009; Hyvönen et al., 2012).

Land use is driven by, and vice-versa drives climate change (Dahle, 1997), but it is also influenced by socio-economic concerns (Gevers et al., 2011; Steinmann and Dobers, 2013). All these triggers are intricately linked with each other. Changes of the environmental conditions away from the current state may require adjustments and adaptation of arable land use on a fine scale, in the current cropping structure (e.g., 
common crops, herbicide usage, earlier drilling, crop rotation, use of irrigation) in order to maintain a high biodiversity and productivity (Gevers et al., 2011; Bradley, 2012; Stratonovitch et al., 2012). However, the suitability and productivity of crops are projected to increase towards the more northern latitudes; this is particularly the case for cereals and cold season seed crops. Crops dominant in southern Europe such as maize, sunflower and soya beans may also become viable further north and at higher altitudes (Gornall et al., 2010). A scenario of change of arable land use for Germany claims the stimulation of energy crops (e.g., maize) due to the increased promotion of renewable energies (Gevers et al., 2011). Land use on a large, and the cropping structure of arable land use on a small scale is known to have an influence on the composition of the in-site weed community (Glemnitz et al., 2010). A change of the cropping structure of arable land, socioeconomically or environmentally driven, may have a severe effect on weed population dynamics, abundance, and the composition of assemblages on the field scale level (Weber and Schrader, 2006; Hyvönen et al., 2011). It may benefit weed species that are already present in that area (e.g., sleeper weeds), lead to introduction and naturalisation of new weed species (e.g., competitive neophytes), and the evolution of new weed taxa in a given area (e.g., invasive aliens) (Pyšek et al., 2005; Broennimann et al., 2007; Scott et al., 2008). These changes are well known threats to agro-ecosystems, causing significant ecological and economic damage (Mack et al., 2000; Weber and Schrader, 2006, McDonald et al., 2009; Bradley, 2012). The forecasted arable land use change (e.g., the increase of the proportion of spring crops) may affect crop-weed and weed-weed interactions, and may lead to advantages of spring crop weeds to a similar or a larger extent than changes in the climate (Glemnitz et al., 2010; Hyvönen et al., 2011; Stratonovitch et al., 2012). In addition, northern regions will probably gain more new species as a consequence of range shifts, due to the higher weed species richness of the southern latitudes, with several noxious weed species not occurring in the north (Glemitz et al., 2006; Hyvönen et al., 2011).

In summary, it can be stated that a combination of manipulative environmental experiments and ecological niche based modelling of the current and future potential distribution and habitat suitability data enabled a better understanding of how the investigated weeds may react under future environmental conditions than a separate analysis would have allowed. Such a coupling approach may hence provide a greater precision in predicting the impacts of a changing environment on plant species and ecosystems processes (Ebeling et al., 2008; Chuine et al., 2012).

The results showed that the target weed species, despite having been selected as a homogenous guild, responded with pronounced idiosyncratic responses at the plant as well as at the spatial level to the changing environmental conditions. We emphasize, in discordance to Hyvönen et al. (2011), that weed species may not be classified into functional groups in terms of their spatial responses. On the contrary, for the individual species we showed a promising approach to a prediction of the probable future morphological, spatial and temporal behavioural responses (Hijmans and Graham, 2006, Wiens et al., 2009). Iva xanthiifolia may suffer a more severe loss of suitable habit than $A$. 
theophrasti, whereas $D$. stramonium may benefit from climate change. This may alter the composition of weed communities under environmental change in northwest Germany.

Undoubtedly, by knowing the underlying assumptions and uncertainties, there is still need for a deeper and broader understanding of influences and interactions of species abundance (Bradley, 2012), limiting environmental variables such as dispersal factors, disturbance factors, and competition factors (Pearson and Dawson, 2003; McDonald et al., 2009; Sexton et al., 2009), land use and land cover change (Pompe et al., 2008; Hyvönen et al., 2012) as well as plant phenotypic, morphological and physiological plasticity and evolutionary adaptation potential (Nicotra et al., 2010; Clements and DiTommaso, 2011; Godoy et al., 2012).

The relative importance of these factors influencing weeds should be taken into account for successfully targeting future high-accuracy predictions, which are aimed to assist the development of appropriate weed management programmes and adaptation strategies for maintaining biodiversity and productivity of northwest Germany's agro-ecosystems under future environmental conditions. 


\section{References}

Andreasen, C., Streibig, J.C. \& HaAs, H. 1991. Soil properties affecting the distribution of 37 weed species in Danish fields. Propriétés du sol affectant la distribution de 37 especes d'adventices dans les champs danois. Weed Research 31 (4): 181-187.

BASsiRIRAD, H. (ed.) 2005. Nutrient Acquisition by Plants. Springer Berlin Heidelberg.

Bradley, B.A., Estes, L.D., Hole, D.G., Holness, S., OpPenheimer, M., Turner, W.R., Beukes, H., Schulze, R.E., Tadross, M.A. \& Wilcove, D.S. 2012. Predicting how adaptation to climate change could affect ecological conservation: secondary impacts of shifting agricultural suitability. Diversity and Distributions 18 (5): 425-437.

BragazZa, L., Parisod, J., Buttler, A. \& BardgetT, R.D. 2013. Biogeochemical plantsoil microbe feedback in response to climate warming in peatlands. Nature Clim. Change 3 (3): 273-277.

Breeuwer, A., Robroek, B.J., Limpens, J., Heijmans, M.M., Schouten, M.G. \& BERENDSE, F. 2009. Decreased summer water table depth affects peatland vegetation. Basic and Applied Ecology 10 (4): 330-339.

Broennimann, O., Treier, U.A., Müller-Schärer, H., Thuiller, W., Peterson, A.T. \& GuISAN, A. 2007. Evidence of climatic niche shift during biological invasion. Ecology Letters 10 (8): 701-709.

Bürger, J., Edler, B., Gerowitt, B. \& Steinmann, H.-H. (2013). Uncertainty in modelling distribution of arable weeds under climate change conditions. European Commission/ BMBF: ECCA European Climate Change Adaptation Conference 2013, 170-171.

Chapin, F.S., III, Rincon, E. \& HuAnte, P. 1993. Environmental responses of plants and ecosystems as predictors of the impact of global change. Journal of Biosciences (18): $515-524$.

Chuine, I., Morin, X., Sonié, L., Collin, C., Fabreguettes, J., Degueldre, D., SAlAGER, J.-L. \& ROY, J. 2012. Climate change might increase the invasion potential of the alien C4 grass Setaria parviflora (Poaceae) in the Mediterranean Basin. Diversity and Distributions 18 (7): 661-672.

Clements, D.R. \& DiTommaso, A. 2011. Climate change and weed adaptation: can evolution of invasive plants lead to greater range expansion than forecasted? Weed Research 51 (3): 227-240.

DALE, V.H. 1997. The relationship between land-use chnage and climate change. Ecological Applications 7 (3): 753-769.

DAVIS, W.J. 2006. Responses of plant growth and functioning to changes in water supply in a changing climate. In: Morison, J.I.L. \& Morecroft, M.D. (eds.) Plant growth and climate change, pp. 97-145. Blackwell Pub., Oxford.

Donohue, K., Casas, R.R. De, Burghardt, L., Kovach, K. \& Willis, C.G. 2010. Germination, Postgermination Adaptation, and Species Ecological Ranges 41: 293319. 
Dormann, C.F., Schymanski, S.J., Cabral, J., Chuine, I., Graham, C., Hartig, F., Kearney, M., Morin, X., Römermann, C., Schröder, B. \& Singer, A. 2012. Correlation and process in species distribution models: bridging a dichotomy. Journal of Biogeography 39 (12): 2119-2131.

Ebeling, S.K., Welk, E., Auge, H. \& Bruelheide, H. 2008. Predicting the spread of an invasive plant: combining experiments and ecological niche model. Ecography 31 (6): 709-719.

Estes, L.D., Bradley, B.A., Beukes, H., Hole, D.G., Lau, M., Oppenheimer, M.G., Schulze, R., Tadross, M.A. \& Turner, W.R. 2013. Comparing mechanistic and empirical model projections of crop suitability and productivity: implications for ecological forecasting. Global Ecology and Biogeography 22 (8): 1007-1018.

Follak, S., Dullinger, S., Kleinbauer, I., Moser, D. \& Essl, F. 2013. Invasion dynamics of three allergenic invasive Asteraceae (Ambrosia trifida, Artemisia annua, Iva xanthiifolia) in central and eastern Europe. Preslia 85 (1): 41-61.

Gevers, J., Høye, T.T., Topping, C.J., Glemnitz, M. \& SchröDER, B. 2011. Biodiversity and the mitigation of climate change through bioenergy: impacts of increased maize cultivation on farmland wildlife. GCB Bioenergy 3 (6): 472-482.

Glemnitz, M., Hyvönen, T., Radics, L., Hoffmann, J. \& Czimber, G. 2010. Weeds in changing climate - a north european perspective. NJF Report 6 (1): 55-57.

Glemnitz, M., Radics, L., Hoffmann, J. \& Czimber, G. 2006. Weed species richness and species composition of different arable field types: a comparative analysis along a climate gradient from south to north Europe. ournal of Plant Diseases and Protection : Special Issue 20: 577-586.

Godoy, O., Valladares, F. \& CASTRO-DíEZ, P. 2012. The relative importance for plant invasiveness of trait means, and their plasticity and integration in a multivariate framework. New Phytologist 195 (4): 912-922.

Gornall, J., Betts, R., Burke, E., Clark, R., Camp, J., Willett, K. \& Wiltshire, A. 2010. Implications of climate change for agricultural productivity in the early twentyfirst century. Philosophical Transactions of the Royal Society B: Biological Sciences 365 (1554): 2973-2989.

Guillemin, J.-P., Gardarin, A., Granger, S., Reibel, C., Munier-Jolain, N. \& COLBACH, N. 2013. Assessing potential germination period of weeds with base temperatures and base water potentials. Weed Research 53 (1): 76-87.

HARTGERINK, A.P. \& BAZZAZ, F.A. 1984. Seedling-Scale Environmental Heterogeneity Influences Individual Fitness and Population Structure. Ecology 65 (1): 198-206.

HumAnS, R.J. \& GRAHAM, C.H. 2006. The ability of climate envelope models to predict the effect of climate change on species distributions. Global Change Biology 12 (12): 2272-2281.

HiLlel, D. 1998. Environmental soil physics. Academic Press, San Diego, CA. 
HulmE, P.E. 2009. Relative roles of life-form, land use and climate in recent dynamics of alien plant distributions in the British Isles. Weed Research 49 (1): 19-28.

Hyvönen, T., Glemnitz, M., RADics, L. \& HofFMANN, J. 2011. Impact of climate and land use type on the distribution of Finnish casual arable weeds in Europe. Weed Research 51 (2): 201-208.

Hyvönen, T., Luoto, M. \& Uotila, P. 2012. Assesment of weed establishment rick in a changing European climate. Agriculture and Food Science (21): 348-360.

Ise, T., Dunn, A.L., Wofsy, S.C. \& Moorcroft, P.R. 2008. High sensitivity of peat decomposition to climate change through water-table feedback. Nature Geosci 1 (11): 763-766.

Lloret, F., Peñuelas, J. \& Estiarte, M. 2004. Experimental evidence of reduced diversity of seedlings due to climate modification in a Mediterranean-type community. Global Change Biology 10 (2): 248-258.

Mack, R.N., Simberloff, D., Lonsdale, W.M., Evans, H., Clout, M. \& Bazzaz, F.A. 2000. Biotic Invasions: Causes, Epidemiology, Global Consequences, and Control. Ecological Applications 10 (3): 689-710.

McDonald, A., Riha, S., DiTommaso, A. \& DeGaetano, A. 2009. Climate change and the geography of weed damage: Analysis of U.S. maize systems suggests the potential for significant range transformations. Agriculture, Ecosystems \& Environment 130 (34): 131-140.

Morison, J.I.L. \& Morecroft, M.D. (eds.) 2006. Plant growth and climate change. Blackwell Pub., Oxford.

Nicotra, A.B., Atkin, O.K., Bonser, S.P., Davidson, A.M., Finnegan, E.J., Mathesius, U., Poot, P., Purugganan, M.D., Richards, C.L., Valladares, F. \& Van Kleunen, M. 2010. Plant phenotypic plasticity in a changing climate. Trends in plant science 15 (12): 684-692.

PAU, S., EDWARDS, E.J. \& STILL, C.J. 2013. Improving our understanding of environmental controls on the distribution of C3 and C4 grasses. Global Change Biology 19 (1): 184-196.

PeArson, R.G. \& DAwson, T.P. 2003. Predicting the impacts of climate change on the distribution of species: are bioclimate envelope models useful? Global Ecology and Biogeography 201312 (5): 361-371.

Peterson, A.T., Soberón, J., Pearson, R.G., Anderson, r.P., Martínez-Meyer, E., NAKAMURA, M. \& ARAÚJO, M.B. 2011. Ecological niches and geographic distributions. Princeton University Press, Princeton, NJ.

Pompe, S., Hanspach, J., Badeck, F., Klotz, S., Thuiller, W. \& Kühn, I. 2008. Climate and land use change impacts on plant distributions in Germany.2008. Climate and land use change impacts on plant distributions in Germany. Biology Letters 4 (5): 564-567. 
PregitZer, K.S. \& KING, J.S. 2005. Effects of Soil Temperature on Nutrient Uptake. In: BassiriRad, H. (ed.) Nutrient Acquisition by Plants, pp. 277-310. Springer Berlin Heidelberg.

PyŠEK, P., JARoŠík, V., Chytrý, M., KropáČ, Z., TiChÝ, L. \& WiLD, J. 2005. Alien plants in temperate weed communities: Prehistoric and recent invaders occupy different habitats. Ecology 86 (3): 772-785.

Rosenzweig, C. \& Hillel, D. 2000. Soils and global climate change: Challenges and opportunities. Soil Science 165: 47-56.

SAAVEDRA, S., RoHR, R.P., DAKOS, V. \& BASCOMPTE, J. 2013. Estimating the tolerance of species to the effects of global environmental change. Nat Commun 4.

Scott, J.K., Batchelor, K.L., OtA, N. \& Yeoh, P.B. 2008. Modelling Climate Change Impacts on Sleeper and Alert Weeds: APPENDIX B: RESULTS OF CLIMEX MODELS - Part 1. [CSIRO Entomology, Private Bag, P.O. Wembley WA 6913, Australia].

Sexton, J.P., McIntyre, P.J., Angert, A.L. \& Rice, K.J. 2009. Evolution and Ecology of Species Range Limits. Annual Review of Ecology, Evolution, and Systematics 40 (1): 415-436.

SteInMAnN, H.-H. \& DobeRs, E.S. 2013. Spatio-temporal analysis of crop rotations and crop sequence patterns in Northern Germany: potential implications for plant health and crop protection. Journal of Plant Diseases and Protection 120: 85-94.

Stratonovitch, P., Storkey, J. \& Semenov, M.A. 2012. A process-based approach to modelling impacts of climate change on the damage niche of an agricultural weed. Global Change Biology 18 (6): 2071-2080.

Thomas, C.D. 2010. Climate, climate change and range boundaries. Diversity and Distributions 16 (3): 488-495.

Verdú, M. \& Traveset, A. 2005. Early emergence enhances plant fitness: A phylogentically controlled meta-analysis. Ecology 86 (6): 1385-1394.

Weber, E. \& Schrader, G. 2006. New weed threats; extent, origins and proper managment. Perspectives in Agriculture, Veterinary Science, Nutrition and Natural Resources 47 (1).

Weller, S.G., Suding, K. \& SAKA, A.K. 2013. Botany and a changing world: Introduction to the Special Issue on Global Biological Change. American Journal of Botany 7 (100): 1229-1233.

Wiens, J.A., Stralberg, D., Jongsomjit, D., Howell, C.A. \& Snyder, M.A. 2009. Niches, models, and climate change: Assessing the assumptions and uncertainties. Proceedings of the National Academy of Sciences. 


\section{Summary}

In the course of the past decades, various impacts of climate change have been recognized to pose a challenge to arable production systems. Among others, shifts in the species composition of weed communities, particularly the rising importance of highly competitive neophytic weed species and sleeper weeds, cause yield losses and additional management costs. This thesis aimed to provide insights into the response to changed environmental conditions of a selection of arable weeds. We examined the effects of the projected future climatic conditions in Lower Saxony (northwest Germany) on emergence, morphological traits, habitat suitability and potential geographical distribution of the weed species. We used different methods to address these targets: a mechanistic processed-based experimental approach, as well as a correlative maximum entropy approach of bioclimatic niche modelling (software MaxEnt). Focus was put on three weed species, which may alter their distribution under the predicted conditions of environmental change: Abutilon theophrasti, Datura stramonium and Iva xanthiifolia were selected as examples of a guild of highly competitive, ruderal, stress-tolerant, thermophile, annual C3 weeds, which have a distinct effect on the agricultural productivity, or, in case of I. xanthiifolia, which cause human harm. They are currently expanding their range in Europe, but are still differing in their biogeographic importance for Lower Saxonys' agro-ecosystems.

In a first experimental study, a manipulative approach was used to analyse the effects of elevated temperature (ambient temperature $+2.5^{\circ} \mathrm{C}$ ), reduced soil moisture (soil moisture content between -0.1 to $-1.5 \mathrm{MPa}$ ) versus ambient temperature conditions and soil moisture content of $-0.0036 \mathrm{MPa}$ in four soil type (loess, clay, peat and sand), and their interactions on the emergence characteristics of the target weeds. The emergence patterns were significantly influenced by the environmental conditions. A linear-mixed effects model and a survival analysis revealed that drought conditions decreased the number of emerged seedlings and the probability that seedlings will emerge in most environmental settings, especially in combination with warmer temperature and in sand rich soils. In dry conditions, emergence was highest in peat compared to the other soil types. The results showed that for I. xanthiifolia the warmer temperature treatment and the reduced water availability were outside of the optimum conditions for emergence.

Within the second experimental study, the stress treatment factors which were applied to the emergence stage were continued during the establishment stage. Higher temperatures and reduced soil water content produced negative effects on the overall growth performance - as measured by total biomass and traits indicating biomass allocation (e.g., leaf area, root length)- for the three weed species. Peat and clay rich soils provided better growing condition than other soil types under warming and drought. I. xanthiifolia did not respond to the tested conditions in a consistent way, but positive growth performance of this species was most strongly related to good moisture supply and colder temperatures. For A. theophrasti and D. stramonium, we observed a tendency of a higher total biomass in clay and peat rich soils than in the other soil types under warm-dry conditions. These two 
species showed a higher plasticity than I. xanthiifolia in all of the tested environmental treatments.

The results from the first and the second experimental studies demonstrated that the three weeds which were assumed to have similar environmental requirements responded in rather idiosyncratic ways the variety of microsite conditions. Under future climate, emergence and growing conditions for plants may differ more distinctly than today between sand and peat rich sites. We further concluded from our results that future climatic conditions may impair the emergence and growth performance of I. xanthiifolia. For A. theophrasti and D. stramonium, we deduced tolerance to a wide range of environmental conditions. These two species may benefit from the predicted future climate.

In the ecological niche modelling approach on a small, regional scale, it was demonstrated that there will be moderate to high impacts on the distribution of the target weed species in Lower Saxony as based on a gain and loss of suitable habitat areas. The environmental influences varied with regard to their relevance for the three weeds. The modelled prediction, and the experimental findings did differ in the case of A. theophrasti. The model predicted a decline in potential distribution and habit suitability for this species. This was in disagreement with our experimental findings, were we estimated a high plasticity and a wide range of tolerance of the species. The results of the modelling approach indicated further an increase of D. stramonium and a decrease of I. xanthiifolia in potential distribution and habitat suitability for northwest Germany, which was conform to the findings from our experiments. We demonstrated that even for weed species with similar ecology, under future climatic conditions dissimilar responses concerning morphological traits and distributional shifts have to be expected.

In conclusion, this thesis provides evidence that an integrative approach, combining manipulative environmental experiments, and ecological niche based modelling on the current and future potential distribution and habitat suitability data, enabled a better understanding of how the target weeds may react under future environmental conditions, than a separated analysis would have allowed. Such a comprehensive approach may lead to greater precision in predicting the impacts of a changing environment on plant species and ecosystems processes for Lower Saxony. 


\section{Zusammenfassung}

Eine Veränderung der Standortfaktoren, beispielsweise bedingt durch den Klimawandel, kann mehr oder minder starke Effekte auf die Lebensbedingungen von Pflanzen ausüben. In landwirtschaftlich genutzten Ökosystemen betrifft dies sowohl die Kulturpflanzen, als auch die mit ihnen vergesellschaftete Ackerunkrautflora. In den vergangen Jahrzehnten konnten Veränderungen in der Abundanz, der Physiologie und der geographische Verbreitung einzelner Unkrautarten festgestellt werden. Die Verbreitung von Unkräutern wird im Allgemeinen durch ein plastisches Verhalten gegenüber ökologischen Faktoren (z.B. Temperatur, Feuchte, Boden usw.), oder durch eine Adaption an diese, durch die Konkurrenzbeziehungen zueinander, sowie zur Kulturpflanze und durch anthropogene Einflüsse bestimmt.

In Ackerunkrautfloren wird verstärkt ein Wandel der Zusammensetzung des Artenspektrums und eine Verschiebung der Bedeutung einzelner Arten beobachtet. Unkräuter, die aktuell lediglich auf Ruderalstandorten, oder in geringem Abundanzen vorkamen (,sleeper weeds“), erfuhren durch die Veränderung ihrer Umweltbedingungen die Gelegenheit zur Ausbreitung. Demgegenüber stehen Unkrautarten, die bereits in einem Gebiet etabliert sind und möglicherweise mit Verschiebungen ( $\mathrm{Zu}-$ und Abnahmen) im Verbreitungsgebiet reagieren. Dabei ist ein besonderes Augenmerk auf Ausbreitungstendenzen von konkurrenzstarken Neophyten, aber auch auf sleeper weeds zu legen. Aus den klein- und großräumigen Areal- und Nischenverschiebungen folgen mögliche Gleichgewichtsveränderungen zwischen den Nutzpflanzen und den Unkräutern. Diese können zu Ertragsverlusten in Ackerkulturen führen und erfordern gezielte Anpassungsmaßnahmen in der Unkrautbekämpfung.

Das Ziel dieser Arbeit war es, die Auswirkungen veränderter Umweltbedingungen, insbesondere der für die Zukunft prognostizierten Klimabedingungen, auf Ackerunkräuter für den Raum Niedersachsen für das Jahr 2100 zu untersuchen. Dies wurde anhand von zwei unterschiedlichen Methoden - von prozessbasierten, experimentellen Gefäßversuchen und von korrelativer bioklimatischer Nischenmodellierung mit einem maximum Entropieansatz- für eine Auswahl an Unkrautarten vorgenommen. Der Fokus lag dabei auf drei Unkräutern, die Tendenzen zeigen, ihre Verbreitung in Europa zu verändern, und die aktuell in unterschiedlicher Häufigkeit in Niedersachsen vorkommen: Abutilon theophrasti, Datura stramonium und Iva xanthiifolia. Sie repräsentieren eine Artengruppe mit ähnlichen ökologischen Merkmalen: kompetitive, ruderale, stresstolerante, wärmeliebende, sommerannuelle C3-Ackerunkräuter. Ein Vorkommen dieser Arten wirkt sich negativ auf die landwirtschaftliche Produktivität aus; Iva xanthiifolia kann zusätzlich durch Allergene schädlich auf die menschliche Gesundheit wirken.

Die in Rahmen dieser Arbeit durchgeführten manipulativen experimentellen Studien erfassten, wie sich veränderte Umweltbedingungen in Form einer Temperaturerhöhung (Umgebungstemperatur $+2,5^{\circ} \mathrm{C}$ ) und einer Reduktion der Bodenfeuchte (Feuchtigkeit des Bodens zwischen $-0,1$ bis $-1,5 \mathrm{MPa}$ ) im Vergleich zu Umgebungstemperatur und guter Wasserversorgung (-0,0036 MPa) in unterschiedlichen Bodenarten (Lehm, Ton, Torf und 
Sand), sowie deren Wechselwirkungen, auf die Auflaufcharakteristika und das Wachstum der untersuchten Unkräuter auswirkten.

Das Auflaufverhalten der Unkräuter war wesentlich durch die Umgebungsbedingungen (Nischenbedingungen) beeinflusst. Die Anwendung eines linearen gemischten Models und Ereigniszeitanalyse ergaben, dass Trockenheit die Anzahl der aufgelaufenen Keimlinge, und auch die Wahrscheinlichkeit, dass diese in den meisten Umweltbedingungen auflaufen könnten, verringerte. Dies war ergänzend in Umweltkombinationen mit erhöhter Temperatur und sandigen Boden signifikant feststellbar. Bei trockenen Bedingungen konnte die höchste Auflaufrate in torfhaltigen Bodenfestgestellt werden. Es konnte zudem nachgewiesen werden, dass für I. xanthiifolia die erhöhte Temperatur und reduzierte Wasserverfügbarkeit außerhalb der Optimalbedingungen für das Auflaufen lagen.

Als direkte Fortsetzung des Auflaufexperimentes, unter selbigen Umweltbedingungen wie in der Auflaufphase, folgte das Wachstumsexperiment. Es zeigte sich, dass eine Erhöhung der Temperatur und eine verringerte Wasserverfügbarkeit sich negativ auf vegetative Merkmale (z.B. Gesamtpflanzenbiomasse, Blattfläche oder Wurzellänge) der untersuchten Unkräuter auswirkten. Torf -und tonhaltige Böden boten bessere Wachstumsbedingungen bei Trockenheit und Erwärmung als andere Bodentypen. Ein positives Pflanzenwachstum von I. xanthiifolia war stärker in guten Feuchtigkeitsbedingungen und kühleren Temperaturen festzustellen. Für $A$. theophrasti und D. stramonium konnte eine gesteigertes Wachstum in torf -und tonhaltige Böden unter Trockenheit und Erwärmung beobachtet werden. Diese beiden Arten wiesen eine höhere Plastizität als I. xanthiifolia in allen getesteten Nischenbedingungen auf.

Die Ergebnisse aus den experimentellen Versuchen zeigten, dass unter zukünftigen klimatischen Bedingen besonders in torf- und sandhaltigen Böden stärker Veränderungen im Wachstums- und Auflaufverhalten der Unkräuter auftreten könnten. Des Weiteren schließen wir aus unseren experimentellen Ergebnissen, dass der prognostizierte klimatische Wandel das Auflauf- und Wachstumsverhalten von I. xanthiifolia beeinträchtigen könnte. Für $A$. theophrasti und D. stramonium leiteten wir hingegen aus ihrer hohen Toleranz gegenüber einem breiten Spektrum von Nischenbedingungen einen Vorteil unter den für die Zukunft prognostizierten klimatischen Bedingungen ab.

Im zweiten Teil dieser Arbeit wurde eine ökologische Nischenmodellierung für die drei betrachteten Unkrautarten mit der Software MaxEnt erstellt. Die Modellierung wurde von Jana Bürger durchgeführt. Alle von ihr bearbeiten Teile, sind als dieses gekennzeichnet und sind von den Eigenteilen klar ersichtlich und voneinander abgrenzbar. Die Ergebnisse zeigten, basierend auf geeignetem Habitatszuwachs oder -verlust, dass die prognostizierten Klimabedingungen mäßige bis starke Auswirkungen auf die potentielle Verbreitung der Zielunkrautarten in Niedersachsen ausüben könnten. Die relevanten Umweltfaktoren (z. B. Temperatur, Feuchte, Boden, Landnutzug und Landbedeckung) für die potentielle zukünftige Verbreitung und Habitateignung unterschieden sich für die einzelnen Unkrautarten. 
Die Ergebnisse der Artverbreitungsmodellierung ergaben für A. theophrasti eine andere Aussage als die manipulativen Experimente. Das Model beschrieb eine mögliche Abnahme des potentiellen Verbreitungsgebietes und der Habitateignung für diese Art in Niedersachsen, wohingegen die Gefäßversuche eine hohe Plastizität und Toleranz gegenüber unterschiedlichen Nischenbedingungen ergaben. Bei den anderen beiden Arten stimmten die Ergebnisse der Modellierung mit den experimentellen Ergebnissen insofern überein, als dass eine mögliche Zunahme der Habitateignung für D. stramonium und eine Abnahme für I. xanthiifolia in Niedersachsen prognostiziert wurde.

Mit dieser Arbeit konnte gezeigt werden, dass obwohl die untersuchten Unkräuter als eine Gruppe von Arten mit ähnlichen ökologischen Merkmalen ausgewählt wurden, unterschiedliche artspezifische Reaktionen in Bezug auf ihre Morphologie und ihre Verbreitung unter künftigen klimatischen Bedingungen zu erwarten sind. Des Weiteren sollten zukünftige Untersuchungen $\mathrm{zu}$ einem Ackerunkrautwandel neben veränderten Umweltbedingungen auch einer Veränderung der Landnutzung (Anbauspektrum) und der Bewirtschaftungsweise (Fruchtfolgen, Bodenbearbeitung, Pflanzenschutzmaßnahmen) einen höheren Stellenwert einräumen.

Dieser integrative Ansatz, welcher manipulative Experimente und ökologische Nischenmodellierung verband, erklärte die aktuelle und die zukünftige potentielle Verbreitung und Habitateignung präziser, als eine getrennte Analyse es ermöglicht hätte. Ein solch kombinierter Ansatz kann zu einer höheren Vorhersagegenauigkeit der Auswirkungen von veränderten Umweltbedingungen auf Pflanzen- und Ökosystemprozesse in Niedersachsen beitragen. 


\section{Contribution of authors:}

Jana Bürger, Johannes Isselstein and Horst-Henning Steinmann were instrumental in all aspects of the development and writing of chapters 2 and 3. Jana Bürger was involved in the design, the performing and writing of chapter 4 . Her contribution is marked and clear distinguishable from to own performed work. Horst-Henning Steinmann, Laura Breitsameter and Jana Bürger were involved in editing and proofreading of the thesis.

\section{List of Publications}

Peer reviewed journal publications

Edler, B., BÜrger, J., Breitsameter, L., Steinmann, H.-H. \& Isselstein, J. (accepted). Growth responses to elevated temperature and reduced soil moisture during early establishment of three annual weeds in four soil types. Journal of Plant Diseases and Plant Protection.

\section{Conference \& workshop proceedings}

Bürger, J., Edler, B., Gerowitt, B. \& Steinmann, H.-H. (2014). Predicting weed problems in maize cropping by species distribution modelling. 26th German Conference on Weed Biology and Weed Control, Julius-Kühn Archiv 443, 379-386.

Bürger, J., Edler, B., Gerowitt, B. \& Steinmann, H.-H. (2013). Uncertainty in modelling distribution of arable weeds under climate change conditions. European Commission/ BMBF: ECCA European Climate Change Adaptation Conference 2013, 170-171.

Bürger, J., Edler, B., Gerowitt, B. \& Steinmann, H.-H. (2012). Modellierung der zukünftigen Verbreitung von Ackerunkräutern unter den Bedingungen des Klimawandels. Julius-Kühn-Archiv 438, 439-440.

Edler, B., Steinmann, H.-H. \& Isselstein, J. (2012). Auswirkungen veränderter Umweltbedingungen auf das Auflaufen und die Entwicklung von ausgewählten sommerannuellen Unkrautern. Julius-Kühn-Archiv 438, 439-440.

Edler, B., Peters, K., Isselstein, J., Bürger, J., Steinmann, H.-H. \& Gerowitt, B. (2012). Unkräuter im Wandel - Welche Auswirkungen haben veränderte klimatische Bedingungen auf ausgewählte Unkräuter in Norddeutschland?. Julius-Kühn-Archiv 438, 134-135.

Peters, K., Edler, B., Steinmann, H.-H. \& Gerowitt, B. (2010). Unkräuter unter zukünftigem Klima - Wie beeinflusst der Klimawandel die Unkrautflora?. JuliusKühn-Archiv 428, 331-332. 


\section{Acknowledgements}

I acknowledge the support of the following people, who have been helpful for the completion of this thesis:

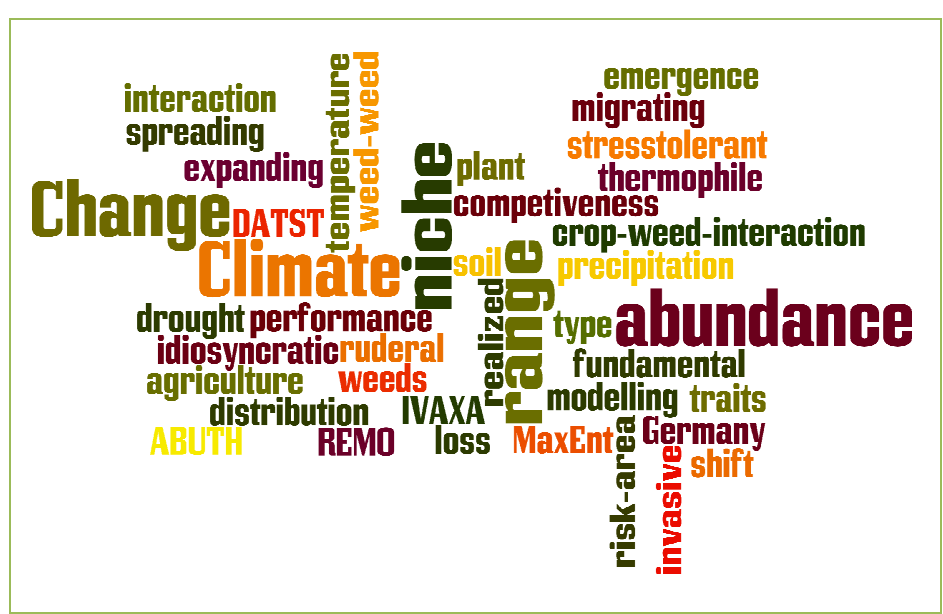

First and foremost, I would like to express my special gratitude to Prof. Johannes Isselstein (Göttingen, Germany) for supervising this thesis.

Further, I thank Prof. Bärbel Gerowitt (Rostock, Germany) for co-referring the thesis.

Dr. Horst-Henning Steinmann (Göttingen) for his support during planning and realisation of all experiments and manuscripts.

My greatest thanks are probably reserved for Dr. Jana Bürger (Rostock), and Dr. Laura Breitsameter (Göttingen), who patiently provided me with support regarding virtually all issues related to statistical analyses, planning and writing of manuscripts and encouraging words. Their way of thinking and the discussions have been very inspiring and helpful for this work.

In addition, the following people have helped me in many different ways:

Prof. Johannes Glauninger (Vienna, Austria), Dr. Martin Pothoff (Göttingen) and Dr. Lena Ulber (Braunschweig, Germany), who provided me with additional advice.

Arne Tichter, Dr. Stefan Meyer, Dr. Tatiana From, Sabrina Jerentrup, Magdalena Werner, Susanne Stein, Dr. Mark Winter, Hagen Hartmann, Elke Schröder, Eugen Hodyl for providing such a nice working atmosphere at the university.

Dr. Giulia Frontoni and Thomas Pichler for their mental backups.

Ines Pichler, Dr. Heidrun Åm and Angelika Schirgi for being friends for such a long time.

Finally, I would like to thank my parents, Christine and Josef Edler, my sister, Christiane, and my little nice Rosa, for their boundless patience, support and love for so many years.

This thesis was embedded in the KLIFF project as a part of the Lower Saxony's Climate Impact Research Program and funded by Ministry for Science and Culture of Lower Saxony.

Arnstein, March 2015 


\section{Curriculum vitae}

Barbara Edler

born 13.04.1982 in Voitsberg (Austria)

$09 / 2009-11 / 2013$

PhD Study at the Research Centre for Biodiversity and Sustainable

Land Use, Faculty of Agricultural Sciences, Georg-August-

University Göttingen (Germany) under the supervision of Prof. Dr.

Johannes Isselstein.

PhD thesis: WEEDS IN CHANGING ENVIRONMNET.

Responses to altered temperature and soil water potential in four soil types and relative future habitat suitability for potential distribution of three range-expanding weed species in northwest

Germany.

07/2007-08/2009

Masters Study in Phytomedicine (Dipl.-Ing.) at the University of Applied Science (Vienna, Austria) under the supervision of Prof. Dr. Johannes Glauninger

Master thesis: Occurrence of stunning problems in plant protection in commercial hop (H. lupulus L.) production area of South-Styria in the year 2008 .

09/2002-07/2007

Bachelors Study in Agricultural Sciences (Bakk.techn.) at the University of Applied Science (Vienna, Austria).

09/2000-09/2002

Study at the University of Veterinary-medicine (Vienna, Austria)

09/1992-05/2000

Secondary Education at BG/BRG Gymnasium (Köflach, Austria) 


\section{E r k l är u n ge n}

1. Hiermit erkläre ich, dass diese Arbeit weder in gleicher noch in ähnlicher Form bereits anderen Prüfungsbehörden vorgelegen hat.

Weiter erkläre ich, dass ich mich an keiner anderen Hochschule um einen Doktorgrad beworben habe.

Arnstein, den

(Unterschrift)

2. Hiermit erkläre ich eidesstattlich, dass diese Dissertation selbständig und ohne unerlaubte

Hilfe angefertigt

wurde.

Arnstein, den

(Unterschrift) 